Portland State University

PDXScholar

Spring 7-9-2018

\title{
The Role of Caregiver Disruption in the Development of Juvenile Sexual Offenders
}

\author{
Miranda Sitney \\ Portland State University
}

Follow this and additional works at: https://pdxscholar.library.pdx.edu/open_access_etds

Part of the Psychology Commons, and the Social Work Commons Let us know how access to this document benefits you.

\section{Recommended Citation}

Sitney, Miranda, "The Role of Caregiver Disruption in the Development of Juvenile Sexual Offenders" (2018). Dissertations and Theses. Paper 4474.

https://doi.org/10.15760/etd.6358

This Thesis is brought to you for free and open access. It has been accepted for inclusion in Dissertations and Theses by an authorized administrator of PDXScholar. Please contact us if we can make this document more accessible: pdxscholar@pdx.edu. 


\title{
The Role of Caregiver Disruption
}

in the Development of Juvenile Sexual Offenders

by

Miranda Hope Sitney

A thesis submitted in partial fulfillment of the requirements for the degree of

\author{
Master of Science \\ in \\ Psychology
}

Thesis Committee:

Keith Kaufman, Chair

Joel Steele

Greg Townley

Portland State University

2018 


\begin{abstract}
In the last decade, it has been recognized that juveniles commit as much as $20 \%$ of all sexual offenses in the United States (DOJ, 2004). Research that attempts to understand why young people commit sex crimes points to an array of family factors that may uniquely contribute to the development of sexual offending over and above general juvenile delinquency. This study specifically examines disrupted caregiving, or receiving insufficient or substitute care, as a potential moderator in the relationship between offense status and caregiver-child relationship quality. Four distinct moderators were tested: gender of caregiver, biological relationship between caregiver and child, number of times the youth has changed caregivers, and child maltreatment history. Results indicate that juvenile sexual offenders have particularly poor relationships with their primary caregivers, and that caregiver gender, biological relationship between caregiver and child, and child maltreatment history act as moderators. Thus, while juvenile sexual offenders in general have poor relationships with their caregivers, those with male caregivers and those who have experienced physical abuse, sexual abuse, and neglect, have relationships that are even worse. In contrast, sexual offenders raised by nonbiological caregivers showed better relationship quality than did youth raised by their biological parents. These findings suggest opportunities for early intervention, before caregiving is disrupted. Furthermore, additional supports may be offered to youth whose family structures suggest that they may be at increased risk.
\end{abstract}




\section{Acknowledgements}

I would like to thank my advisor, Dr. Keith Kaufman, as well as my committee members Dr. Joel Steele and Dr. Greg Townley for their guidance and input through this process. I would also like to thank my father, P. Adams Sitney, for reading every draft along the way. Finally, a special shout out to Thythy Bui, for diligently digging through the literature and finding me the best reference studies. 


\section{Table of Contents}

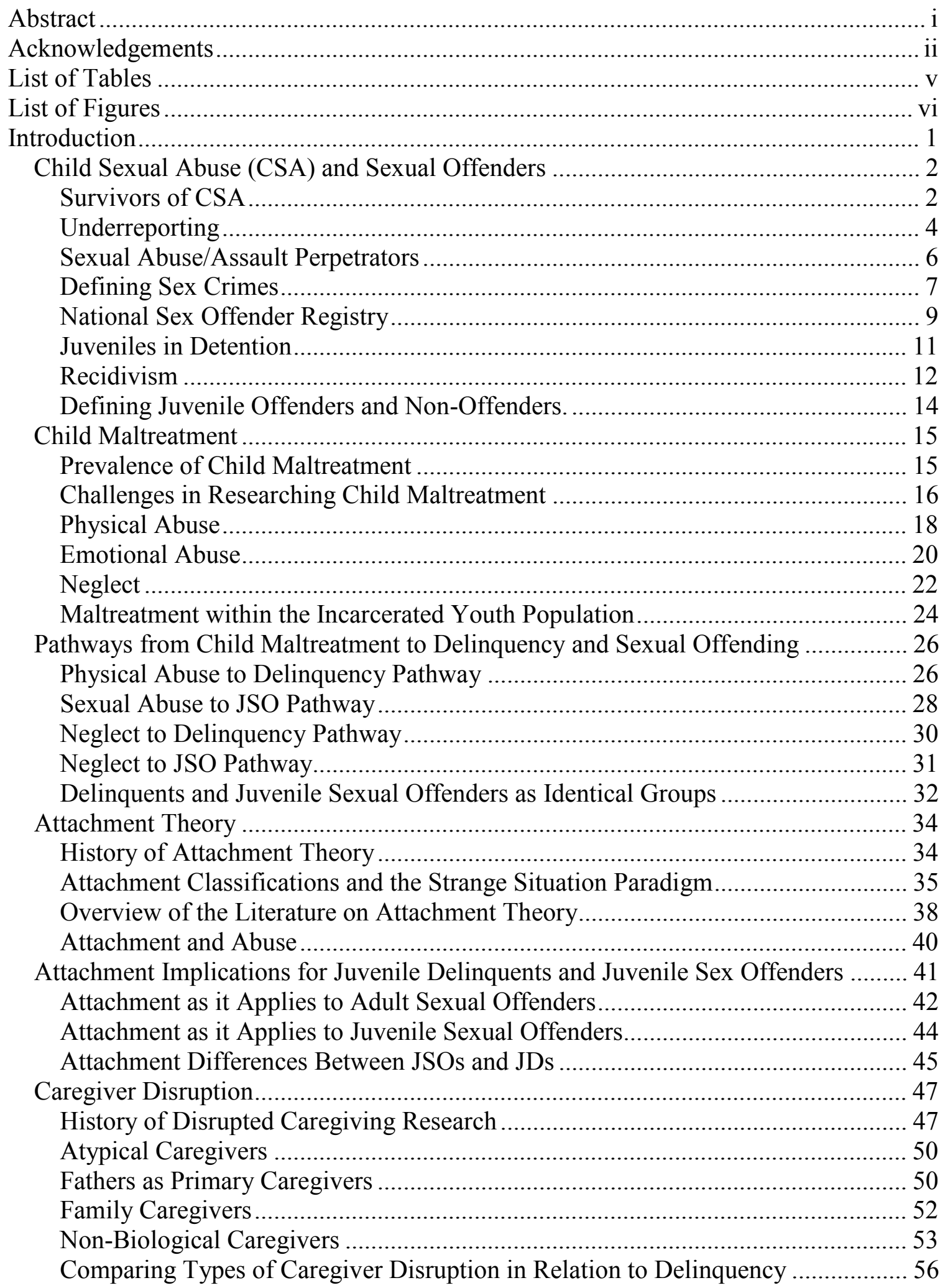




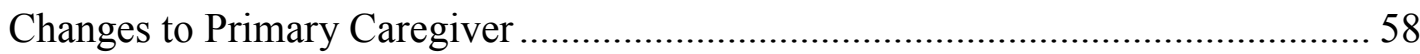

Caregiver Disruption from an Attachment Perspective ............................................ 59

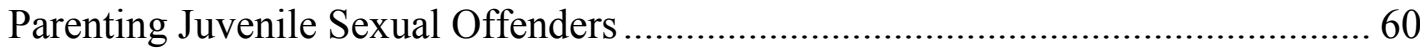

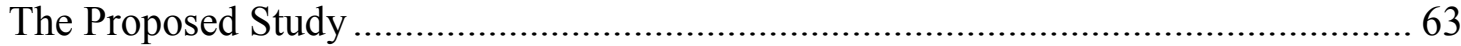

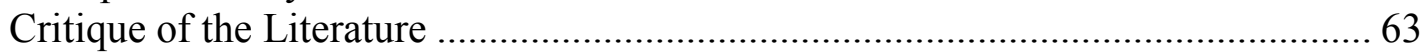

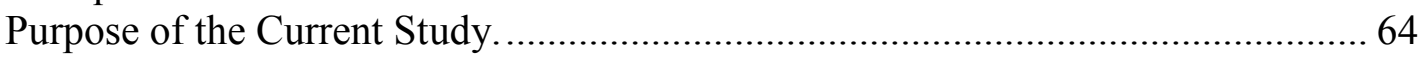

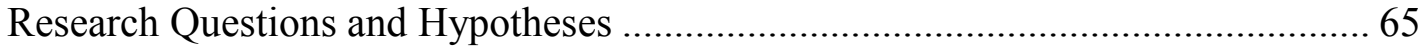

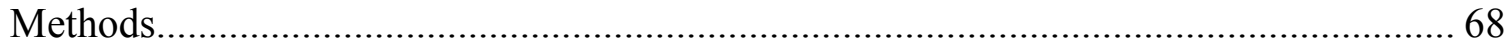

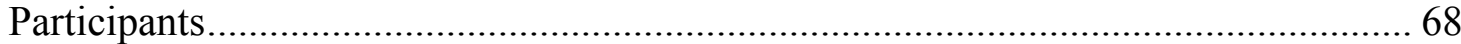

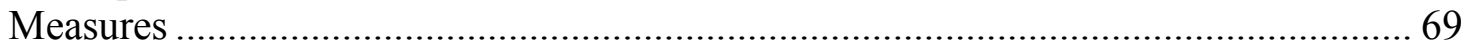

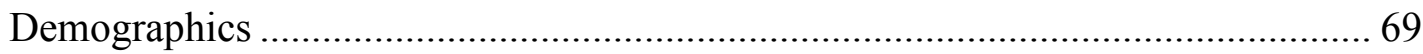

Perceived Relationship with Supervisor Scale ……………....................................... 69

Experiences of Childhood Abuse..................................................................... 70

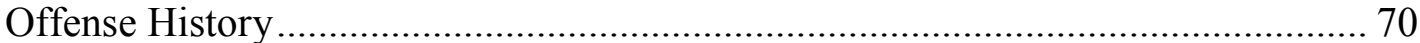

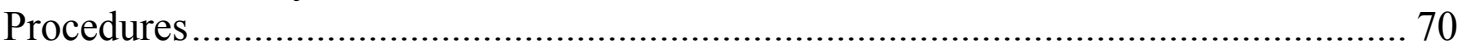

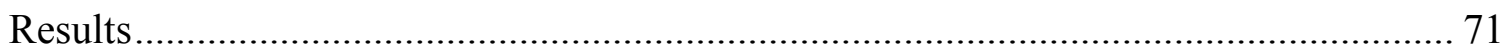

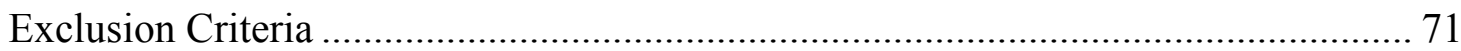

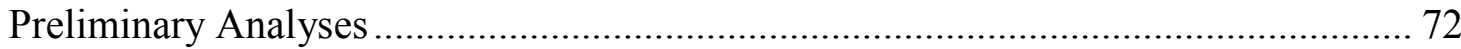

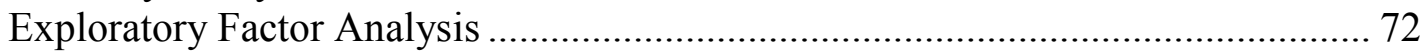

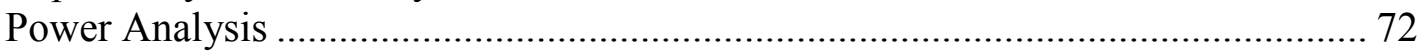

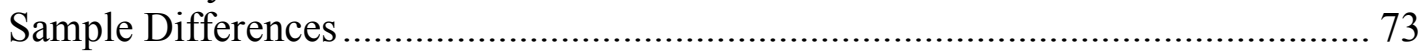

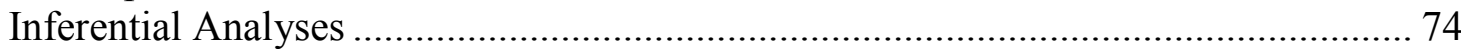

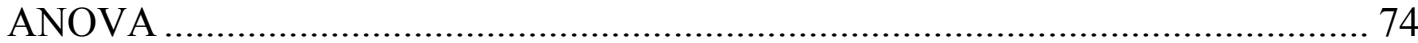

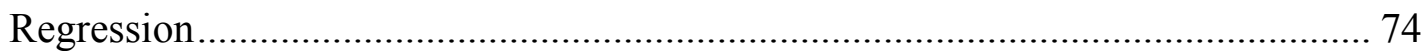

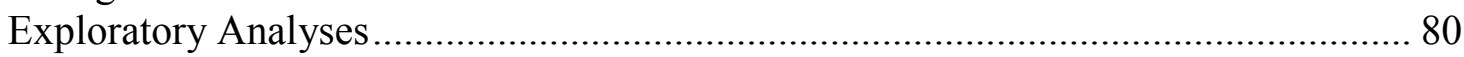

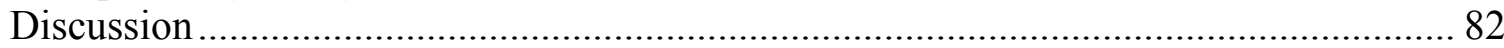

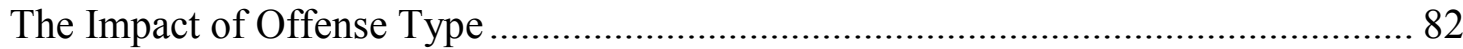

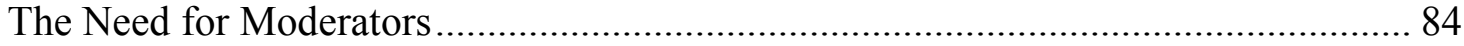

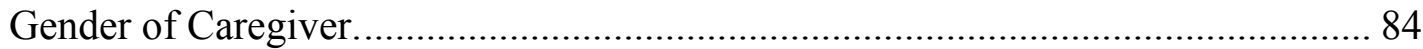

Biological Relationship Between Caregiver and Child. .......................................... 86

Changes to Primary Caregiver........................................................................... 88

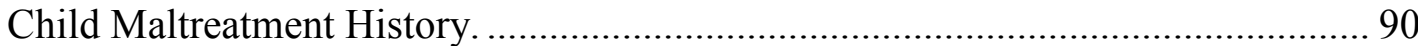

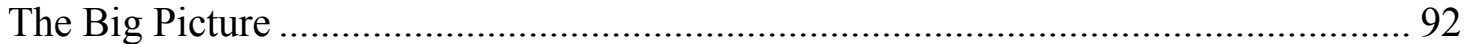

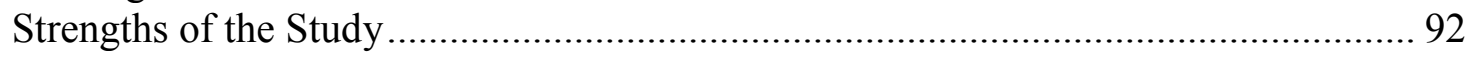

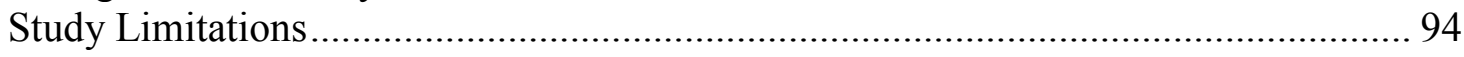

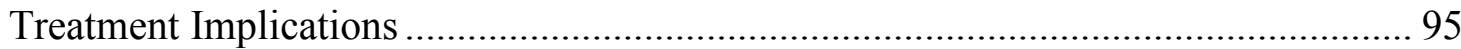

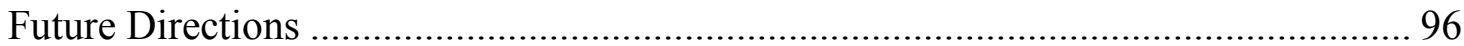

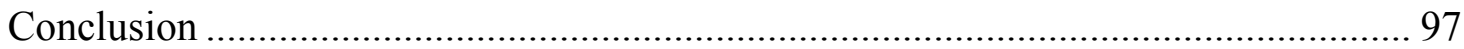

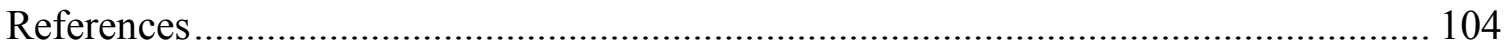




\section{List of Tables}

Table 1.

pg. 98

Charge coding

Table 2.

pg. 98

Raw count and percentages of disrupted caregiving by offense type

Table 3.

pg. 99

Model summary for the full moderated multiple regression

Table 4.

pg. 99

Full model of the moderated multiple regression 


\section{List of Figures}

Figure 1.

pg. 101

Scree plot of the Perceived Relationship with Supervisor Scale

Figure 2.

pg. 101

Mean values of the PRSS by offense type

Figure 3.

pg. 102

Moderating effect of gender of caregiver between offense status and relationship quality

Figure 4.

pg. 102

Moderated effect of biological-parent on the relationship quality of JCs and JSOs

Figure 5.

pg. 103

Moderated effect of physical abuse on the relationship quality

Figure 6.

pg. 103

Mean differences of maltreatment on the relationship quality of JSOs 


\section{Introduction}

This investigation focuses on the role of caregiver disruption in the etiology of juvenile sexual offenders. Beginning with a summary of the literature on child sexual abuse (CSA), it discusses how CSA affects most, if not all, individuals in the United States. It then provides background and descriptive statistics concerning juvenile offenders, including both sexual offenders and those who have committed non-sexual crimes. After the discussion of juvenile offenders, there follows a summary of the relevant literature concerning attachment and child maltreatment to the development of these youth. Furthermore, the multiple pathways through which poor parental attachment patterns may lead to various offenses are evaluated. Finally, it investigates three types of caregiver disruption that are commonly experienced by juvenile sexual offenders: male primary caregivers, non-biological caregivers, and multiple changes of primary caregiver. A critique of the existing literature follows, leading to the proposal of a novel study that offers methodological and conceptual advancements.

Improvements associated with the proposed study will contribute to an enhanced understanding of early childhood attachment patterns, family systems dynamics, caregiver disruption, and juvenile sexual offending. These are interconnected areas demanding urgent attention. The most recently available statistics indicate that one out of every four girls and one out of every twenty boys is a victim of child sexual abuse (CSA) (Finkelhor, Shattuck, Turner, \& Hamby, 2014). This staggering statistic is even more startling when one considers the profound and long lasting effects that CSA produces, not just for the survivors, but also for their family, friends, community, and society. Naturally, the focus of these statistics has been the victims of sexual abuse. At the same 
time, it is important to recognize that for every act for which there is a victim, there is also a perpetrator. This study, then, examines attachment related dimensions that are critical to a better understanding of offense typology in adjudicated youth.

\section{Child Sexual Abuse (CSA) and Sexual Offenders}

Survivors of CSA. This section clarifies the many short- and long-term consequences that result from CSA victimization. Specifically, it reviews the documents relating to general and specific symptoms common in CSA survivors. It also examines the far-reaching consequences of CSA, as it affects families, communities, and the broader society.

As stated above, the best estimates indicate that $26.6 \%$ of girls and $5.1 \%$ of boys will experience sexual abuse before their eighteenth birthdays (Finkelhor et al., 2014). Child sexual abuse has been associated with many long-term negative outcomes for survivors. A meta-analysis of 37 studies using adult CSA survivors found that these individuals were at significant risk for PTSD, depression, suicide, sexual promiscuity, and low academic achievement (Paolucci, Genuis, \& Violato, 2001). Subsequent metaanalyses have found major impairments in psychological adjustment, including increased prevalence of anxiety disorders, eating disorders, and sleep disorders (Chen et al., 2010). Physical health is affected by victimization as well. Irish, Kobayashi, and Delahanty (2009) demonstrated that experiencing CSA increased poor general health and physical pain in their meta-analysis of 31 studies related to CSA. Furthermore, these negative repercussions have often turned out to be long-lasting. Research using a sample of participants with a mean age of 56-years-old found higher rates of alcohol and 
drug problems, suicidal tendencies, and current marital or family problems for those participants who had experienced CSA (Dube et al., 2005).

Additionally, the consequences of childhood sexual assault do not exist in a vacuum. Family members, friends, and communities are also affected in the aftermath of a CSA disclosure (Daane, 2005). These "ripple effects" are just as profound as they are for the survivor themselves. Parents of children who have disclosed sexual abuse have been found to be three times more likely to suffer clinical distress and meet PTSD criteria than the general population (Manion et al., 1996; Newberger, Gremy, Waternaux, \& Newberger, 1993). Further, as the perpetrator of child sexual assault is oftentimes a parent or step-parent, the non-offending parent is left to deal with the fallout of both the destruction of their romantic relationship and the abuse of their child in the wake of the disclosure. Elliott and Carnes (2001) found that non-offending parents experienced a host of negative outcomes following their child's disclosure including financial impacts (e.g., losses in income, more dependence on government programs, employment disruption) and social damage (e.g., weakening of relationships to family and friends).

The aftershocks of CSA extend outside of the immediate family as well. In adults, sexual assault disclosures are often first told to a friend. Research using a sample of university students indicated that approximately $30 \%$ of students have had a friend disclose their abuse to them (Banyard, Moynihan, Walsh, Cohn, \& Ward, 2010). Additionally, friends who heard the disclosure, especially women, often described the experience as emotionally distressing and anger inducing. Furthermore, women reported that the disclosure made them fear for their own safety and increased their anxiety that they too may be assaulted. Widening the scope further still, economic researchers 
reported that the estimated cost of child maltreatment, per victim, is $\$ 210,000$ in lost income and increased medical costs. Multiplied across the United States, the economic burden of child maltreatment is approximately $\$ 124$ billion per year (Fang, Brown, Florence, \& Mercy, 2012).

Underreporting. Following this outline of the consequences of CSA, some consideration of the reliability and validity of CSA estimates is in order. The widespread issue of underreporting makes this a pressing matter (Collin-Vézina, Daigneault, \& Hébert, 2013).

Many have noted that the one in four CSA estimate presented earlier in this manuscript accounts only for sexual abuse incidents that have been reported or investigated by law enforcement or Child Protective Services (Bachman \& Saltzman, 1995; Finkelhor, 1994; Green, 1996). In reality, it is likely that many more children were sexually assaulted each year without a subsequent report or investigation. Estimates by the Department of Justice suggest that, in college students, only 344 out of every 1000 sexual assaults have been reported to the police (RAINN, 2015). This is equivalent to one out of every three assaults having been reported. In a meta-analysis of CSA prevalence, Stoltenborgh, van IJzendoorn, Euser, and Bakermans-Kranenburg (2011) found that studies using self-reported data collection noted incidences of CSA that were, on average, 30 times higher than studies using data from national reporting agencies such as Child Protective Services. These results suggest that many, if not most, sexual assaults are unknown to official service organizations.

Notably, the issue of underreporting is not unique to sexual assaults. Finkelhor and Hashima (2001) found that guardians reported physical abuse incidents at twice the 
corresponding prevalence rates reported by Child Protective Services. Even seemingly more objective incidents of abuse, such as child maltreatment resulting in fatalities, are suspected of being underreported. For example, Ewigman, Kivlahan, and Land (1993) found that only $47.9 \%$ of child deaths, resulting from maltreatment, were classified as such in official documents.

There are many reasons for these crimes to go unreported. Studies using adult survivor populations found that abused individuals described fearing retaliation as the number one reason that they remained silent (22\%), followed by the beliefs that: the police could not help (13\%); it was a personal matter (13\%); it was not important enough to report (8\%); and they didn't want to get the perpetrator in trouble (7\%) (Planty, Langton, Krebs, Berzofsky, \& Smiley-McDonald, 2013). For child sexual assault, researchers have found that: children may have not yet developed the cognitive processes necessary to voice their abuse histories; children's feelings of shame or fear might have stopped them; and that feelings of responsibility for the abuse may have reduced reporting (Wissow, 1996). Other reasons for not reporting included the youth's close relationship with the perpetrator, as happens in situations of intra-family abuse, or the perpetrator may have threatened to hurt them or a loved one if they disclosed the abuse (Jensen, Gulbrandsen, Mossige, Reichelt, \& Tjersland, 2005). In some cases, youth may not even have recognized that what they experienced was abuse (Brown, 2011). In American society, sex and sexual matters are rarely discussed, especially with children. As a result, children often lack the words or the understanding to express how something that perhaps felt good, was in fact bad (Chaffin, Lawson, Selby, \& Wherry, 1997; Finkelhor, 1994; MacMillian et al., 1997). Additionally, offenders often frame their 
abuse of children in terms of a "game." This may confuse victims who have been induced to believe that they were willing and active participants (Leclerc \& Tremblay, 2007).

Sexual Abuse/Assault Perpetrators. This subsection attempts to summarize the literature regarding typologies for sexual offenders. Recognizing these typologies does not necessarily illuminate offender risks, but does help to illustrate the heterogeneous nature of sexual abuse. In particular, this section details what is known about sexual offenders' patterns of perpetration.

As already noted, sexual abuse/assault perpetrators are a highly-heterogeneous group. Although, reliable ways to classify this group of offenders as a whole have not been established (CSOM, 2008), there is value in isolating different forms of sexual aggression. Generally speaking, researchers divide sexual offenders into two typologies: "rapists" or "child molesters" (Simons, 2015). A substantial body of work indicates that these two criminal types are associated with different histories of abuse, psychosocial development, and mental health (Valliant, Pottier, Gauthier, \& Kosmyna, 2000). However, additional studies examining crossover effects (e.g., rapists who have also offended against children) powerfully suggests that typologies based on victim type may not have been the most effective way to categorize or plan treatment for sexual offenders (Simons, 2015). Additionally, the scope of individuals who commit sex crimes is quite large; $57 \%$ of perpetrators against female victims in 1994-2010 were white, $27 \%$ were black, and $16 \%$ were classified as "other." Half of perpetrators were older than 30 years-old; and $37 \%$ had a prior felony conviction. Fifty-five percent (55\%) of sexual assaults occurred at or near the victim's home, while 33\% took place in a public space 
(Planty et al., 2013). Clearly, these differences underscore the challenge in identifying a risk profile or that would indicate a particular treatment focus.

At the same time, there are some commonalities across sexual offenders. Approximately $94 \%$ of sex crimes are committed by men (Planty et al., 2013); 93\% of victims of sexual violence are known to their perpetrator (i.e., $71 \%$ of adults knew their abuser, 93\% of children were abused by a family member or friend) (Snyder, 2000; Truman \& Morgan, 2016); and 90\% of rapes are committed by a lone individual (Planty et al., 2013). Further, studies have found that sexual offenders exhibited some similar clinical patterns, including difficulties with emotional regulation and interpersonal interactions, poor empathy development, and deviant sexual arousal (Fapul, 2014; Simons, 2015).

In the United States, 92,720 arrests were made for sexual offenses in 2010 (Snyder, 2012). Twenty-thousand of those arrests were for forcible rape, while the other 72,000 were for a variety of other sexual offenses. Eighteen percent (18\%) of those arrested were juveniles (i.e., 14\% of the forcible rapes were committed by juveniles). Given what is now known about the underreporting of CSA, these numbers are conservative estimates of the sexual offenses that occur each year.

Defining Sex Crimes. What, then, constitutes a sexual crime? Before proceeding further, it is critical to turn our attention to definitions. This section clarifies how one is labeled a perpetrator of sexual abuse. Specifically, it examines Oregon laws that distinguish sexual offending from other types of crimes against persons, and how those laws are separately applied to juveniles. 
Definitions of sexual offenses vary by state, and consequences for offenses vary by county. In Oregon, there are currently 29 charges that fall under the "sex crimes" category (ORS 181.805). Criminal sexual offenses are categorized as varying degrees of rape, statutory rape, sodomy, unlawful sexual penetration, or sexual abuse. Crimes are categorized as rape if 1 ) the victim was forced into a sexual act, 2) the victim was age 12 or younger, 3) the victim is incapable of consent due to mental incapacitation or physical helplessness, or 4) the victim is under the age of 16 and the perpetrator was related to the victim (parent, sibling, half sibling) (ORS 163.375). The only difference between the definitions of rape and sodomy is that rape refers to the "ordinary meaning" of sexual intercourse, while sodomy refers to "deviant" sexual behaviors (i.e., penetration of the mouth or anus) (ORS 163.405). Unlawful sexual penetration differs in that the penetration is committed with any object other than a penis or mouth (ORS 163.411). Finally, sexual abuse, contrary to the popular definition, means any sexual molestation that does not involve penetration (e.g., touching, groping) (ORS 163.427).

Oregon law separately classifies a number of specific offenses involving sexual acts with children, including purchasing sex from a minor, online sexual corruption of a child, contributing to the sexual delinquency of a minor, and possession of materials depicting sexual conduct of a child (ORS 163.432 - 163.689). By law, anytime a youth under 12 in Oregon engages in sexual activity with another person, someone is guilty of a criminal offense. If both individuals are children under 12 , they both are guilty of perpetrating sex crimes against each other (Lahna \& Long, 2014). If both youth are over the age of 12, but have an age gap of three or more years, the older youth is deemed to be abusing the younger. There are even further examples of special consideration for the sexual activity 
of youth. For instance, if two teenagers made a videotape or took pictures of themselves engaging in voluntary sexual contact, both youth may be guilty of possessing child pornography. If adjudicated in court, both this example and the previous "Romeo and Juliet" situation are classified as felony sex crimes, and the youth would have a mandatory requirement to register for life as sexual offenders (Lahna, \& Long, 2014).

National Sex Offender Registry. After that glance at Oregon laws, it is necessary to turn to federal laws pertaining to sexual offending. The focus of this section is on the history of the national sex offender registry and its consequences for offenders.

The US justice system has dealt with sexual offenses differently than any other type of crime. Sex crimes are the only category of criminal activity that possibly require lifetime tracking through the use of a registry. The sex offender registry was first introduced as a consequence of the high profile abduction, rape, and murder of 11-yearold Jacob Wetterling in 1991. At the time, law enforcement felt that a comprehensive database for offenders would help them navigate leads during massive manhunts, such as the one that occurred in the search for Jacob. In 1994, the Jacob Wetterling Crimes Against Children and Sexually Violent Offender Registration Act was passed requiring every state to track their convicted sexual offenders in a searchable database. At that point, the database was accessible only to law enforcement officials. However, the subsequent rape and murder of seven-year-old Megan Kanka by her neighbor, a man previously convicted for pedophilia, prompted an addendum to be added to the Registration Act. In 1996, Megan's Law was passed, which required offender information to be viewable by the general public (Terry \& Ackerman, 2009). Today, over 850,000 individuals are listed nationally on a sexual offender registry (NCMEC, 2016). 
There is no minimum age for placing someone on the registry, and in fact, many youths are registered as sexual offenders. In Delaware alone, statistics from 2011 document that 639 children were registered sexual offenders in that state. Fifty-five of those offenders were under the age of 12. One was nine-years-old (SURJ, 2011).

According to the National Center for Missing and Exploited Children's most recent statistics, Oregon has the highest national percentage of registered sexual offenders per capita at 718 per every 100,000 (NCMEC, 2016). That is almost 1.5 times the percentage of the next highest state (Arkansas, with 530 registries per 100,000), and almost three times the national average (264 per 100,000). Some attribute the magnitude of this disparity to the differences in sex offender laws between Oregon and neighboring Washington, suggesting that homeless offenders in particular migrate south to Oregon to evade the harsh oversight requirements placed on those on Washington's registry (Korn, 2013). Additionally, Oregon affords greater anonymity than Washington does, so that comparably few offenders are listed on publicly available internet registries. However, it is undeniable that Oregon's extraordinarily high rates of registered sexual offenders are created, at least in part, by both the large number of crimes that require registration and Oregon's resistance to removing anyone from the registry once placed on it.

Yet in some ways Oregon's practice is typical of the nation as a whole. It is one of 35 states that includes juveniles, the youngest of whom was eight-years-old, on their sex offender registry. By extending that registry to incorporate minors it does nothing to distinguish them from older criminals. Thus, in keeping with the adult registry system, these youths are required to be registered for life. Consequently, the punishment for young abusers is de facto more severe than for more hardened criminals. As of 2014, 
approximately 3,000 of the 25,000 offenders listed in Oregon were juveniles.

Additionally, Oregon law currently states that any youth convicted of a felony sexual offense is required to register, without any option for judicial discretion. (Lahna \& Long, 2014).

Juveniles in Detention. The registration of sexual offenders is an important consequence of adjudicated sex crimes. However, before being inscribed in the registry, these sexual offenders are often incarcerated. Therefore, for this section, a discussion of the detention of juveniles in the United States precedes a consideration of what juvenile incarceration looks like in the state of Oregon.

A recent examination of the justice system, largely focused on the treatment of incarcerated juvenile offenders, created a push for community-based sanctions designed to keep youth at home or in their neighborhoods following adjudication. Still, in 2013, 54,148 youth were held in juvenile detention centers across the United States. An additional 10,000 were held within the adult correction system (Neelum, 2011). The vast majority of these youth were male (86\%), non-white (68\%), 16 - 17-years-old (54\%), and were being held for burglary, robbery, or simple assault (27.5\%) (Hockenberry, 2016). Juvenile sexual offenders make up $3.1 \%$ of all juvenile offenders, and $7.4 \%$ of all violent juvenile offenders (Finkelhor, Ormrod, \& Chaffin, 2009). In 2013, the most recent year for which we have data, the national average length of stay for a youth in a locked detention facility was 4.5 months. Fourteen percent (14\%) of youth, however, were incarcerated for over a year (Sickmund, Sladky, Kang, \& Puzzanchera, 2008).

In Oregon, youth offenders are by-and-large diverted out of prisons and are placed instead in residential treatment centers or specialized group homes. However, that is not a 
universal path. As of 2017, Oregon Youth Authority (OYA), the governing organization that houses and provides services to adjudicated juveniles, serves approximately 1,400 youth, 600 of whom are currently being held in one of their ten juvenile detention centers across the state. An additional 300 youth are being held in adult prisons (OYA, 2017). The diversion programs have been generally successful, so the average age of a youth in OYA services is older than one would perhaps think. The largest percentage of OYA youth (i.e., over 50\%) are between 18 and 24-years-old. An additional 38\% are between the ages of 16 and 17-years-old. Eighty-seven percent (87\%) of the youth in OYA's care are male. Representative of Oregon's population profile, 57\% of OYA youth are Caucasian, 23\% are Hispanic, and 11\% are Black. Turning to offense status, 29\% percent of OYA youth are being held in detention for a sex crime, making sexual offenses the most likely reason a youth to be in detention. This is followed by $20 \%$ of the youth arrested for assault or battery and $19 \%$ of the youth adjudicated for property crimes. Youth are held in detention for a mean length of 466 days, with longer stays associated with being male and being in adult prison (OYA, 2017).

Recidivism. Recidivism constitutes a chief consideration with juvenile offenders and is examined in this section. Recidivism is defined as a "person's relapse into criminal behavior, often after the person receives sanctions or undergoes intervention for a previous crime" (National Institute of Justice, 2014). Recidivism is measured by re-arrest, which may not actually be the first offense committed after release. Here, it is necessary to take up this complex problem by comparing sexual recidivism to general criminal recidivism, in order to provide a relative context for this important concern. 
The existence of a lifetime registry and the particularly harsh punishments of adult and juvenile sexual offenders alike, give the public the notion that recidivism rates must be particularly high for this population. However, especially for juveniles, rates of sexual assault recidivism are remarkably low. In fact, research suggests that sex offenders are some of the least likely criminals to recidivate (Levenson, Brannon, Fortney, \& Baker, 2007). Two separate meta-analyses of studies that followed adult sexual offenders after treatment found that approximately $10 \%-11 \%$ of convicted adult sexual offenders went on to sexually recidivate within five years of their release (Hanson, Bourgon, Helmus, \& Hodgson, 2009; Lösel \& Schmucker, 2005). The Department of Justice also tracked criminal re-offense rates for five years following release from prison. The most recent report, using adults released in 2005 , found that $5.6 \%$ of men who had been incarcerated for rape were arrested for another sexual offense before 2010. Comparatively, $13.1 \%$ of men who committed a person-to-person robbery were arrested for another robbery during that same time frame, $23.2 \%$ of men who committed burglary (a property crime, rather than a persons crime) were rearrested for burglary, and $34.4 \%$ of men arrested for assault were charged for a second time (Durose, Cooper, \& Snyder, 2014). Notably, convicted sex offenders were also less likely to be charged with any type of re-offense than other types of criminals. Approximately $60 \%$ of rapists were charged with another crime within five years of release. While high, this was significantly lower than the $77 \%$ of robbers, the $81 \%$ of burglars, or the $84 \%$ of car thieves who were rearrested during that same time period.

Juvenile sexual offenders often have even lower reported recidivism rates than their adult counterparts. Meta-analyses show that approximately $7 \%-13 \%$ of juvenile 
sexual offenders commit a second sex crime (Lobanov-Rostovsky, 2014). Indeed, juvenile sexual offenders were more than six times as likely to be arrested for a nonsexual re-offense than a sexual one (Caldwell, 2002). Furthermore, a meta-analysis of 17 studies revealed that, compared to other types of juvenile offenders, youth who had been convicted of sex crimes had less extensive criminal histories, fewer contacts with police overall, less substance use, and were doing better in school (Seto \& Lalumiere, 2010).

Defining Juvenile Offenders and Non-Offenders. Before concluding this chapter, it is important to clarify just who is referred to when using the terms juvenile sexual offender or juvenile delinquent. For the purposes of this study, juvenile sexual offenders (JSOs) have been identified using the criteria utilized by the Oregon Judicial System. Therefore, JSOs are considered a) any youth adjudicated under the age of 18 who were b) adjudicated for one of the 29 crimes identified as "sex crimes" in Oregon. Youth are included as JSOs even if they have additional convictions for non-sex crimes.

Juvenile delinquents - violent (JD-Vs) are defined here as a) youth convicted of a crime under the age of 18 , who b) have never been convicted of any "sex crime" under Oregon law, and c) whose primary criminal offense involved violence in some way. Violent offenses are categorized as any crime against persons that involve the threat of harm. Most commonly, these crimes are assault, battery, and robbery (McCurly \& Snyder, 2004).

In this proposal, juvenile delinquents - nonviolent (JD-NVs) have been partitioned into a separate category. JD-NV youth meet identical requirements as JD-Vs, with the exception that their primary offense was one that does not involve potential harm 
to persons. Not involving harm to persons does not necessarily mean that their crimes were less serious than JD-Vs. Burglary and arson, for instance, fell into this category. However, the large proportion of youth incarcerated for relatively minor crimes are also included in this distinction. For example, the most common offense that a juvenile had been incarcerated for is "Disorderly Conduct," a catch-all category for any number of disruptive behaviors that do not indicate that the youth had any intention of causing serious harm or damage to any individual or their property.

Finally, juvenile controls (JCs) are non-incarcerated youth with no criminal history. While it is possible that these youths may have committed a crime in their lifetimes, they have never been arrested or incarcerated for any offense. As such, these youths do not reside in any kind of controlled care environment (e.g., detention), but rather live at home in their community.

\section{Child Maltreatment}

Any consideration of child sexual abuse must also survey the broader child maltreatment literature. This section reviews that literature and examines three common types of maltreatment beyond sexual abuse: physical abuse, emotional abuse, and neglect. Finally, it takes account of the prevalence and potential pathways whereby various forms of child maltreatment manifest themselves in juvenile sexual offending and juvenile delinquency.

Prevalence of Child Maltreatment. Approximately 2.2 million children are victims of substantiated child maltreatment each year, or about 29 out of every 1,000 children in the United States. Since this number does not include unreported incidents, it is certainly an underestimate (Children's Bureau, 2016). The consequences of child 
maltreatment can be extremely serious. In 2014, 1,580 children died as a direct result of abuse or neglect. Yet, the protection of children from abuse remains a relatively recent concept. The first federal legislation outlawing child abuse was not passed until 1974 (Child Abuse Prevention and Treatment Act, 1974). Consequently, the societal costs of child maltreatment is still being estimated. Even the phrase, "child maltreatment" is relatively new and still an ambiguous umbrella term covering all types of abuse and neglect. Crucial discriminations need to be made between various forms of maltreatment. For example, both abuse and neglect can be physical (i.e., hitting or withholding food) or emotional (i.e., saying hurtful things or failing to interact with the child). In its overly broad formulation, sexual abuse also is included under the term child maltreatment.

Challenges in Researching Child Maltreatment. Child maltreatment is a particularly difficult topic to study. Methodological issues arise due to poly-victimization, ambiguous definitions, and the problems of parsing maltreatment from other related societal issues. In this section, each of these challenges are discussed separately and attempts have been made to clarify the true incidence rates and effects of maltreatment.

Researchers often examine the different types of maltreatment separately, though in actuality, different forms of abuse/neglect often overlap. For instance, it is hard to imagine a parent who is physically abusive without also being emotionally abusive. Further, research has determined that youth who experience one type of abuse are at higher risk of experiencing other types as well. Dong et al. (2004) found that $85 \%$ of individuals who had experienced one adverse childhood event also reported at least one other type of abuse. Turner, Finkelhor, and Ormond (2010) found similar results. In their study, $66 \%$ of the sample experienced two or more types of abuse in childhood, and $30 \%$ 
of their participants reported experiencing five or more types of abuse. Clearly, experiencing abuse is an interrelated construct.

Even if one could accurately control for poly-victimization, ambiguities surrounding the definitions of 'abuse', 'neglect', and 'maltreatment' would persist. These terms are often culturally inflected. In other words, behavior considered abusive for one culture may be viewed as normal, or even sanctioned, in another. For example, parents in some cultures immediately and consistently respond to their child's cries, while other cultural norms advise ignoring them in order to teach the child that he or she can soothe him/herself. Is the latter parent being emotionally neglectful? The answer to that depends on whom you ask. Admonitory phrases such as "does not attend to the child's needs," generate inconsistency in reporting the incidence rates of maltreated youth.

In the case of child maltreatment, difficulties inherent in reporting are amplified when one tries to distinguish both abuse and neglect from the consequences of poverty. Take the example of withholding food: one must ask if the child is capable of distinguishing the difference between going without food because the family is too poor to afford groceries and not being permitted to eat because the parent refuses to give the child a meal. Additionally, when looking at outcomes attributed to maltreatment, one must be careful to consider socio-economic status. For instance, cognitive and emotional delays in children may be misattributed to abuse histories when in fact they are the result of living in a low-SES household.

Despite these methodological concerns, researchers in the last 30 years have made tremendous strides at parsing out the effects of various forms of child maltreatment. 
Following that research, the next sections outline the overarching findings for each of the three child maltreatment subtypes: physical abuse, emotional abuse, and neglect.

Physical Abuse. This section defines the term "physical abuse" and highlights the most recent literature on prevalence rates and outcomes of experiencing physical abuse in childhood.

When non-professionals first hear the term "child abuse," it is often physical abuse that comes to mind. This is not surprising given that, of all forms of maltreatment, physical abuse is the most likely to leave outward evidence (e.g., bruises, broken bones). As is the case with all forms of maltreatment, there is no officially recognized definition of physical abuse. The National Society for Prevention of Cruelty to Children (NSPCC) defines physical abuse as "deliberately hurting a child, causing injuries such as bruising, broken bones, burns, or cuts." However, the injury to the child does not have to be observable. Shaking a baby, for instance, constitutes physical abuse. NSPCC's definition also includes "fabricating symptoms of illness or deliberately making a child sick" (NSPCC, 2017). Oregon law defines three types of physical abuse. First, as "an assault on a child that has been caused by other than accidental means, including injury that appears to be inconsistent with the explanation given for it." Second, as "threatened harm to a child, which means subjecting a child to a substantial risk of harm to the child's health or welfare." Third, as "unlawful exposure to a controlled substance that subjects a child to a substantial risk of harm to his or her health or safety" (ORS 419B.005).

Estimates suggest that approximately three out of every 1,000 children in the US will be physically abused (McCoy \& Keen, 2009; CDC, 2014). Physical abuse accounted for $17 \%$ of substantiated child abuse cases in 2014 . Furthermore, physical abuse was the 
primary cause $(41.3 \%)$ of maltreatment-related child fatalities that year (CWIGa, 2016). Approximate percentages for Oregon were consistent with these national numbers. Officials in Oregon substantiated 1,008 cases of physical abuse and seven child abuserelated fatalities in 2014 (Oregon DHS, 2016).

The most obvious consequences of physical abuse are the immediate medicallyrelated injuries. However, many physically abused children also require long-term physical and emotional health care as a consequence of their abuse. A meta-analysis of studies with adults found higher prevalence of depressive disorders, anxiety disorders, eating disorders, behavioral disorders, alcohol abuse, suicide, STIs, and obesity associated with early physical abuse histories (Norman et al., 2012). Neuro-imaging studies found that physical abuse was associated with smaller hippocampal volumes (Hanson et al., 2015) and less activity in the anterior cingulate (Hanson, 2016), indicating that these individuals may struggle with regulating emotions and detecting errors. These brain deficits could be the cause of the most commonly cited consequence of physical abuse: aggressive behavior. Many correlational studies demonstrated a consistent relationship between early physical abuse and the development of aggressive behavior in adolescence and later adulthood (Kaplan et al., 1998; Keene \& Epps, 2016; Pelcovitz, Kaplan, DeRosa, Mandel, \& Salzinger, 2000).

It is obvious from the evidence cited above that the issue of physical abuse demands attention and remediation. Yet the consequences of these blatant manifestations of criminal child-rearing ought not to completely monopolize our attention as similar issues, like psychological abuse, are both harder to detect and much more pervasive. 
Emotional Abuse. After defining "emotional abuse," this section highlights the most recent literature on prevalence rates and outcomes of experiencing psychological abuse in childhood.

At what point does parental impatience or strictness cross the line into abuse? Emotional abuse is the most difficult form of maltreatment to define since it can entail a variety of parenting practices such as yelling at children, harshly criticizing them, and generally failing to provide support and warmth. While a parent who hits a child once is considered physically abusive, one would be unlikely to say that a parent who yells at a child once has been emotionally abusive. Thus, emotional abuse often is defined by its chronic nature. Further complicating the issue is the fact that subtleties of language can distinguish almost identical situations as being either abusive or not. Phrases like "I can't believe you are my child!" can be perfectly pleasant and non-abusive coming from modest, science-inclined parents when their child wins an award for art. However, a slight change of context and tone-of-voice can turn that same phrase into one implying that the child is unwanted and unloved by the parents. In order to account for the intricacies of language, legal definitions of emotional abuse most often include a parameter for inflicting psychological harm or damage on the child. This is true in Oregon, where emotional abuse is defined as "any mental injury to a child, which shall include only observable and substantial impairment of the child's mental or psychological ability to function caused by cruelty to the child, with due regard to the culture of the child" (ORS 419B.005).

Under definitions similar to Oregon's, the Department of Health and Human Services estimated that approximately six percent of substantiated cases of child 
maltreatment in 2014 were considered emotional abuse. This translates to 42,290 youth nationally being victims of emotional abuse (Children's Bureau, 2016). One percent (1\%) of child abuse fatalities in the United States in 2014 were attributed to emotional abuse. This statistic represents the youth who committed suicide due to the psychological harm inflicted upon them (CWIGa, 2016). In 2014, eight percent of Oregon's child maltreatment cases involved emotional abuse, or approximately 200 youth in the state (Children's Bureau, 2016). When considering the prevalence of emotional abuse, it is important to remember the high likelihood that it overlaps with other forms of abuse. The general pattern of poly-victimization across child maltreatment, previously discussed, is especially prevalent with regard to emotional abuse. As an example, Claussen and Crittenden (1991) asked families accused of child abuse to allow researchers to monitor them for the prevalence of other forms of abusive behavior. They found that in $91 \%$ of physically abusive homes, emotional abuse tactics were also being used. However, in homes that had been reported for emotional abuse, only $18 \%$ of families engaged in physically abusive behaviors. The authors concluded that emotional abuse was likely present in homes that engage in other forms of abuse, but that there were also many homes that commit emotional abuse exclusively.

Emotional abuse has a wide range of consequences. A meta-analysis of the longterm effects of child maltreatment found that emotional abuse was associated with depressive and anxiety disorders, suicidal behavior, drug use, and sexual risk-taking behaviors (Norman et al., 2012). Additional research demonstrated that adults who experienced severe emotional abuse as children had underdeveloped orbitofrontal systems, a common impairment seen in adults with Antisocial Personality Disorder 
(Schore, 2001). Additionally, these adults were less resistant to illness and less satisfied with life in general (Gavin, 2011).

The evidence for emotional abuse may not be as overwhelming as that of physical abuse, but there has been sufficient research and documentation to mark it as a crucial social problem. However, there is an even more subtle and elusive form of parental maltreatment that must also be taken into consideration, that is, neglect.

Neglect. In addition to the various forms of abuse previously discussed, child maltreatment also encompasses the experience of neglect. This section explains how neglect differs from other forms of abuse and highlights the most recent literature on prevalence rates and outcomes of experiencing neglectful parenting in childhood.

Neglect is the most common form of child maltreatment. In 2014 , a startling $75 \%$ of substantiated cases of child maltreatment involved neglect. This puts national estimates of neglected children at around seven in every 1,000 children in the United States (CDC, 2014). The CDC defines neglect as an "act of omission," or an instance when something that should be undertaken as part of appropriate parenting is ignored. That is in contrast to an "act of commission" which involves the intentional harming of a child. More specifically, neglect is the intentional absence of a parental action, such as not providing food or love to a child in one's care (Leeb, Paulozzi, Melanson, Simon, \& Arias, 2008). Due to the broad variety of potential acts of omission to which a child could be subjected, McCoy and Keene (2009) offered a definition of neglect that was broken down into four subcategories: (1) Physical neglect; (2) Emotional neglect; (3) Medical neglect; and (4) Educational neglect. Physical neglect covers most of the instances commonly thought of in this category, and includes the failure to meet the minimum needs of the child. 
Children who do not have access to food, water, shelter, clothing, or supervision are being physically neglected. In contrast, emotional neglect is the failure to provide love, support, and psychological care for the child. Emotional neglect also covers exposure to situations that aren't suitable for children to witness (e.g., domestic violence). Medical neglect covers situations in which the caregiver does not seek timely medical care for a child in need, or fails to follow through with medical appointments or administering medication. Finally, educational neglect is defined as the caregivers' failure to support their child's right and obligation to attend school.

Under Oregon law, neglect of a child is defined as the "failure of a parent or guardian to provide adequate food, clothing, a safe shelter, supervision, or medical care." Additionally, parents and guardians can be charged with child neglect for allowing a child to stay in a home where drugs (except marijuana) are being manufactured or sold, or if the caretaker leaves a child under the age of ten unattended (ORS 163.545 - 547).

The consequences of neglect can be less obvious than those experienced by physically or sexually abused children, but are no less serious. Nevertheless, its effects can sometimes be quantified with devastating results. Neglect was the primary determinate of $73 \%$ of maltreatment-related child deaths in 2014 . In that year, 1,153 children died of neglect in the United States (CWIGa, 2016). A meta-analysis of the adult consequences of child maltreatment found that experiencing neglect was associated with high levels of depression, problem drinking, drug use, sexual risk-taking behavior, and obesity (Norman et al., 2012). Further, studies have linked neglect to cognitive delays, especially involving language (Allen \& Oliver, 1982) and poor social and emotional deployment, whereby the children become isolated and withdrawn (Hildyard \& Wolfe, 
2002; Manly, Kim, Rogosch, \& Cicchetti, 2001). In conclusion, we can see that sexual abuse, physical abuse, emotional abuse, and neglect constitute four closely connected forms of child maltreatment. It is not surprising that all four can be found in the histories of many young people who have been imprisoned.

Maltreatment within the Incarcerated Youth Population. Beyond the general forms of child maltreatment, this study specifically examines how maltreatment histories are represented in populations of incarcerated youth. This section highlights the prevalence of child maltreatment histories within this specialized population and the extent to which children are further victimized inside the prison system.

Given what is now known about prevalence rates and long-term consequences of child maltreatment, it is predictable that the majority of incarcerated youth have a history of early childhood trauma, and have experienced abuse at higher rates than have their non-incarcerated peers (Brosky \& Lally, 2004; Coleman, 2005). A 25-year prospective study on the relationship between child maltreatment and incarceration found that experiencing child abuse or neglect increased one's risk of being incarcerated as a juvenile by $59 \%$ and as an adult by $27 \%$ (Maxfield \& Widom, 1996). A second retrospective study found that adults who had substantiated childhood abuse or neglect cases were 4.8 times more likely to be arrested as a juvenile, two times more likely to be arrested as an adult, and 3.1 times more likely to be arrested for a violent crime than were a group of matched controls (English, Widom, \& Brandford, 2002).

Reported rates of maltreatment vary significantly from study to study, but in general, reports indicate that $38 \%-50 \%$ of incarcerated youth were physically abused at some point in their life (Colman \& Stewart, 2010; Dembo et al., 2000; Gore-Felton, 
Koopman, McGarvey, Hernandez, \& Canterbury Ii, 2002). Additionally, incarcerated youth have been found to be almost twice as likely as the general population to experience child sexual abuse (Coleman, 2005). Probably due to its high correlation with other types of abuse, as many as $73 \%$ of incarcerated youth reported experiencing emotional abuse in childhood (Silva, Graña, \& González-Cieza, 2013). Finally, reports indicated that incarcerated youth were more likely to have experienced neglect than any other form of child maltreatment, though this was likely a function of the huge percentage of CPS substantiated reports that involved neglect (Johnson-Reid \& Barth, 2000). Oregon Youth Authority only reports sexual abuse statistics for their incarcerated youth. Their most recent annual report found that $15 \%$ of their boys and $45 \%$ of their girls had experienced CSA (OYA, 2017).

A related issue worth mentioning, is the prevalence of abuse that occurs within "prison walls," both sexual and physical. In 2006, there were 732 substantiated incidences of sexual violence perpetrated on incarcerated youth nationally. Two hundred and ninety-five (295) of those sexual assaults were perpetrated by staff members (Beck, Adams, \& Guerino, 2008). As with all types of child maltreatment, it is likely that such incidents were under-reported. Similar high rates have been found for experiencing physical violence while incarcerated. Wolff, Blitz, Shi, Siegel, and Bachman (2007) found that incarcerated males were $18 \%$ more likely to be physically victimized than were men in free society. Moreover, women were $27 \%$ more likely to be victimized if incarcerated. Additionally, $24 \%$ of incarcerated men felt that they had been physically bullied, threatened or abused by a staff member. While no equivalent research has examined the prevalence of physical abuse in juvenile detention, there are indicators of 
abuse in these settings. For example, in 2016, Lincoln Hills School, a juvenile detention facility in Irma, Wisconsin, was raided by the Federal Bureau of Investigation after allegations surfaced that the staff were physically abusing the youth. Results of that investigation showed that there were more than 500 documented incidents of aggression and violence between youth and staff in the four months before the raid. The most horrific of these incidents entailed the amputation of a 16-year old youth's toes when a staff member slammed a seclusion door on his foot (Beck, 2016).

\section{Pathways from Child Maltreatment to Delinquency and Sexual Offending}

Having established the working definitions, incidence rates, and consequences of child maltreatment, this section outlines four possible mechanisms whereby youth who experience certain types of child maltreatment go on to commit criminal offenses. It begins with an analysis of the physical abuse to delinquency pathway, followed by the sexual abuse to sexual offender pathway, before turning to an examination of neglect. Here, a potential neglect to delinquency pathway, as well as a neglect to sexual offending pathway must be considered.

Physical Abuse to Delinquency Pathway. This subsection outlines the literature which argues that youth who are physically abused as children become more aggressive. These aggressive young adults, in turn, are more likely to commit crimes.

As noted previously, physical abuse has been found to be associated with deficits in the brain regions responsible for the regulation of emotions. Recall, too, that these brain deficits also explained increases in aggressive behavior that were often seen in physically abused youth. There is a large body of evidence that supports a relationship between physical abuse and aggression in children (Connor, 2012; Malinosky-Rummell 
\& Hansen, 1993). Physically abused youth are also at higher risk for "aggressive" disorders, such as Oppositional Defiant Disorder (Burke, Loeber, \& Birmaher, 2002), Conduct Disorder (Murray \& Farrington, 2010), and Callous-Unemotional Traits (Pardini, Lochman, \& Powell, 2007). In addition to aggression, physical abuse can also lead to alienation from peers (sometimes mediated by aggressive acts), so that the youth becomes isolated (Egeland, Yates, Appleyard, \& Van Dulmen, 2002). This creates a secondary risk factor for the development of juvenile delinquency and adult criminality. It is not surprising that an angry and withdrawn youth, who may also be experiencing a mental-disorder characterized by low-empathy, would act out criminally.

Support for this pathway was also provided by retroactively examining the histories of already incarcerated individuals. Lansford et al. (2005) found that adults who had been incarcerated for a violent crime were three times more likely to report a physical abuse history before age five than were non-violent offenders. Dutton and Hart (1992) similarly found that being the childhood victim of physical abuse lead to a fivefold increase in the likelihood of arrest for domestic violence, and a two-fold increase in the likelihood of arrest for assaulting a stranger. Moreover, Rebellon and Van Gundy (2005) found that youth who were beaten by their parents were more likely to be arrested for violent crimes, even after controlling for their frequency of prior offenses, educational status, substance use, and parental bond.

Importantly, some research studies contended that this pathway may not hold true for juvenile sexual offenders. Van Wijk et al. (2005) found that juvenile sexual offenders were exposed to significantly less harsh parental discipline as children than were juvenile delinquents. Limited exposure to physical abuse has been suggested as a contributing 
factor for common finding that incarcerated sexual offenders, in general, are less violent and hostile than the general inmate population (Kempton \& Forehand, 1992). These authors concluded that juveniles who commit a sexually aggressive act may be a distinct sub-population of the general population of juvenile delinquents who have committed aggressive non-sexual crimes.

In conclusion, there is some evidence to support the hypothesis that physical abuse may lead to aggression and thus may significantly influence engagement in violent criminal behavior. Furthermore, as the general inmate population may have experienced more physical abuse than have sexual offenders, physical abuse history may be one way of distinguishing juvenile sexual offenders as a distinct group of prisoners.

Sexual Abuse to JSO Pathway. Since the physical abuse to delinquency pathway may not accurately capture the development of juvenile sexual offenders, a second pathway (proposed specifically for JSOs) requires attention. This section outlines the literature on the high prevalence rates of sexual offenders who have themselves been sexually abused.

There is a deep-seeded myth in our society that the majority of sexual offenders have been sexually abused. While this relationship is by no means as highly related as the media sometimes suggests, there is some empirical validity for the pathway. Two separate meta-analyses, one with adult sexual offenders and one with JSOs, found that sexual offenders were more frequently victims of sexual abuse than were other non-sexoffender inmates (Jespersen, Lalumière, \& Seto, 2009; Seto \& Lalumière, 2010). It is notable that, in the adult meta-analysis, sexual victimization history was much higher for offenders who committed crimes against children, rather than adult rapists. Since JSOs 
also predominantly offend against same age or younger children, there is perhaps a particular mechanism by which sexual victimization in childhood increases the likelihood that one will offend against a child later in life. This hypothesis was proposed by Starzyk and Marshall (2003), who found that boys who were sexually victimized by adult men were more likely to choose male child victims themselves.

Imitation is one possible mechanism for this pathway to develop. Burton (2003) suggested that sexual offenders could be mimicking their own abuser's tactics, or that they could have become conditioned to pair sexual stimulation with the specific cues that were present in their own abuse dynamics. His research found that JSOs who had been abused themselves tended to reenact their own abuse on their victims. A second relevant finding, possibly linked to the abused/abuser pathway, is that sexually abused youth tend to go through puberty earlier than their peers (Brown, Cohen, Chen, Smailes, \& Johnson, 2004). It is unclear if the act of engaging in sex triggers early puberty, or if youth who go through puberty at an early age are at greater risk for sexual abuse. In either case, both juvenile and adult sexual offenders acknowledged earlier onset of masturbatory practices than did other types of offenders (Cortoni \& Marshall, 2001; Smallbone \& McCabe, 2003). This finding reinforces the suggestion that sexually abused youth might be hypersexualized, which may have lead them to direct their impulses toward sexual gratification as compared to later sexually developed youth.

Both this pathway and the previous section that argued for the development of delinquency via physical abuse can be considered under the umbrella of theories involving the "cycle of violence" hypothesis (Widom, 1989). This theory specifically argues that having an abuse history pushes that individual toward committing similarly 
abusive acts against others. Notably, Widom demonstrates that the cycle of violence data only distinguishes between law-abiding individuals and criminals. In other words, abuse history does not play a role in recidivism rates for individuals who have already begun to engage in criminal behavior. This finding suggests that the theory of cyclical violence might be especially applicable to juvenile delinquents, many of whom have just experienced their first contact with the legal system. However, it is important to be mindful of the minimal effect sizes seen in recorded cycle of violence studies. Rather than the emphasis on this hypothesis alone, several alternative pathways suggest useful venues of investigation.

Neglect to Delinquency Pathway. Separate from the cycle of violence pathways, some researchers have begun to examine the role of neglect on the development of delinquency. This section outlines that literature and contrasts it to the previously presented pathways.

As stated, neglect is the most common form of child maltreatment. This fact led some researchers to wonder if the relationships seen in both of the cycle of violence pathways are really a result of the long-term effects of neglect. Part of the reason for the ambiguity around these pathways results from what has been termed "the neglect of neglect." Namely, that researchers have not devoted sufficient time or resources into considering the role of neglect in the etiology of sexual criminality (Wolock \& Horotwiz, 1984).

The limited research that has been conducted suggests that there may be a connection between early childhood neglect and later delinquency. Schaffer, Clark, and Jeglic (2009), for instance, found that permissive, rather than authoritarian parenting, 
contributed to low levels of empathy and higher levels of antisocial behavior in adults. This finding would suggest that aggressive parenting, like that seen in physically abusive households, is not the direct cause of delinquency. Rather, youth whose parents did not create or enforce rules were more likely to become criminals later in life. Steinberg, Blatt-Eisengart, and Cauffman (2006) reported similar findings. Their work determined that delinquent children of neglectful parents had more severe psychological and behavioral dysfunctions than did the delinquent children of any other type of parents. This study was conducted using low-SES, ethnic-minority families, further legitimizing the role of neglect as a construct separate from poverty and cultural discrimination. Additional research has determined that some youth with substantiated neglect histories were more likely to recidivate than delinquent youth without neglect histories, a finding that directly contradicts the cycle of violence hypothesis (Ryan, Williams, \& Courtney, 2013). Although the data on the relationship between neglect and later delinquency is inconclusive, the issue of neglect is so central to the problems of child abuse that a consideration of its relation to sexual misconduct deserves more attention.

Neglect to JSO Pathway. This section explores the relationship between neglect and juvenile sexual offending. Authors in this area argue that JSOs constitute an extreme class in the neglect to delinquency path. Although research on this neglect pathway is still in its infancy, a small but growing body of literature emerged proposing that neglect may play a special role in the development of juvenile sexual offenders, beyond its role in general juvenile delinquency. Once again, researchers have determined that juvenile sexual offenders often come from neglected homes (Starzyk \& Marshall, 2003). Moreover, Seto and Lalumière (2010) noted that juvenile sexual offenders came from 
homes where neglect prevailed significantly more than juvenile delinquents who had not committed sex crimes.

Maniglio (2012) proposed a model for this relationship, suggesting that children from neglectful homes do not develop appropriate bonds with their parents. This lack of bonding leads to loneliness and difficulties socializing with others outside of the family (e.g., peers). This lonely and isolated child begins to develop deviant sexual fantasies, in which he is able to experience power, control, and intimacy. Eventually, the youth acts on these fantasies, committing a sexual assault.

In a second model, the development of a JSO results from the fusion of both sexual abuse and neglect. Poor supervision is a risk factor for being a victim of a sex crime as a child. With parents who do not provide adequate supervision or enforce rules and boundaries about interacting with adults, the child is susceptible to sexual victimization. In this model, the combined sexual abuse and neglect of such children dramatically increases their likelihood of becoming an abuser themselves (Salter et al., 2003). Thus, both of these hypothetical models have proposed a unique etiology of sexual criminality for youth.

\section{Delinquents and Juvenile Sexual Offenders as Identical Groups. Yet, in} contrast to these proposed pathways, some research studies postulated that there are no differences between youth who commit sex crimes and youth who commit other types of crime. This section analyzes that position and the research that supports it.

Despite the strengths associated with the four potential mechanisms for categorizing criminal youth based on their specific abuse histories, there is a significant literature which suggests that this sub-categorization is inappropriate. Authors in this 
camp argue that juvenile delinquents and juvenile sexual offenders constitute part of the same population. They suggest that the groups differ merely in that one youth had access and skills specific to a crime such as robbery (e.g., availability of a gun or weapon, freedom to prowl at night, etc.), while the other youth had access and skills particular to sexual assault (e.g., babysitting a younger cousin alone, access to money or material for bribes) (Smallbone, 2006).

This position has garnered some support from the statistics previously noted that indicated that juvenile sexual offenders were much more prone to have a second conviction for a non-sex offense than for another sex crime. Several authors argued that juveniles do not specialize in sexual offending. Instead, youth who commit sex crimes are really "generalist delinquents" who dabble in various forms of criminal behaviors. Indeed, both Starzyk and Marshall (2003) and Smallbone (2006) concluded that juveniles who sexually offended had profiles more congruent with other types of juvenile delinquents than with adult sexual offenders. Additional support came from nonsignificant findings when JSOs and JDs were compared on key dimensions. For instance, Zankman and Bonomo (2004) found that, while both groups were characterized by parental relationships that were low in warmth and cohesion, there were no measurable differences between the groups in their abuse histories. The conflicting views in this area point to the need for more research to determine the extent, if any, of the differences in child maltreatment experienced by youth who sexually offend as opposed to those who commit non-sexual crimes. 


\section{Attachment Theory}

This section explores how early childhood attachments influence the development of general and sexual delinquency. A brief overview of the history and conceptualization of Attachment Theory will begin this chapter. This will be followed by an elaboration of the outcomes associated with Attachment Theory in general, with particular attention paid to how early childhood attachments can assist in our understanding of the effects of child maltreatment. The chapter will conclude with a more targeted exploration of how this theory can be used to explain adult sexual offending, juvenile sexual offending, and juvenile delinquency.

History of Attachment Theory. In this subsection, the main principles of Attachment Theory are considered as they emerged historically. It clarifies both the fundamental hypotheses and their subsequent development. This theory will prove central to the future arguments presented in this study.

Attachment Theory was jointly conceptualized by Mary Ainsworth and John Bowlby (1991). The theory suggested that infants seek to create a bond with a caregiver (or "attachment figure") in order to protect themselves from harm. Bowlby (1969) argued that the successful "attachment" of a child to its caregiver creates a sense of security. $\mathrm{He}$ theorized that children who were securely attached to their mothers would grow to believe the world to be a safe place. These children, Bowlby thought, would feel that other people were kind and gentle, and that strangers could be trusted. This infantile attachment was thought to provide children with the confidence to explore their environments and create social bonds with new people. On the other hand, children who failed to develop this critical attachment bond would view the world as unsafe, scary, and 
malicious, and as a result would become introverted and afraid of venturing into their outer environments or interacting with strangers.

Bowlby first began to write about the underpinning of what would eventually become Attachment Theory based on his study of children who had been institutionalized or hospitalized for extended periods. Psychological thinking at the time was unable to explain the mindset of these institutionalized children; for even when their basic needs were met, they failed to thrive and displayed little affect. While working at a boarding school for maladjusted children, Bowlby conducted 44 case studies of affectless youth who had been caught stealing. He was able to show that maternal neglect in childhood was one of the features shared by these children (Bowlby, 1944). This early discovery led Bowlby to a lifetime of examining the relationship between parenting practices, early childhood maladjustment, and longitudinal outcomes.

At about the same time, Mary Ainsworth was completing her doctorate at the University of Toronto. She had focused her graduate work on the need for children to feel a sense of security within their families before venturing into unfamiliar situations or relationships. Her notion of a "secure base" would eventually become her major contribution to the development of Attachment Theory. In 1950, Ainsworth responded to a newspaper advertisement for a research position in John Bowlby’s lab. The pair of researchers continued to work together for the remainder of their careers. Jointly, they integrated their ideas on the importance of parenting for child development and co-wrote the foundational texts on Attachment Theory that are still used today (Bretheran, 1992).

Attachment Classifications and the Strange Situation Paradigm. At this point, it is incumbent to pause to describe in some detail the Strange Situation paradigm: an 
experiment that generated the fundamental categories within Attachment Theory. Its experimental procedure and the four attachment types that have resulted from the analyses of this paradigm, require attention.

One of Mary Ainsworth's further contributions was the development of a classification system for identifying the nature of the attachment between child and mother. Originally, she had classified children into one of three categories: securely attached, insecurely attached, or non-attached (Ainsworth \& Bowlby, 1991). She described the securely attached child as confident that his mother is a "secure base" to whom he can return anytime he requires comfort or confidence. The insecurely attached child views his mother as inconsistent in her ability to provide comfort for him. According to the original theory, an insecurely attached child will remain close to his mother if at all possible, in order to increase the likelihood of receiving attention and care, if necessary. Finally, a non-attached child does not view his mother as different from a stranger in any significant way. He is just as likely to seek comfort and support from another individual as he is to return to his mother in times of distress.

Ainsworth developed a procedure for assessing attachment that is still used today. It is referred to as the Strange Situation paradigm. In this experiment, a child and his mother enter a playroom to play together with the available toys. They are promptly joined by another female research assistant whom the child does not know. As the researcher begins to play with the toys, the mother leaves the room. After a period in which the child is alone in the room with the researcher, the mother then returns to the playroom and again interacts with the child. This is followed by a second exit by both the 
mother and the researcher, leaving the child completely alone in the room. Finally, the mother and the researcher re-enter the room and greet the child.

This experiment allows for the attachment of the child to be determined. The observers are able to code the child's reaction to playing with a stranger, to being alone, and to having their mother return after an absence. During the Strange Situation paradigm, the child's behavior is watched closely and examined for signs of anxiety, fear, avoidance, and positive affect. After determining the extent to which the children attempted to gain comfort and closeness to their mothers, Ainsworth categorized them into one of three attachment patterns: securely attached, insecure-ambivalent attachment (sometimes known as insecure-anxious attachment), or insecure-avoidant attachment. Eventually, a catch-all fourth categorization, called disorganized attachment, was added to the classification system (Main \& Solomon, 1990).

A child who is classified as securely attached happily explores the playroom while his mother is present. He has positive interactions when the stranger joins them in play. However, he stops interacting with the stranger when his mother leaves the room. The child is comfortable in that environment only when he is assured that he can return to his secure base (his mother). When his mother returns following her absence, the securely attached child greets her enthusiastically. A child with insecure-ambivalent attachment is hesitant to explore the room or interact with the stranger, even if his mother is present. When his mother leaves the room, the child becomes distraught. Interestingly however, when his mother returns and greets the child again, he throws a tantrum and pushes away from her. This captures the dual dynamic of insecure-ambivalent attachment. Such children feel a desire to be near their mothers at all times, but they also reject their 
mothers' attention when it is offered to them. In contrast, a child who is categorized as insecure-avoidant demonstrates that he is not particularly attached to his mother. This child explores the environment and interacts with the stranger whether or not their mother is present. When the mother returns after her absence from the room, the child shows indifference towards her. Such children are generally affectless. They show few behavioral changes regardless of being alone, being left with a stranger, or being cared for by their mothers. Disorganized children do not fall into any of the three main classifications for attachment. The name reflects the disorder and the chaos felt by children in this category. A disorganized child may display any of the behavior seen in securely or insecurely attached children, but he does so inconsistently and switches between modes randomly (Main \& Solomon, 1990).

Overview of the Literature on Attachment Theory. With the dissemination of the Strange Situation paradigm researchers have used Attachment Theory to explain a wide variety of developmental behavior across the lifespan. The popularity of this theory has led to a wealth of studies examining the role of attachment in both normative and pathological development. This section provides a brief summary of that general literature.

A recent meta-analysis of the attachment literature (Groh, Fearon, IJzendoorn, Bakermans-Kranenburg, \& Roisman, 2016), found that secure attachment in infancy has been associated with high social competence $(d=.39)$ and low-levels of externalizing problems $(d=.31)$. Being securely attached was also somewhat predictive of lower levels of internalizing problems $(d=.15)$ compared to insecurely attached children. On the other hand, children classified as avoidant had low social competence $(d=.17)$, and were 
significantly higher in both internalizing $(d=.17)$ and externalizing symptoms $(d=.12)$ than were their securely attached peers. Ambivalent children too demonstrated low social competence $(d=.29)$ but instead of internalizing and externalizing problems, they had elevated levels of negative temperament $(d=.23)$. Finally, children with a disorganized attachment pattern were the most likely of any of the attachment types to display problematic externalizing behaviors $(d=.34)$. Notably, these findings did not significantly vary with the age of the participants. Early childhood attachment patterns were related to similar socio-emotional development regardless of whether the child was assessed in early infancy or mid-adolescence (range 1-14 years). Together, these findings provide evidence for the longstanding effects of attachment types on a number of socioemotional scales, particularly those related to social competence.

Groh et al.'s findings reflected the earlier literature, which noted that infant attachment classifications remain relatively stable into adulthood (Chris Fraley, 2002). Multiple meta-analyses have found that childhood attachment had significant effects in predicting psychological and behavioral outcomes in adults. For instance, Woodhouse, Ayers, and Field (2015) found that securely attached adults had fewer symptoms of PTSD following trauma. Securely attached adults also have greater therapeutic alliance than do insecurely attached adults (Diener, Hilsenroth, Weinberger, \& Monroe, 2014). Finally, Hadden, Smith, and Webster's (2014) meta-analysis found that insecurely attached adults were less satisfied with their romantic relationships than were securely attached adults. The consistency of these findings reinforces the accuracy and usefulness of Ainsworth's categories for distinguishing the styles of attachment and for their predictive value from childhood through adulthood. 
Attachment and Abuse. In a previous section, this manuscript explored the effect of early childhood maltreatment on a host of negative outcomes. Here, it is important to discuss how the categories of attachment bear direct relations to the different forms of abuse and neglect.

A large portion of the literature exploring Attachment Theory focused on the relationship between childhood maltreatment and insecure or disorganized attachment. The hallmark characteristic of a poor attachment style is the display of a negative emotion by the child upon the return of their mother in the Strange Situation paradigm. Avoidant children ignore their mothers, ambivalent children throw tantrums, and disorganized children "freeze" (Ainsworth, Blehar, Waters, \& Wall, 1978; Main, Kaplan, \& Cassidy, 1985). Ainsworth and Bowlby suggested that maternal maltreatment could be the cause of these unusual responses. It has been posited that children who have been maltreated by their primary caregiver are wrought with internal conflict. They view their caregiver both as a source of comfort and support as well as discord and fear. As such, they are unable to choose whether or not they want to move toward, or away from their mothers when they reappear (Main \& Hesse, 1990; Van Ijzendoorn, Schuengel, \& Bakermans-Kranenburg, 1999). The statistical evidence supports this hypothesis. It showed a clear correlation between maltreatment and attachment classifications. Baer and Martinez (2006), using over 80 studies, found that $80 \%$ of maltreated children had an insecure attachment style, compared to only $36 \%$ of non-maltreated youth. This finding convincingly supports the connection between the fundamental classifications of Attachment Theory and abuse typology. 
As we learned from the previous section, however, child maltreatment comes in many forms. With this in mind, Crittenden (1992) utilized the Strange Situation paradigm to examine how various forms of abuse and neglect might be mapped onto the four types of attachment. The results were unsurprising. Children with no abuse history were most likely to be coded as securely attached. Children who had experienced physical abuse alone were most often coded as anxious/ambivalent: they were likely to fight or tantrum when their mothers returned to the room. Children who had experienced only neglect were most often coded as avoidant: they ignored or appeared disinterested in their mothers. Finally, children who had experienced both abuse and neglect were most likely to be classified as disorganized (in this paper disorganization was conceptualized as a mix of both avoidant and ambivalent attachment styles). Crittenden concluded that children generally reflect their experience of abuse in their attachment styles. Those whose families were quick to anger and violence reacted to the presence of their mothers with anger and violence. On the other hand, children who were ignored and neglected learned to ignore and neglect their mothers. Thus, the distinctions between various types of abuse and the corresponding styles of attachment provide a schema for understanding populations that are at high risk for experiencing child maltreatment.

\section{Attachment Implications for Juvenile Delinquents and Juvenile Sex Offenders}

At this point, the discussion of attachment must be directed to the specific populations of interest in this manuscript: sexual offenders and delinquents. The first matter of concern is how attachment patterns influence adults' sexual offending behavior. The subsequent sections explore the role of attachment in the development of juvenile 
sexual offending, and how attachment patterns do and do not differ between JSOs and JDs.

Attachment as it Applies to Adult Sexual Offenders. This initial subsection reviews what is known about the relationship of Attachment Theory to adult sexual offenders. It examines the functions of isolation and insecure attachment in the etiology of sexual offending.

Marshall (1989) was the first to discuss attachment as it related to sexual offending. He noted that adult sexual offenders have failed, overwhelmingly, to form secure attachments as children. Marshall went on to describe a pathway, similar to the neglect-to-sexual abuse pathway described earlier in this text. He posited that men who were insecurely attached as children fail to develop appropriate emotional bonds with others as adults. This, in turn, led to isolation, loneliness, and frustration that may have expressed itself as sexual aggression. Marshall additionally noted that this attachment perspective may shed light on the sexual abuse-to-sexual abuser pathway, especially as an explanation for why experiencing sexual abuse is a relatively weak overall predictor of sexual offending. Marshall argues that:

...it might very well be that a child who has himself experienced ineffective parenting, and thereby failed to achieve secure attachment bonds, will find the experience of sexual molestation by an adult as far more significant and attractive, since it clearly involves a form of intimacy, than will a child who has a secure attachment bond and whose need for intimacy is therefore satisfied in more appropriate ways. It is, perhaps, no accident that nonfamilial child molesters seek, as victims, children who appear to be in need of attention and affection (Marshall, 1989).

The crux of Marshall's argument was that the combination of sexual abuse as a child and a pre-existing insecure attachment bond creates an opportunity for an adult to become a 
sexual offender. Either situation, on its own, may not account for driving the individual to that extreme, but in combination, the likelihood of offending may increase substantially.

Since 1989, additional researchers have supported Marshall's conclusions (Seidman, Marshall, Hutson, \& Robinson, 1994; Ward \& Marshall, 1996). Studies comparing sexual offenders, both incarcerated and in the community, to other populations have found that those who commit sex crimes have greater deficits in loneliness and intimacy than do other types of offenders or non-criminal populations (Seidman et al., 1994). Further, the finding that sexual offenders are more likely to be insecurely attached than other populations (i.e., both criminal and non-criminal) has been replicated a number of times (Sigre-Leiros, Carvalho, \& Nobre, 2016; Smallbone \& Dadds, 1998; Smallbone \& Dadds, 2001). It has been suggested that as many as $93 \%$ of sexual offenders had some type of insecure attachment pattern (Marsa et al., 2004). Extending this research, Ward and Marshall (1996) compared four types of offenders on attachment styles (i.e., rapists, child molesters, violent non-sexual offenders, and nonviolent/non-sexual offenders). They found that rapists, who as a group had elevated levels of hostility and callousness, were more likely to have an insecure-avoidant attachment style with their primary childhood caregiver. On the other hand, child molesters, who had elevated levels of fear and anxiety, were more likely to be categorized as having an insecure-ambivalent attachment style. Therefore, the authors posited that not only does one's insecure attachment style generally contribute to sexual offending in adulthood, but the characteristics of the offender types corresponded to their modes of infantile attachment. 
Attachment as it Applies to Juvenile Sexual Offenders. As in previous sections, the portion of the literature that extends findings regarding adult sexual offenders to juvenile offenders is of interest here. More specifically, this section considers a pathway whereby poor attachment relates to juvenile sexual offending through social isolation from peer groups.

Following up on his early writings about attachment in adult sexual offenders, Marshall extended his research to juvenile sexual offenders (Marshall, Hudson, \& Hodkinson, 1993). In this article, the authors pointed to research coming out of the field of developmental psychology that established a connection between insecure parental bonds and poor peer social skills (Cohn, 1990; Jacobson \& Wille, 1986). This work has been reaffirmed and amplified in the last 20 years, providing the consistent conclusion that insecure parental attachments predict weak friendship bonds among children and adolescents (Pallini, Baiocco, Schneider, Madigan, \& Atkinson, 2014; Schneider, Atkinson, \& Tardif, 2001). These findings were even more pronounced in offender samples. Longitudinal research found that many juvenile sexual offenders reported having remarkably few friendships through their teenage years. Fehrenbach, Smith, Monastersky, and Deisher (1986) found that $32 \%$ of JSOs in their sample reported having no friends at all, and another 34\% reported having no close friends. Furthermore, Fagen and Wexler (1988) found that JSOs reported higher levels of social isolation than did other violent criminal youth. More recently, a review of the literature conducted by Van Wijk et al. (2006) found that JSOs reported having poorer peer social relationships across a variety of dimensions than did other types of juvenile offenders. Finally, Miner et al. (2010) found that adolescents who sexually offended were more likely to be socially 
isolated from their peers and to desire more emotional closeness than other juvenile delinquents. Adolescence is a time in the individual's development when social relationships are of primary importance. It has been theorized that adolescent isolation may lead the youth toward a rich fantasy life dominated by thoughts of power, control, and intimacy. In combination with the intense hormonal pressure of the teenage years, these fantasies may increase the potential for committing a sexual offense (Daversa \& Knight, 2007; Manigilo, 2012; Ward \& Beech, 2006).

Attachment Differences Between JSOs and JDs. There is considerable controversy amongst experts over whether attachment functions differently in JSO samples compared to general juvenile delinquents. This section explores both viewpoints on this matter.

Although Marshall presented a clear path for the development of juvenile and adult sexual offending through poor attachment bonds in infancy, there was one serious flaw in his conclusions. He failed to account for evidence suggesting that poor parental attachments were seen in overwhelmingly high rates for all types of delinquents and incarcerated adults, not just in sexual offenders. For instance, in a series of metaanalyses, Loeber and Southamer-Loeber (1986) found that poor parenting was the primary predictor of general juvenile delinquency. Many psychologists have ascribed to this line of thinking. Researchers endorsing the argument that most juvenile sexual offenders are generalists, not specialists, have argued that JSOs do not represent a separate typology from other kinds of delinquents (Zankman \& Bonomo, 2004). They maintained the position that all types of juvenile offenders are likely to have been both maltreated and to have insecure attachment styles. Specifically, in adult samples, Ward, 
Hudson, and Marshall (1996) concluded that there may not be differences in attachment patterns between sexual offenders and other inmates, and that attachment insecurity may be more related to general criminality than any specific offense type. In juveniles, Rich (2006) argued that there is no strong evidence for the direct connection between insecure attachment and sexual offending in adolescents at all, and even less of a case to be made that juveniles who sexually offend had different levels of insecure attachment than did other types of juvenile delinquents.

At the same time, there is a second body of literature that has found important differences in the attachment patters of sexual offenders in comparison to general criminals. In adult samples, Marsa et al. (2004) found that only seven percent (7\%) of child molesters had a secure attachment type, compared to $30-45 \%$ of other, non-sexual offenders. Lyn and Burton (2005) found similar results when they compared incarcerated sex offenders to other violent offenders. This pattern held true in juvenile samples, as well. Smallbone (2006) and Whitaker et al. (2008) discovered that JSOs had less attachment to parents overall than did JDs. More specifically, Funari (2005) found that JSOs had higher levels of disorganized attachment than did other violent or non-violent juvenile offenders. Additionally, some authors suggested that it was the combination of insecure attachment style and early exposure to sexual material or sex acts that separated juvenile delinquents from juvenile sexual offenders (Burk \& Burkhart, 2003; Marshall et al. 1993). In combination, these results problematize the notion that attachment functions identically for juvenile sexual offending and general criminal offending. Consequently, these and other authors argued that there is a true difference between these populations, 
though it is not as simple as a matter of attachment or maltreatment history, insofar as early exposure to sex and social isolation might mediate the relationship.

The evidence and arguments are strong on both sides of this discussion. More research is warranted to determine the degree to which attachment is related to juvenile sexual offending over and above general juvenile delinquency. Almost certainly, no particular attachment style, by itself, can be highly predictive of sexual offending. However, in combination with the other risk factors explored in this manuscript, a consideration of attachment may help explain some of what causes youth to sexually offend.

\section{Caregiver Disruption}

In this section the term "caregiver disruption" is used to discuss any instance in which children receive insufficient or substitute care as a result of their biological parents' inability to meet their physical and emotional needs. This term helps to clarify the family configurations common to juvenile sexual offenders. These youths are likely to live in non-nuclear families, with non-biological caregivers, or with male primary caregivers. They tend to change or add new primary caregivers throughout their childhoods. Each of these abnormalities is examined and the literature relevant to caregiver disruption and youth offending is discussed. At the end of this section there is a brief discussion of the application of these issues specifically to juvenile sexual offenders.

History of Disrupted Caregiving Research. Over the last 50 years, the structure of the "nuclear" family has changed dramatically. Recent census data reported that 33\% of American children were living without their biological father (U.S. Census Bureau, 
2016). Seven percent (7\%) of all children in the United States were living in a home without either of their biological parents. In comparison, in 1970, the US Census reported that $11 \%$ of children were living in a single-mother household and $.003 \%$ of children were in families without either biological parent (U.S. Census Bureau, 1970). There are multiple reasons for this shift. Rising divorce rates, diminished stigma surrounding bearing children out of wedlock, the increasing numbers of blended step-families, and a rise in LGBT families all contribute to the panoply of potential family systems in which a child may live. In response to the quickly changing landscape of family structures, researchers in psychology and sociology have made efforts to map the outcomes for children living in non-nuclear homes. That literature is briefly reviewed in this section.

More research has examined outcomes for children of divorce than on any other aspect of caregiver disruption. Large meta-analyses have found that children with divorced parents scored particularly low on measures of well-being (Amato \& Keith, 1991). After controlling for divorce's other potentially adverse effects, such as increased stress and economic hardship, researchers still found that divorce has a powerfully negative effect on children. Amato continued to produce updates to his 1991 publication as the divorce rate soared throughout the 1990s. In 2001, he added an additional 67 studies to his meta-analysis. These more recent studies supported his initial conclusions. Children of divorced parents scored lower on measures of academic success, psychological well-being, and prosocial behavior/social relationships than their peers with still-married parents (Amato, 2001). Similar results have been found for "blended" homes. Manning and Lamb (2004) examined over 13,000 families from the National Longitudinal Study of Adolescent Health dataset and found that teens who lived with a 
step-parent had low scores on psychological well-being when compared to children living with their biological parents. In fact, children with step-parents had well-being scores that were just as low as children in single parent households, again suggesting that this effect may have been independent of third variables such as stress.

After psychological well-being, delinquency is the most studied outcome in the family disruption literature. Since the early $19^{\text {th }}$ century, social scientists have been writing about the link between "broken homes" and delinquency. Originally, authors posited that children with non-nuclear families turn to crime due to a failure of parents to instill proper moral values in their children and a lack of sufficient disciplining practices (Frazier, 1950). In fact, John Bowlby tackled the broken homes theory of delinquency in his early work. He studied youth who had been caught stealing and attempted to find patterns in their early life experiences which could explain their later delinquent behavior. He discovered that 12 of the 14 delinquent youth he studied had experienced separations from their mothers during their early childhoods (Bowlby, 1944). This study eventually led Bowlby to formulate his theory of the critical early attachment window for children to develop into well-adjusted teens and adults.

Obviously, the research on the potential relationship between parental separation and juvenile delinquency did not end with Bowlby. Later studies have found that nonoffenders were significantly less likely to come from homes characterized by caregiver absence, such as in the case of divorce or single-parenthood, than were incarcerated youth (Gormon-Smith, Tolan, Loeber, \& Henry, 1998). Additionally, serious and chronic offenders were more likely to come from homes with disruptions in caretaking than were less serious or infrequent offenders (Gormon-Smith et al., 1998). Further research linking 
caregiver disruption and delinquency, which specifically examined the effects of parental incarceration on youth, found that boys whose parents were incarcerated were more likely to become delinquent themselves, even after controlling for exposure to criminal activities by the parents (Murray \& Farrington, 2005). In this study, almost 50\% of boys whose parents were incarcerated before they were ten, would ultimately be convicted of a criminal offense themselves. Finally, a meta-analysis consisting of 50 studies which involved broken homes and delinquency found that youth in non-nuclear families were $10-15 \%$ more likely to become delinquent than were youth in intact families (Wells \& Rankin, 1991). Whether from divorce, the death of a parent, or parental incarceration, the outcomes for youth involved in disrupted families are negative.

Atypical Caregivers. At this juncture in the discussion, it is important to consider various types of non-nuclear families in order to illustrate the broad range of family configurations. The research in this area focuses on three familial structures: (1) fathers as primary guardians; (2) non-parental family members like custodial grandparents; and (3) non-biological guardians, such as foster families. Each of these disrupted family systems has been applied to the study of juvenile delinquency and that literature is reviewed here.

Fathers as Primary Caregivers. National statistics, predictably, report that youth in the United States are unlikely to live with a male as their sole primary guardian. In 2016, only five percent (5\%) of all US households had a single male as the head of household (U.S. Census Bureau, 2016). However, a number of studies have demonstrated that youths' relationships with their fathers are particularly significant for the potential development of delinquency and externalizing disorders. In his comprehensive review of 
the literature on parenting outcomes amongst fathers, Coles (2015) demonstrated that nearly all of the studies of conduct disorders and delinquency outcomes as functions of family systems show that youth raised by men were the most likely to engage in delinquent behavior or be diagnosed with an externalizing disorder. In a second example, Shears, Robinson and Emde (2002) asked adult men to report retrospectively on their relationships with their fathers when they were teens. They found that the negative quality of the father-son relationship was directly related to delinquent acts. Additionally, Breivik and Olweus (2006) found that youth who ended up in single-father households following their parents' divorce had significantly higher levels of externalizing problems than did children with married parents, post-divorce children living with single-mothers or mothers and stepfathers, or children whose divorced parents were sharing custody.

The most commonly proposed mechanisms for the relationship between primarymale parenting and delinquency is the reduction of emotional closeness and a lack of monitoring or supervision. A consistent body of literature has shown that fathers are less close to their children, know less about their children's friends and school behaviors, and are less likely to supervise their children than are single-mothers or married parents (Breivik \& Owleus, 2006; Bronte-Tinkew, Scott, \& Lilja, 2010; Coles, 2015). Lack of involvement in the child's life may leave the child available to begin experimenting with substances, engaging in delinquent behavior, and forming negative peer relationships (Demuth \& Brown, 2004). Though these outcomes may be poor, living with a biological parent perhaps offers at least some protective effects. Unfortunately, some children are unable to live with either biological parent, and thus may be at even greater risk for 
delinquency. This is the case in the following section, which details the research on extended family as primary guardians.

Family Caregivers. There is a growing population of American children whose primary guardian is a non-parental family member. US Census data documented a $64 \%$ increase in children living with at least one grandparent between the years of 1991 and 2011. In total, over 2.5 million grandparents in the US were responsible for the primary care of their grandchildren in 2011 (Ellis \& Simmons, 2014). This trend is reflected in the psychological literature, where studies on the effects of custodial grandparents and other family members is increasing. This literature is new, and it is mixed. Poehlmann (2003) argued that the presence of a primary custodial grandparent can foster resilience in the child, such as when the child has left a very unstable or abusive home with his biological parent and enters a stable, authoritative home with an attentive grandparent. Further research has shown that children who were primarily cared for by their grandparents had more positive experiences than those raised in foster care or other non-parental placements, due to having had a caregiver who knew them personally and was invested in their success (Hanlon, Carswell, \& Rose, 2007; Hayslip \& Kaminski, 2005).

More often, however, the presence of custodial grandparents is associated with emotional and behavioral disturbances in the youth (Bachman \& Chase-Lansdale, 2005; Emick \& Hayslip, 1999; Pruchno \& McKenney, 2002). For example, Poehlmann (2005) found that children who lived with their grandparents due to their mother's incarceration had overwhelmingly negative relationships with both their mother and their custodial grandparent. Poor behavioral and emotional outcomes for children with custodial grandparents persisted even when controlling for depression in grandparents or economic 
burdens (Poehlmann et al., 2008). However, there may not be anything inherent in the grandparent-grandchild relationship that causes these conduct problems. Indeed, it is more likely that the conduct problems precipitated the move out of the parents' home and into the grandparents', or that the youth was removed by the state due to allegations of abuse or neglect by the parents. In earlier sections of this manuscript it was noted that abuse and neglect are often the cause of conduct disorders in youth. Even before the recent boom in custodial grandparents in America, Kelly (1993) found that child abuse, child neglect, and parental substance abuse were the predominant reasons for placing a child with a grandparent. One qualitative study examining the lived experiences of custodial grandparents found that $71 \%$ of the interviewed grandmothers reported that their grandchildren had suffered abuse or neglect in their previous home before being placed with them (Williamson, Softas-Nall, \& Miller, 2003).

Yet, little to no research has been conducted examining the relationships of children living with other types of non-parental family members (e.g. aunts and uncles, older siblings). Since the negative outcomes associated with familial placements seem to be independent of such factors as economic hardship, one might assume that a similar pattern would hold true under those circumstances as well. Furthermore, it is reasonable to assume that other family members might be able to provide the same protective factors that have been shown to benefit children with custodial grandparents, as opposed to foster care or other non-familial placements. Empirical research is needed in this area in order to validate those assumptions.

Non-Biological Caregivers. Many children live with caregivers with which they share no genetic relationship. In 2015, just under 500,000 youth were actively in the 
foster care system in the United States (CWIGb, 2016). An additional two million children lived with adopted parents, and over four million children lived in a home with a step-parent (Kreider \& Lofquist, 2014).

The literature on outcomes associated with non-biological caregivers is ambiguous. Much of the data is the result of program evaluations of interventions that were specifically designed to help children transitioning into the foster care system. This research found that living with a biological family member has proven largely unsuccessful at improving wellbeing and stability, or in reducing externalizing behavior over and above a non-biological placement. Leon, Saucedo, and Jachymiak (2016) found that children who were exposed to a family-finding foster care intervention would ultimately experience as many placement changes - i.e., about three changes in caregivers - as control foster care youth. Some studies have also shown that being cared for by a family member does not significantly impact the chance that the youth will ultimately be reunified with their biological parents or reduce their total time in foster care (Vandivere \& Malm, 2015).

Besides the foster care system, researchers have also mapped outcomes for adoptive children. This research has primarily focused on assessing differences between early and late adoption. Like the broader literature on caregiver disruption, outcome studies have overwhelmingly focused on the potential for adopted children to become delinquent or mentally ill. Large-scale survey data suggested that there is some cause for concern in this regard. A study of over 90,000 teenagers in the United States found that adopted youth had poorer school performance, lower psychological well-being, and greater substance use than did non-adopted youth (Miller, Fan, Christensen, Grotevant, \& 
Van Dulmen, 2000). Meta-analyses have pointed to similar problematic outcomes for adopted children. Juffer and van Ijzendoorn (2005) found that adopted children were more likely to receive mental-health services and were more likely to exhibit externalizing conduct problems than were non-adopted controls. In fact, one study directly compared adopted children to both children living with their birth families and children living with grandparents (but without their parents) and largely confirmed Juffer and van Izdndoorn's findings (Adopted Children in the US, 1995). This study also found that adopted children had more behavior problems and developmental delays than did children in the other family systems. However, studies also suggest that early placement may alleviate some of these concerns (Palacios \& Brodzinsky, 2010). In fact, Adopted Children in the US (1995) found that the negative outcomes associated with adoption were dramatically reduced when the child was adopted within their first year of life.

Outcome studies on the effects of step-parents have also produced variable results. As noted previously, one study found that children living in mother-stepfather households had fewer problems with externalizing disorders than children in single, biological father households (Breivik \& Olweus, 2006). However, there are two notable cautions in interpreting this study's findings. First, mother-stepfather households still produced children who were significantly more likely to have an externalizing disorder than were children with joint-custody divorced parents or married parent households. Second, father-stepmother households were not included in these analyses at all. To help fill this gap, Bronte-Tinkew et al. (2010) cited evidence that "single custodial-father families with a co-resident partner" were the least likely to engage in family-oriented 
activities and showed the greatest neglect of children, even compared with single fathers who had not re-partnered.

In the child maltreatment literature, the "Stepfather Effect" is used to refer to the consistent finding that stepfathers are more abusive toward their step-children than their biological children, even when all of the children live in the same household (Hilton, Harris, \& Rice, 2015). Studies examining police reports for the Stepfather Effect have found that fathers were more than twice as likely to assault their genetically-unrelated children than their biological children, even when the number of children in the household and level of paternal antisociality were controlled for in the analyses (Hilton et al., 2015). Horrifyingly, one study found that children were more than 70 times more likely to be murdered by a stepfather than their biological father (Daly \& Wilson, 1988). The Stepfather Effect has been observed in child reports, as well. Evenhouse and Rilly (2004) gathered reports on well-being and family harmony from cohabitating stepsiblings, one of whom was genetically related to both parents and one of whom was a non-biological stepchild of one parent. Their results indicated that children living in mother-stepfather families had the lowest levels of parental-involvement, poorest educational outcomes, were the most likely to engage in risky behavior, and had the poorest relationship quality with their stepfather than did all other groups (i.e. fatherstepmother, single-mother, both bio parents). These results persisted when controlling for the scores produced by their cohabitating step-sibling, which theoretically should eliminate any impact of external factors unrelated to the family dynamic.

\section{Comparing Types of Caregiver Disruption in Relation to Delinquency. One} potential limitation of this line of research is a reliance on an overly simplistic coding 
scheme related to key study variables. The studies presented above often categorize youth through the use of a dichotomous variable: youth either live in a nuclear home or not; their fathers are either present or absent, etc. Yet, one can easily imagine family systems in which that distinction is muddied. For instance, a youth living with a biological mother and biological grandfather would be classified as non-nuclear, just the same as would a youth who is living with a single adoptive parent. To date, only two studies have attempted a more sophisticated and detailed examination of the broken home theory of delinquency. First, Demuth and Brown (2004) found that adolescents raised in singleparent households were more delinquent than youth who lived with their two, biological, married parents. Further, among youth raised by single parents, those who were living with only a father were more likely to be delinquent than those raised by a single mother. Second, using the 1997 National Longitudinal Survey of Youth, Apel and Kaukinen (2008) compared youth living with two, biological, married parents to a wide array of disrupted caregiving situations. They found that youth who lived with a biological father and their father's new cohabitating partner exhibited unusually high rates of antisocial behavior. Youth living in foster care, with adoptive families, or with other variations of primary-father custody (father-stepmother, single-father) were also at high risk for delinquency. Additionally, these authors found a protective effect of living with a nonparental family member. Youth living with a grandparent or another older relative were more likely to be delinquent than youth in nuclear families, but were significantly less prone to be delinquent than were youth living with single biological parents, non-related caregivers, or biological parents with new partners. 
Since Demuth and Brown and Apel and Kaukinen executed the only two studies that combine family systems in a comparative analysis, it is premature to assert that delinquency is found more frequent in disrupted families, and that in such families, that absence of the biological mother is a crucial factor in increasing the potential for delinquency. In light of the paucity of research in this area and the limitations of available data, two important and related issues - the consequences of changing family structures for the child, and the relevance of the Attachment perspective - can only be outlined briefly and inconclusively.

Changes to Primary Caregiver. The problems of family disruption are complicated and exacerbated by the multiple placement changes that may occur in a child's life. James (2004) found that children who "bounced around" from placement to placement, were more likely to experience externalizing difficulties than were children who found a stable home. A similar finding was discovered by Barber and Delfabbro (2003), who tracked foster care kids longitudinally across an eight-month period. They found that youth who remained in the "unstable" group for the entire time (i.e. lived in at least three different placements during the eight months between assessments) had significantly higher conduct problems than did children who found a stable foster home during that time period. This latter group of children switched placements at least once during those eight months but then stayed in that placement. Furthermore, children who did not switch placements at all had the least amount of conduct problems. This result was maintained even when the authors controlled for moves that were provoked due to the child's unmanageable behavior. 
In this complex web of potential causes for delinquent behavior in children, the failure to account for changing guardians creates an obstacle to efforts to understand the root causes of sexual offending. Children of divorced families, those living with grandparents, or those placed in foster care have all experienced at least one dramatic change of the family structure (and many have had to endure several). The absence of data on the impacts of changing households is a glaring gap in the literature on caregiver disruption.

Caregiver Disruption from an Attachment Perspective. A second serious outcome of changing placements may be the inability to foster secure attachments with a primary caregiver. Through the lens of Attachment Theory, emotionally distant fathers may be seen as lacking the skill or empathy to forge secure attachment bonds with their sons. Further, children who are incorporated into stepfamilies after the early attachment period may struggle to bond with their new family members. Attachment Theory also offers an explanation as to why early-adopted children (who are still within their critical attachment window) are less likely to present with the same difficulties that their lateadopted peers do.

In general, research findings on caregiver disruption and attachment have been relatively consistent. For example, in a study on adults who had lived in adoptive families, those who had been adopted before age two were more than twice as likely to report a secure attachment relationship with their adoptive mother (Howe, 2001). In a summary of attachment studies using children in alternative care (i.e., orphanages, institutions, foster care, etc.), Quiroga and Hamilton-Giachritsis (2016) found, unsurprisingly, that the literature overwhelmingly supports the assertion that attachment 
is negatively affected by alternative care. The studies they reviewed suggested that children in these types of placements were unlikely to have secure attachment patterns to any adult and were much more likely to exhibit a disorganized attachment pattern than are youth in a stable caregiving environment. Therefore, in order to fully understand the connections between caregiver disruption and juvenile offending, relationship quality between the youth and caregiver must be assessed.

Parenting Juvenile Sexual Offenders. The preceding review has set the background for the central topic of this study: the family systems of juvenile sexual offenders. Since juvenile sexual offenders can be thought of as a special type of juvenile delinquent, that literature may help explain how and why a youth sexually offends. However, it is also possible that JSOs experience caregiver disruption in a different way than do their delinquent counterparts. Less research has been conducted to examine specifically how parenting dynamics influence the development of juvenile sexual offending in particular. This section summarizes what is known about the impact of the biological relationship to caregivers, gender of caregivers, and number of times a youth has changed caregivers using samples of JSOs.

Felizzi (2015) provides the most relevant study on the topic of caregiver disruption and JSOs. He reported that caregiver instability, and the subsequent disruptions in child-parent attachment that follow from such instability, was predictive of juvenile sexual offending. More specifically, this study found that incarcerated juvenile sexual offenders had lower maternal and paternal attachments than did incarcerated youth who had committed a non-sexual offense. This research also found that "lots of moves or homelessness" was the strongest predictor of sexual offending status in their sample, 
followed by "children placed out of the home" and "abuse history." Notably, "frequent changes to who lives in the home" was not a significant predictor. Felizzi concluded his article by noting that his study is one of only a handful to directly discuss parental instability, attachment, and juvenile sexual offending. Further research is needed in this area to clarify the relationship between instability and sexual offending.

While Felizzi's study did an excellent job of applying multiple dimensions of the family disruption literature into one analysis, studies that have taken a more targeted approach also add to the understanding of how parenting problems affect JSOs. One area of interest has been the influential role of fathers in the development of juvenile sexual offending behavior. There is some evidence that the strain between father-son relationships may be an even stronger predictor of juvenile sexual offenses than of more general delinquent offenses. As explained in the earlier section on Attachment Theory in regards to JSOs, sexual offenders often have problematic relationships with their parents. McCormack, Hudson, and Ward (2002) interviewed males with no history of offenses, male sexual offenders, and male offenders who had committed other non-sexual crimes. They concluded that sexual offenders rated their relationships with their fathers significantly worse than did the other two groups. Furthermore, Knox (2014) found that JSOs had significantly poorer attachment to their fathers, and were less trusting of their fathers, than were JDs.

Broken homes theory, too, has been tested within a juvenile sexual offender population, though the results have been inconclusive. Van Wijk et al. (2005) found that JSOs and JDs were more likely to come from broken homes than were community controls. However, the two groups of incarcerated youth were equally likely to have 
come from such homes. Alternatively, some studies have found that JSOs are less likely to have lived in intact families, and are more likely to have lived in out-of-home placements than are JDs. Duane, Carr, Cherry, McGrath, and O’Shea (2003) compared Irish JSOs, community controls, and youth in a clinical mental hospital. They found that JSOs were significantly more likely to have lived in an out-of-home placement than either of the other two groups. Similarly, Funari (2005) found support for her hypothesis that JSOs were less likely to have lived in intact families and more likely to have lived in foster care than JDs.

Finally, although very little research has included the number of primary caregivers as a variable in the etiology of sexual offenders, one study is of considerable value. Smith, Wampler, Jones, and Reifman (2005) found that a history of changing caregivers was one of the significant predictors of an unstable home life, which characterized most of the juvenile sexual offenders in their sample. They concluded from this finding that constantly changing "safety nets" (i.e., primary caregivers) made it more difficult for the child to feel safe, exacerbated behavioral problems, and reduced the influence of the caregiver, all of which increased the risk that the child will offend.

In conclusion, a large number of overlapping factors must be taken into account in analyzing the family situations of juvenile sexual offenders. More research is still needed to identify the primary guardians of JSOs and assess their relationship quality to those caregivers. Special attention to the roles of fathers, extended-family caregivers, and nonbiological caregivers, as well as number of placement changes may also shed light on the relation between caregiver disruption and sexual offending. 


\section{The Proposed Study}

The previous chapters detailed what is currently known about juvenile offenders and how their early experiences of abuse or caregiver disruption might have stimulated their criminal activity. This section will summarize the gaps that still exist within those literatures and highlight areas of primary concern. Finally, a study is proposed, which attempts to add clarity to the role that caregiver disruption may play in the etiology of juvenile sexual offending.

Critique of the Literature. The previously detailed literature on the quality of caregiver-child relationships is both expansive and through. Yet, there remains a number of methodological and conceptual issues that are yet to be addressed. This subsection will highlight three of those issues: (1) whether or not juvenile sexual offenders and general juvenile delinquents are unique populations; (2) the lack of a non-incarcerated comparison group in the vast majority of empirical research on JSOs; and (3) a paucity of research on the role of caregiver disruption within the JSO literature.

JSO/JD Differences. Throughout the previous chapters, the controversy surrounding the representation of juvenile sexual offenders as a unique population, separate from juvenile delinquents generally, has been constant and unresolved. Indeed, if the research has made one thing clear, it is that no single variable can distinguish JSOs from JDs. Literature examining differences in abuse history (Smallbone, 2006; Zankman $\&$ Bonomo, 2004) and various types of disrupted caregiving (Van Wijk et al., 2005) between these populations have all produced mixed results. Instead, more complex models need to be posited in order to clarify the differences between these adolescent 
groups. Models of this nature may allow us to create nuanced distinctions that can reliably differentiate JSOs from JDs.

JC Comparison Group. The lack of examination of non-incarcerated comparison groups in the existing literature is remarkable. Only a handful of studies have directly compared juvenile sexual offenders to non-criminal youth (McCormack et al., 2002; Van Wijk et al., 2005). Furthermore, those studies that do involve a JC comparison group overwhelmingly fail to include an appropriate incarcerated control group, as well (i.e., a JD group). The utilization of both types of comparison groups is necessary to identify the variables that are unique to juvenile sexual offenders.

Caregiver Disruption. It is well known that youth in prison have overwhelmingly experienced inadequate guardianship. Yet the overriding category of caregiver disruption has not been thoroughly examined within this population. Studies that have been undertaken so far have examined particular aspects of the construct, such as the effect of divorce or foster care, on youth offending. These studies are important first steps, but they lack sufficient generalizability to other forms of disrupted caregiving that are particularly relevant to juvenile offender populations. Additionally, studies that have examined multiple aspects of caregiver disruption have not extended those findings to subgroups within the large body of incarcerated youth. Thus, these findings are unable to illuminate patterns of caregiving disruption that correspond to sexual offenses in particular.

Purpose of the Current Study. The role that disruptions in relationships between juveniles and primary caregivers may play in the development of juvenile sexual offenders is a critical, yet still underexplored area of concern. Thus, the purpose of the 
current study is to determine the independent, unique contributions of caregiver gender, biological relationship between caregiver and child, number of changes in primary caregiver experienced by the youth, and the youth's history of maltreatment in determining the quality of the relationship between JSOs and their primary guardians. It is probable that factors related to caregiver relationship quality affects JSOs' ability to form appropriate relationships with their peers and to integrate the behaviors learned in therapy into their lives after being released from incarceration. Findings associated with JSO-caregiver relationships will also allow for treatment professionals to tailor family interventions to those most at risk. Finally, this study will add to a very limited body of literature that distinguishes between types of non-nuclear families in relation to delinquency in general, and juvenile sexual offending specifically.

Research Questions and Hypotheses. In order to address these gaps in the literature, two research questions are posed in this section.

Research Question One (RQ1): Are there differences in the quality of the caregiver-child relationship between juvenile sexual offenders, general juvenile delinquents, and juvenile controls? To date, there have been no studies that have directly compared the perceived relationship quality between these three groups of youths and their respective caregivers. Some studies have retrospectively asked adults to rate their relationships with their caregivers when they were children (Shears, Robinson, Emde, 2002). Similarly, some studies have compared only juvenile delinquents to controls (Hoeve et al., 2009). However, in order to understand with precision if JSOs constitute a unique group of offenders and on which variables differences lie, more specificity is necessary. Thus, the following hypothesis will be tested: 
Research Question One - Hypothesis One (R1H1): Offense status is expected to predict relationship quality scores such that JSOs will have the lowest mean relationship score of any offense type, closely followed by JD-Vs. JD-NVs and JCs are expected to have higher relationship scores, with JCs representing the best overall relationship quality

Research Question Two (RQ2): If there are differences in caregiver relationship quality between groups, are those differences moderated by factors related to caregiver disruption? Apel and Kaukiken's (2008) investigation has most clearly identified the specific impact of "caregiver disruption" on delinquency. However, no study has applied these findings to a group of juvenile sexual offenders. Replicating some of Apel and Kaukiken's study questions with the subgroups of violent juvenile delinquents, nonviolent juvenile delinquents, and convicted juvenile sexual offenders, may provide a more nuanced insight into how caregiver disruption relates to various types of offending. Furthermore, comparing these groups of incarcerated youth to an additional sample of juvenile controls will extend the generalizability of the findings and allow for a discussion of how caregiver disruption may function differently between incarcerated and non-incarcerated youth. Thus the following moderators will be tested:

Research Question Two - Hypothesis One (R2H1): Gender of the primary caregiver is expected to moderate the youth's perceived relationship quality with that guardian such that youths who identify males as their primary guardians are expected to endorse poorer quality relationships than youths who identify females as their primary guardians.

Research Question Two - Hypothesis Two (R2H2): Biological status is expected to moderate the youth's perceived relationship quality with their caregiver such that 
youth raised by their biological parents are expected to have higher relationship quality scores than those raised in substitute care.

Research Question Two - Hypothesis Three (R2H3): The experience of changing primary caregivers is expected to moderate the youth's perceived relationship quality with their caregiver such that youth are expected to report poorer quality relationships if they have changed caregivers.

Research Question Two - Hypothesis Four (R2H4): Maltreatment history is expected to moderate the youth's perceived relationship quality with their caregiver such that youth who have experienced abuse and neglect will have poorer quality relationships with their primary guardians. 


\section{Methods}

\section{Participants}

The data utilized in this study comes from a larger investigation conducted by Dr. Keith L. Kaufman, Ph.D (CDC Grant R49/CCR016517-01). Participants included convicted juvenile offenders who were incarcerated in correctional facilities in five states across the United States. These states included Florida, New York, Oregon, South Carolina, and Texas. A second sample of juvenile control participants were recruited from community centers in those same states.

Thus, participants in this study comprised four distinct groups. Juvenile sexual offenders (JSOs, $n=310$ ) were found guilty of committing a sexual offense before their 18th birthday and were incarcerated for that sex crime. Violent juvenile delinquents (JDVs, $n=119$ ) were incarcerated for a crime they committed as a youth that was intended to cause harm against persons. Nonviolent juvenile delinquents (JD-NVs, $n=139$ ) had identical screening criteria to JD-Vs, except with regard to the crime for which they were incarcerated. These youths committed crimes that did not include an intent to harm others (See Table 1 for crime coding examples). Finally, juvenile control participants (JCs, $n=$ 258) were non-incarcerated youth who had never been convicted of a crime. Screening criteria ensured that the youth were literate through the use of the Wide Range Achievement Test - Third Edition (WRAT-3; Wilkinson, 1993), and that they did not have an interfering mental illness (e.g., psychotic disorder, depressive disorder).

The average age of the youth in this sample was 15.90 years old ( $S D=1.77$ years) All youth identified as male. Overall, $41 \%$ of youth identified as White/Caucasian, $21.6 \%$ identified as Black/African American, 17.1\% identified as Hispanic/Latino and 23.1\% 
identified as Other or Mixed Race. In the overall sample, $51.0 \%$ of youth reported that they were raised in nuclear families (biological mother and father present, with no changes in caregiving prior to incarceration).

\section{Measures}

Demographics. This measure asked participants questions regarding their demographic characteristics. The questions used in the current study solicited the participants' (1) age, (2) biological sex, (3) race or ethnicity, and (4) current education level. The youth were also asked to identify their primary caregiver(s) for each year of their life (1-17). Additionally, youth were asked to indicate at which ages they switched or added a primary caregiver.

Perceived Relationship with Supervisor Scale. A six-item questionnaire was used to examine how the youth perceived their relationship with their primary caregivers (PRSS; Kaufman, 2001). Of note, this measure is not designed to assess Bowlby and Ainsworth's attachment styles, but rather was created to assess how adolescents view their relationships with the people who care for them. For incarcerated youth, the instructions asked that they report on the last year in which they lived in the community. Participants were asked to indicate their answers on a five-point Likert scale where $0=$ never and 4 = always. Items assessed youths' perceptions of trust ("my supervisor trusted me"), acceptance (“my supervisor accepted me for who I am”), morality ("my supervisor expected me to do the "right thing"'), understanding ("my supervisor understood where I was coming from"), respect ("my supervisor asked for my opinion on things"), and attention ("my supervisor asked about personal things"). The dependent variable used for these analyses is the composite mean score of these six items. 
Experiences of Childhood Abuse. Participants were asked to circle "yes" or "no" to indicate if they had ever experienced neglect, physical abuse, or sexual abuse. If they circled "yes," they were then asked to indicate (1) the number of people who had abused them, (2) if the person committing the abuse was related to them or not, and (3) the biological sex of their abuser(s).

Offense History. Incarcerated youth were asked to indicate the criminal charge that resulted in their incarceration. Furthermore, they were asked the total number of times they had been arrested, their age at their first arrest, the age that they began engaging in criminal behavior, and the date that they began serving their sentence. These questions also ensured that the juvenile controls did not have a criminal record.

\section{Procedures}

IRB approval was obtained from Portland State University before the beginning of data collection. As the current project relied solely on a secondary analysis of deidentified data, the IRB board at Portland State University determined that it did not meet criteria for further review and approval (\#174411). The original data collection procedure was as follows: incarcerated youth were presented with an assent form that was then read aloud to them. Youth were assured that their participation was voluntary and would be kept anonymous. Youth who chose to participate in this study signed the assent form. Additionally, consent was provided by the head representatives of the state facilities, who have legal custody of the youth during their incarceration. On average, participants took 1.5 hours to complete all the questionnaires (including questions not utilized in the current study). Packets were then returned to Portland State University where they are housed in a locked filing cabinet. 


\section{Results}

The following section will first provide further details regarding the sample chosen for this investigation. Second, all preliminary analyses will be described, which allow for an examination of the assumptions underlying this model. Third, the inferential analyses will be described with regards to each of the five proposed hypotheses. Finally, there is a description of the exploratory analyses conducted to aid in the interpretation of these findings.

\section{Exclusion Criteria}

Since this data was first collected as part of a much larger study, a subsample was selected for these analyses through the following exclusion criteria. First, as the research questions presented in this study involve the relationship quality between male youth and their caregivers, youth who did not identify as male $(n=64)$ were excluded from analyses. Second, as youth were being asked to rate their relationship with their caregivers, participants who were over the age of 21 at the time of data collection were excluded $(n=12)$ as they had likely not lived with a caregiver for many years. Third, youth who did not list their current criminal charge $(n=109)$ could not be categorized by offense type and thus were excluded from analyses. Fourth, youths who failed to completely fill out the Perceived Relationship with Supervisor Scale $(n=16)$ were excluded as this was the dependent variable for all analyses. Finally, participants who had scores on the dependent variable that were both outliers (more than two standard deviations away from the mean) and had high leverage (scores greater than $.024 ; n=11$ ) were excluded from analyses to avoid their scores having undue influence on the results. The resulting final sample consisted of 889 juvenile participants. 
Preliminary Analyses

Exploratory Factor Analysis. The dependent variable in this study, the youths' perceived relationship quality with their primary caregivers (relationship quality), comes from an unvalidated measure. As such, it was imperative to explore the factor structure of the items on the Perceived Relationship with Supervisor Scale (Kaufman, 2001) before proceeding with the analyses. An eigen-analysis was conducted using SPSS 24 to determine if a single-factor structure best explained the pattern of data from this measure. Results from this analysis determined that a single-factor model was indeed best, as indicated through the use of Kaiser's criteria for Eigenvalues as well as by examining a Scree Plot and the item's correlation matrix to determine the amount of variance explained by this assessment device. All items loaded adequately and cleanly onto one factor, with the smallest loading being .35 and the highest being .83 . Additionally, an examination of the Scree Plot clearly indicated the presence of one primary factor (See Figure 1). This factor alone accounted for over half (57.7\%) of the co-variability between all items. Cronbach's alpha was also calculated and reflected good internal consistency $(\alpha$ $=.86)$. Thus, all six items in this measure are used in the subsequent analyses to represent youths' perceived relationship with their primary caregivers.

Power Analysis. In order to determine if our sample size was sufficient to detect the expected effects, a post-hoc power analysis was conducted using G*Power. Previous similar research has produced small to medium effect sizes, therefore this analysis used the smallest effect size reported in a similar study $\left(\eta^{2}=.026\right.$; Knox, 2014). With an alpha of .05, five predictors, and the entire sample of 889 participants, our power (1- $\beta$ err prob) $=.966$. A second sensitivity power analysis that used the same criteria determined that 
effects as small as .026 at a power level of .08 could be found. Therefore, power is well beyond sufficient for conducting these analyses.

Sample Differences. Offense groups were examined for systematic differences on variables that may impact study findings but were not investigation outcomes. Juvenile control participants were significantly younger $(M=14.7, S D=1.73)$ than were any of the incarcerated groups (JSO: $M=16.7, S D=2.16$; JD-NV: $M=16.4, S D=1.27$; JD-V: $M=17.1, S D=1.72), F(3,839)=74.6, p<.001$. Despite the significance of this difference, middle adolescence is often conceptualized as occurring between ages 14 and 16 for males (Ritakallio, Kaltiala-Heino, Kivivuori, \& Rimpelä, 2005), suggesting that all four groups of youth are developmentally comparable. A chi-square analysis revealed that White participants were more likely to fall in the JSO offense-type than any other group, $\chi^{2}(9, \mathrm{~N}=888)=111.68, p<.01$. This finding mirrors Oregon Youth Authority statistics, which suggests that White youth are more likely to be incarcerated for a sexual offense than are any other ethnic or racial group (OYA, 2017).

Offense groups were also examined for differences in the types of disrupted caregiving they experienced (See Table 2). Overwhelmingly, JSOs experienced higher rates of caregiver disruption than all other groups, $\chi^{2}(3, \mathrm{~N}=840)=133.047, p<.001$. Only $29.8 \%$ of JSOs reported that they had lived in a nuclear family for their entire lives prior to incarceration. In contrast, $77.7 \%$ of JCs reported living in nuclear families, as did $56.4 \%$ of JD-NVs and $53.2 \%$ of JD-Vs. Furthermore, compared to JC youth, JSOs were more than three times as likely to have a male primary caregiver, to live with a step parent, or to have changed homes, and ten times more likely to have been in foster care. They were also five times as likely to have been physically abused, six times as likely to 
have been neglected, and a staggering forty-eight times more likely to report being sexually abused.

\section{Inferential Analyses}

ANOVA. Group differences were assessed in order to determine if offense type predicted the relationship quality between a youth and their caregiver.

Research Question One - Hypothesis One (R1H1): Offense status was expected to predict relationship quality scores such that JSOs would have the lowest mean relationship score of any offense type, closely followed by JD-Vs. JD-NVs and JCs were expected to have higher relationship scores, with JCs representing the best overall relationship quality.

R1H1 was confirmed. A univariate analysis of variance found that offense groups differed significantly from one another in terms of perceived relationship quality with their caregivers, $F(3,834)=8.34, p<.001$. As Levene's test for equality of error variances was significant, $F(3,834)=14.82, p<.001$, the Games-Howell post-hoc test was used to assess group differences (See Figure 2). Juvenile sexual offenders ( $M=2.68$, $S D=.84)$ and juvenile delinquents - violent $(M=2.69, S D=1.10)$ had significantly lower relationship quality scores than did juvenile control youth $(M=3.08, S D=.70)$. JSO and JD-V youth did not differ from one another in terms of relationship quality. JDNV youth $(M=2.84, S D=.84)$ formed a middle group that did not significantly differ from either the high-scoring JC group, or the low-scoring JSO/JD-V group.

Regression. As R1H1 was confirmed, a moderated regression analysis was conducted to test the remaining hypotheses. The primary predictor in the regression was offense type (JC, JD-NV, JD-V, JSO). The dependent variable was the composite mean 
value of the Perceived Relationship with Supervisor Scale. The overall model was significant $\left(\mathrm{R}^{2}\right.$ Adj. $\left.=.126, F(23,862)=6.066, p<.001\right)($ See Table 3$)$. This model accounted for $12.6 \%$ of the variance in relationship quality scores. Refer to Table 4 for a complete summary of the results of this regression.

Research Question Two - Hypothesis One (R2H1): Gender of the primary caregiver was expected to moderate the youth's perceived relationship quality with that guardian such that youth who identify males as their primary guardians were expected to endorse poorer quality relationships than youth who identify females as their primary guardians.

R2H1 was partially confirmed. Using JCs with female guardians as the constant, the interaction terms for JSOs $(\beta=-.324, \mathrm{t}(866)=-2.513, p<.05)$ and JD-Vs $(\beta=-.489$, $\mathrm{t}(866)=-1.956, p<.05)$ were significant. These negative beta values indicate that there is a greater drop in relationship quality between JSOs/JD-Vs with male caregivers compared to female caregivers than the corresponding drop for JCs. The simple effect for JCs was non-significant $(\beta=.056, \mathrm{t}(866)=.673, p=n s)$, meaning that there is no discernable change to relationship quality between JCs with female or male caregivers. Similarly, no significant interaction was observed for JD-NVs with regard to caregiver gender $(\beta=.236, \mathrm{t}(866)=1.046, p=n s)$. Thus, this result suggests that the adverse impact of caregiver gender on relationship quality only occurs when JSOs or JD-Vs are being primarily cared for by men (See Figure 3).

As a significant interaction was found, further analyses were conducted in order to gather a full picture of the significance of these results. First, in order to assess differences between JSOs with female guardians and JSOs with male guardians, the 
reference group was then changed so that JSOs with female guardians were the constant. No significant differences were found between JSOs with male and female guardians ( $\beta=$ $-.145, \mathrm{t}(866)=-1.431, p=n s)$. Second, as these mixed results may be caused by multicoliniarity between moderators in the full model, an additional regression analysis was conducted where gender of the primary caregiver was the only moderator included in the model. In this second regression, JSOs with female caregivers represented the constant. This regression was significant, $F(7,827)=6.10, p<.001, R^{2} A d j .=.04$, and produced a significant simple effect for gender $(\beta=-.209, \mathrm{t}(827)=-.105, p<.05)$. Therefore, a tentative conclusion can be made that juvenile sexual offenders who are cared for by men have worse quality relationships to their caregivers than do JSOs who are cared for by women. Furthermore, this effect seems to be unique to youth high in delinquency, as it is not replicated in the JC or JD-NV populations.

Research Question Two - Hypothesis Two (R2H2): Biological status was expected to moderate the youth's perceived relationship quality with their caregiver such that youth raised by their biological parents were expected to have higher relationship quality scores than those raised in substitute care.

R2H2 was partially confirmed. Consistent with the hypothesis, JCs who were raised by their biological parents had significantly higher relationship quality scores than did JCs who were raised in substitute care $(\beta=-.298, \mathrm{t}(866)=-1.758, p<.05)$. Further, no significant interactions were found for JD-NVs $(\beta=1.45, \mathrm{t}(866)=.558, p=n s)$ or JDVs $(\beta=.223, \mathrm{t}(866)=.842, p=n s)$ with regard to the biological relationship of their caregiver. 
However, a significant interaction effect was found for JCs and JSOs $(\beta=.547$, $\mathrm{t}(866)=2.709, p<.01)$. This interaction revealed that, while relationship quality was lower for JCs with non-biological caregivers compared to JCs with biological caregivers, the opposite pattern was true for JSOs. Contrary to the hypothesis, JSO had higher relationship quality scores when their caregivers were non-biological. Furthermore, using JSOs as the reference group, a significant simple effect was obtained, confirming that JSOs with biological guardians had significantly lower relationship quality scores than did JSOs with substitute guardians $(\beta=.274, \mathrm{t}(866)=2.532, p<.05)$.

As this interaction was in the opposite direction of the proposed hypothesis, further investigation was necessary. Therefore, a separate moderated regression was conducted in which biological status was the only moderator entered into the model. The results were consistent with those of the full model, $F(7,827)=6.65, p<.001, \mathrm{R}^{2} \mathrm{Adj} .=$ .04). Again, a significant interaction was found for JSO youth with biological and nonbiological caregivers, such that youth with non-biological caregivers had higher relationship quality scores $(\beta=.743, \mathrm{t}(827)=3.21, p<.01)$. Thus, it appears that for JSOs, having a non-biological caregiver may provide some sort of buffering effect for relationship quality between the youth and their guardian (See Figure 4).

Research Question Two - Hypothesis Three (R2H3): The experience of changing primary caregivers was expected to moderate the youth's perceived relationship quality with their caregiver such that youth are expected to report poorer quality relationships if they have changed caregivers.

Originally, this hypothesis was designed to examine caregiver changes on a continuous scale. However, only three percent of JC youth reported that they had 
changed caregivers more than one time. As such, this variable was dichotomized to reflect either never changing caregivers or experiencing at least one change in guardianship. R2H3 was rejected. No simple effects or interactions were found between offense groups and the experience of changing caregivers.

Research Question Two - Hypothesis Four (R2H4): Maltreatment history was expected to moderate the youth's perceived relationship quality with their caregiver such that youth who have experienced abuse and neglect would have poorer quality relationships with their primary guardians. Originally, this hypothesis was designed to test the effects of physical abuse, sexual abuse, and neglect separately. Due to very small reporting rates for sexual abuse amongst the non-JSO groups, sexual abuse was excluded from this model and examined independently amongst the JSO group.

R2H4 was partially confirmed. A significant simple effect was found for experiencing physical abuse $(\beta=-.303, \mathrm{t}(866)=-2.004, p<.05)$, meaning that for JCs, experiencing physical abuse had a negative impact on their relationship quality with their caregivers. Additionally, a significant interaction effect was found for JD-Vs and JCs ( $\beta$ $=-.488, \mathrm{t}(866)=-1.997, p<.05)$, such that experiences of physical abuse had an even greater negative effect for JD-Vs than it did for JCs. No interactions were found for JDNVs $(\beta=.047, \mathrm{t}(866)=.205, p=n s)$ or JSOs $(\beta=-.051, \mathrm{t}(866)=.272, p=n s)$. However, using JSOs as the reference group also revealed a significant simple effect, such that JSOs who had experienced physical abuse had significantly lower relationship scores than JSOs who did not have a physical abuse history $(\beta=-.243, \mathrm{t}(866)=-2.248, p<.05)$ (See Figure 6). 
As a significant interaction was found, further follow-up tests were warranted to examine the unique predictive power of physical abuse on the relationship between offense status and caregiving quality. Therefore, an additional moderated regression was conducted in which physical abuse history was the only moderator included in the analysis. Thus the constant of this model was JCs with no physical abuse history. This regression confirmed the results found in the full model, $F(7,827)=14.64, p<.001$, $R^{2} A d j .=.10$. Here, a significant simple effect for physical abuse was found $(\beta=-.338$, $\mathrm{t}(827)=-1.977, p<.05)$, as well a significant interaction for violent juvenile delinquents $(\beta=.585, \mathrm{t}(866)=-2.55, p<.05)$. Thus, as part of the full model and on its own, the results of physical abuse experience were clear. Physical abuse negatively affects relationship quality in general, but when violent juvenile delinquents experience physical abuse, their relationships with their caregivers plummet (See Figure 5).

When examining the effect of experiencing neglect on relationship quality, no significant simple or interaction effects were found when JCs were used as a reference group. However, When JSOs were used as the reference group, a significant simple effect was discovered $(\beta=-.309, \mathrm{t}(866)=-.152, p<.01)$. JSOs who have experienced neglect had worse quality relationships with their caregivers than JSOs who had never been neglected (See Figure 6).

As JSOs were the only group with high reporting rates of sexual abuse, differences in relationship quality between JSOs who had been sexually abused and those with no sexual abuse history was examined via a t-test. A significant difference was found, $\mathrm{t}(331)=2.89, p<.01$. JSOs who had experienced sexual abuse $(\mathrm{M}=2.59, S D=$ 
.843) had significantly lower relationship quality scores than did JSOs without a sexual abuse history $(\mathrm{M}=2.85, S D=.797)($ See Figure 6$)$.

\section{Exploratory Analyses}

In order to aid with interpretability, one-way ANOVAs were conducted to assess differences between offense groups on the individual items of the Perceived Relationship with Supervisor Scale. As these analyses were not planned, but rather were added to help contextualize the results, no a priori hypotheses were made about these analyses. As Levene's statistic for homogeneity of variances was significant, $F(835,3)=25.811, p<$ .05 , Games-Howell post-hoc tests were used for all follow-up analyses.

Trust. Juvenile control youth $(M=3.30, S D=.80)$ reported that they felt their caregiver trusted them at higher rates than did any group of incarcerated youth $F(3,835)$ $=18.99, p<.01$, partial $\eta^{2}=.06$. Nonviolent juvenile delinquents $(M=2.59, S D=1.26)$, violent juvenile delinquents $(M=2.60, S D=1.34)$, and juvenile sexual offenders $(M=$ $2.80, S D=1.00)$ did not differ from one another in terms of perceived trust.

Acceptance. Juvenile control youth $(M=3.52, S D=.80)$ reported that they felt their caregiver accepted them at higher rates than did JSO youth $(M=3.25, S D=1.06)$ $F(3,832)=3.48, p<.05$, partial $\eta^{2}=.01$. Nonviolent juvenile delinquents $(M=3.31, S D$ $=1.06)$, violent juvenile delinquents $(M=3.30, S D=1.20)$ did not differ from any other groups in terms of perceptions of acceptance.

Understanding. Juvenile control youth $(M=3.09, S D=1.00)$ reported that they felt their caregiver understood where they were coming from more than did any group of incarcerated youth $F(3,832)=51.73, p<.001$, partial $\eta^{2}=.05$. Nonviolent juvenile delinquents $(M=2.76, S D=1.50)$, violent juvenile delinquents $(M=2.64, S D=1.32)$, 
and juvenile sexual offenders $(M=2.50, S D=1.12)$ did not differ from one another in terms of perceived understanding.

Morality. Violent juvenile delinquents $(M=3.03, S D=1.33)$ were significantly less likely than any other group to report that their caregivers expected them to "do the right thing," $F(3,835)=3.57, p<.01$, partial $\eta^{2}=.06$. On the other hand, juvenile controls $(M=3.72, S D=.58)$ rated their caregivers as significantly more likely to expect moral behavior of them. Nonviolent juvenile delinquents $(M=3.35, S D=.99)$ and juvenile sexual offenders $(M=3.45, S D=.86)$ did not differ from one another in terms of perceptions of caregiver morality.

Respect. Juvenile sexual offenders $(M=2.29, S D=1.22)$ reported that they felt their caregiver respected them less than did any other group, $F(3,835)=12.21, p<.01$, partial $\eta^{2}=.03$. Nonviolent juvenile delinquents $(M=2.70, S D=1.13)$, violent juvenile delinquents $(M=2.40, S D=1.37)$, and juvenile controls $(M=2.74, S D=1.14)$ did not differ from one another in terms of perceived respect.

Attention. Juvenile sexual offenders $(M=1.84, S D=1.36)$ were significantly less likely than any other group to report that they talked with their caregivers about personal things $F(3,835)=18.99, p<.01$, partial $\eta^{2}=.04$. On the other hand, nonviolent juvenile delinquents $(M=3.56, S D=1.37)$ were the most likely to report that they engage in personal conversations with their caregivers. Violent juvenile delinquents $(M=2.30, S D$ $=1.56)$ and juvenile controls $(M=2.17, S D=1.29)$ did not differ from one another in terms of perceptions of attention. 


\section{Discussion}

This study was designed to investigate the unique effects of caregiver disruption on the development of juvenile sexual offending. It does so by analyzing the relationship between offense type and the youths' perceived relationship quality with their caregivers, while including the potentially moderating factors of caregiver gender, biological relationship between caregiver and child, changing primary caregivers, and abuse history. In general, the data supports the hypotheses that offense status and caregiver disruption history are important factors to consider in evaluating the quality of the relationship between a youth and their primary guardian. This section provides a more detailed review and interpretation of study findings relative to the proposed hypotheses. It will then conclude with a consideration of the strengths and limitations of the study, implications for treatment, and future research considerations.

\section{The Impact of Offense Type}

The relationship of youth to their caregivers may prove to be a key to understanding aberrant behavior. The comparison of juvenile sexual offenders, violent and nonviolent juvenile delinquents, and young people who have never been convicted of criminal activity offers the possibility of insights into the impact that criminal offending has on the relationship quality between a youth and their primary caregiver. It is widely accepted that juvenile delinquency is associated with poor quality parenting and strained parent-child relationships (Hoeve et al., 2009). The data from this study support the hypothesis that more serious offense statuses predicts low relationship quality scores. Both juvenile sexual offenders and violent juvenile delinquents reported poor quality relationships, with JSOs reporting slightly worse relationships than JD-Vs. 
However, this study did not address the directionality of the relationship between offense status and caregiver quality scores. It has been suggested that youth with poor quality relationships are more likely to engage in violent or sexually delinquent acts (Felizzi, 2015). Inadequate caregiving may also mean that these youths are poorly supervised and monitored, and thus are at increased risk for delinquency and sexual offending (Zankman \& Bonomo, 2004). On the other hand, a perhaps equally valid argument holds that offense status causes the poor quality relationships. Research examining shame and stigma associated with parenting sexual offenders clearly documents that parents of juvenile sexual offenders struggle with accepting their child's crime and have difficulties expressing love for their child after the offense (Jones, 2015). Thus, there is evidence that the low quality caregiver-child relationships seen in the two high-delinquency groups both influence and are influenced by offense status.

Consistent with the original hypothesis, JC participants had mean relationship scores that were significantly higher than the JSO/JD-V group. While the average JSO/JD-V youth indicated that their relationship with their caregiver was "sometimes" good, the average JC youth reported that their relationship with their caregiver was "almost always" good. This result was consistent with the proposed hypothesis. While the teenage years are often thought of as characterized by high parent-child discord, research suggests that parent-child relationships decline somewhat, but do not drop dramatically, in the teenage years for most non-delinquent teens (Laird, Pettit, Dodge, \& Bates, 2003).

As expected, JD-NV youth did not follow the same pattern as their violent, incarcerated peers. Their mean relationships scores fell in-between the JC youth and the JSO/JD-V youth, and did not significantly differ from any other group. This is consistent 
with findings in the literature on nonviolent juvenile offenders. Many of these youth are incarcerated for circumstantial reasons that do not indicate that they are substantially more delinquent than the average teen (e.g. possession of marijuana). In that sense, many JD-NV youths are identical to the JC youths in terms of their level of delinquency. However, as indicated in Table 2, JD-NV status manifestly shows increased risk for all disrupted caregiving variables compared to JCs. On these variables, JD-NVs are more comparable to JD-Vs. Thus, it should come as no surprise that their relationship quality scores reflect their "dual identities": for they are both prototypical teens, and at the same time they display a unique status as incarcerated youth.

\section{The Need for Moderators}

The initial finding described above is an important contribution to understanding the family dynamics of young offenders. However, it also elicits questions regarding the impact of distinct family systems. Adding nuance to the types of family disruptions that characterize juvenile sexual offenders' households would make those discriminations even more useful. As the ultimate aim of this study is to isolate factors in the genesis of juvenile sexual offenders, four central moderators have been selected for examination and are discussed in detail below.

Gender of Caregiver. The most basic of these moderators is to distinguish the perceptions of relationship quality from youth with male or female caregivers. Overwhelmingly, the literature examining parental gender effects with regards to children's behavior have found that children who are parented by males are at increased risk for a broad range of negative social and emotional outcomes (Coles, 2015). Thus, it 
was the hypothesis of this study that youth with male primary caregivers would report lower quality relationships than would youth who were cared for by women.

Consistent with this hypothesis, the data shows that for certain youth, the presence of a male primary caregiver is associated with a decrease in relationship quality scores. For the youth with low levels of delinquency (JC \& JD-NV), no differences in relationship quality were found between youth who had female or male caregivers. However, for the high delinquency group (JD-NV \& JSO), significant interactions were found, such that high-delinquent youth with male caregivers had much lower relationship quality scores than did high delinquent youth with female caregivers.

One possible interpretation of this finding is that the men who parent the JC/JDNV youth are involved, supportive, and reasonable caregivers. On the other hand, high delinquency youth may be more likely to be parented by absent or hostile male caregivers. Attentive and sympathetic parenting might potentially affect both the relationship quality score and the youth's type of offending. This conclusion is consistent with the body of literature which suggests that attentive and supportive caregiving is a protective factor against juvenile delinquency (Hoeve et al., 2009). The exploratory analyses lend support to this interpretation. Juvenile control youth reported high levels of trust between themselves and their caregivers, while JD-NVs reported high levels of attention. These caregiver qualities may serve as inhibitory factors against engagement in serious delinquent behavior. Further analyses may be conducted using this data that exclusively examine item differences amongst youth with male caregivers, which would add to the interpretability of this result. 
A second, alternative explanation may be gleaned from the data presented in Table 2. This table shows that youth in the low delinquency group are less likely to have experienced caregiver disruption. From this statistic, one might assume that the male caregivers who parent JCs and JD-NVs are more likely to be biological fathers than are the men who parent JD-Vs and JSOs. Thus, it is possible that this finding does not reflect a difference in relationship quality between mothers and fathers as much as it does between a biological parent (i.e., mothers) and a non-biological parent (i.e., adoptive/step/foster fathers). Future research that takes into account the interacting riskfactors of male primary caregivers and non-biological caregivers on the potential development of delinquency and sexual offending would shed light on the validity of this explanation.

Biological Relationship Between Caregiver and Child. Just as youth have distinct reactions to male and female caregivers, they may react in measurably different ways to their natural families or the non-biological caregivers that raise them. Findings such as the "Step-Father Effect" point to a protective factor associated with being raised by one's biological parents. These youth in biologically-intact families are thought to be at lower risk for child abuse and neglect, insecure attachment styles, and engagement in delinquency compared to their peers with substitute guardians (Miller et al., 2000).

Though this research study did not have the cell sizes necessary to examine the interactions between caregiver gender and biological status, the independent impact of biological status was examined as a moderator between offense type and relationship quality. The results of this moderation analysis partially supported the hypothesis. As expected, having a non-biological caregiver resulted in lower relationship quality scores 
for JC, JD-NV, and JD-V youth. Thus, for the majority of youth in this sample, being raised by a biological parent can be considered a protective factor for maintaining a strong and high quality bond, even when that youth is incarcerated.

However, these data yielded surprising results for JSO youth that were inconsistent with the proposed hypothesis. For youth who have committed sexual offenses, relationship quality scores were lower if their primary caregiver was a biological parent. As this difference was not seen in either of the other two incarcerated groups, it is reasonable to conclude that neither criminal offending in general, nor separation from one's biological parents, are the cause of this unusual finding. Instead, the explanation must be indicative of something unique about young sexual offenders and their parents. One possible explanation considers that parents of sexual offenders simultaneously deal with the internal self-blame for their child's offense, the public shame and stigma of having a child convicted of a sex crime, and the exhaustion that comes with navigating the court and juvenile justice system (Smith \& Trepper, 2015). All of this may be overwhelming for the average parent, causing their relationship with their child to suffer. This explanation finds further support from the exploratory analyses, which revealed that JSOs report that their caregivers respect them less and pay less attention to them than did any other group of youth. It is also probable that the social stigma attached to sexual crimes may cause parents to demonstrate a loss of respect for the offending child. That loss, in turn, may further undermine their relationship.

While sexual crimes are more stigmatized than almost all other criminal offenses (Tewksbury, 2012), stigmatization is not the only unique aspect of this sort of offending. Sexual offenses are also one of the rare types of criminal activity that are as likely to 
occur within the household as outside of it, and as likely to include a family member as an extra-familial victim. Intra-family sexual abuse puts parents in an impossible position, for they are emotionally attached to both the perpetrator and the victim. Within this sample of offenders, $48 \%$ of JSO youth reported that they lived in the same household as their victim. Further analysis might investigate the relationship quality between intra- and extra- familial offenses to see if these results can be explained by victim type (i.e., intravs. extra-familial).

Changes to Primary Caregiver. Of course, many children experience more than one caregiver over time. Divorce, death, adoption, foster care, or other complex circumstances all involve a shift in guardianship for a child. Consequently, the question must be posed whether or not relationship quality is affected by these changes. Contrary to the proposed hypothesis, having changed caregivers in one's life was not associated with a drop in relationship quality. This finding is contrary to the trends in the literature, which suggest that multiple placement changes disrupt the formation of attachment bonds and thus both promotes delinquency and reduces the quality of the caregiver-child relationship (Barber \& Delfabbro, 2003).

The simplest and most logical explanation for this lack of a finding is that it is the result of measurement error in this study. There are a number of places where the measurement and data analysis could be improved. First, as this data comes from a larger study that did not explicitly set out to study placement changes, the variable used here was created by tallying the number of times the youth reported that they had a new primary caregiver. However, this is an imprecise metric. A youth who is living in a nuclear family might report in some years that their primary caregiver is their mother and 
in other years that it is their father, simply depending on fluctuations in the amount of time a parent spends with them due to their work demands and the child's school schedule. Further, another child's grandparent may retire and thus take on a primary caregiving role for that child. These are wholly different kinds of changes in primary caregiver as compared to a situation where a child moves from a home with their biological parents to the foster care system. However, nuances of this sort were not recorded within this dataset and thus cannot be commented upon. Future research should explore these different types of changes in primary caregiver to determine their differential impact.

A second methodological challenge occurred in this study due to low variability in reporting for the JC group. Only 3\% of JCs reported that they had experienced more than one change in guardianship in their lifetimes. As a result, it was necessary to dichotomize this variable to ensure that the group sizes were large enough to be statistically relevant. Thus, rather than representing a continuum of changing caregivers, the data simply reflected whether or not the youth had lived with the same caregivers for their entire lives.

Researchers who might wish to continue this line of inquiry should ask youth to report more specifically about the types of guardianship changes they have experienced. Did that change involve living in a new home? Did they remain in close contact with their previous caregiver? Did this change in guardianship involve the addition of a new guardian (e.g. gaining a step-parent) or the loss of a previous guardian (e.g. death of a parent)? Was this change required and why (e.g., foster care placement due to physical 
abuse)? A more detailed analysis of these questions may lead future researchers to much different conclusions than the ones represented in this study.

Child Maltreatment History. Finally, child abuse and neglect experiences cannot be overlooked. Although this is not a universal aspect of parenting, when child maltreatment does occur, it may indeed be a potent factor in stressing caregiver relationships. Consistent with the proposed hypothesis, child abuse appeared to have a negative impact on child-caregiver relationships. Youth who had experienced physical abuse reported lower quality relationships with their caregivers than did youth who had not had that experience. While this trend was consistent across all four groups of youth, it was especially true for JD-Vs. This finding lends support to the cycle-of-violence hypothesis, whereby youth who have had violence inflicted upon them are more likely to become violent themselves. However, as both JD-V and JSO youth were extremely likely to have been physically abused (See Table 2), more information and further distinctions are needed to draw conclusions about the role of physical abuse in the development of a child's perceived relationship quality with their caregiver. One possibility is that JD-Vs experienced a greater severity of physical abuse than did JSOs. This would fit the cycleof-violence theory, insofar as it would suggest that experiencing severe physical abuse leads to engagement in severe acts of violence.

Sexual abuse victimization was not included in this model due to low reporting rates. It is likely that sexual abuse victimization was underreported in this study. As explained in the introduction, national statistics suggest that one in every fifteen boys will experience sexual abuse before his eighteenth birthday. However, only one in every three instances of sexual abuse is likely to be reported to authorities (RAINN, 2015). The 
present study's results are consistent with Stolenborgh et al.'s (2011) findings that studies using self-reported disclosures of sexual abuse find far fewer instances than those investigations the use national reporting statistics.

In this study, $1 \%$ of JCs and $7 \%$ of JDs reported a sexual abuse history. As such, the sample sizes for these groups were too small to be included in the regression. Yet, $58 \%$ of juvenile sexual offenders reported a sexual abuse victimization history. As with the findings for physical abuse, this statistic overwhelmingly supports a cycle-of-violence pathway hypothesis. It indicates that youth who have experienced sexual abuse themselves are more likely to commit sexually abusive acts upon others. Furthermore, JSOs who reported sexual abuse victimization indicated poorer relationships with their caregivers than did JSOs who were not victims of sexual abuse. Thus, for these youth, the risk factors appear to be compounded. JSOs are at higher risk for criminal offending because they have been sexually assaulted and also because they have poor relationship quality to their caregivers.

Similar results were found for the youth who have experienced neglect. Again consistent with the hypothesis, JSOs who had histories of neglect reported that their relationships with their caregivers were worse than did JSOs who had never been neglected. Interestingly, no differences were found in relationship quality between JCs who reported neglect and those who did not. As with physical abuse, it is possible that this outcome may be the consequence of differing degrees of maltreatment severity. Juvenile sexual offenders may have experienced neglect to a greater degree (e.g., not being fed for multiple days), while JCs may be reporting on abuse experiences that were not as prolonged or intense (e.g., left home alone while parents were at work). Further 
research that clarifies the extent and duration of the reported neglect histories would add validity to this interpretation.

\section{The Big Picture}

The primary value of this study is to encourage future examinations of the potentially unique relationships of JSOs and their caregivers. In order to provide the most complete picture possible from this data, all variables were entered simultaneously into a moderated multiple regression model. Combined, these variables explained $12.6 \%$ of the variance in relationship quality scores. Consequently, caution is warranted when considering these results. Nevertheless, it would be hasty to conclude that this model has no predictive utility. Rather, these interesting insights suggest that future research should focus on caregiver disruption in a more detailed fashion that explicates a broader array of variables which may be central to explaining this relationship. The poor model fit seen here may also be the result of using a secondary analysis procedure. Existing variables needed to be re-organized to address these new hypotheses. It is possible that asking youth similar questions, but in a more direct and nuanced way, would improve the predictive utility of this model. The matter is so important and the tentative results so illuminating that even these potentially small findings deserve attention.

\section{Strengths of the Study}

This study contributes to the existing literature in three important ways. First, it succeeded in clarifying crucial distinctions between JSOs and general JDs, while also attesting to their similarities. These results support the classification of JSOs as a similar population to those juvenile delinquents who commit violent crimes. Yet, it is essential to note that the JSOs in this study differed on almost all measures from the JD-NVs. It is 
evident then, that while JSOs and JD-Vs may emanate from a single population, this high delinquency group should not be considered the same as youth who commit minor offenses, even if all of these youth are incarcerated together.

Even though this study suggests that youth who commit sexual offenses are in many ways similar to youth who commit other crimes against persons, JSOs and JD-Vs were not identical on all measures. Two instances stand out: (1) A higher percentage of JSOs were found to have experienced disrupted caregiving than JD-Vs, and (2) The negative impact of physical abuse on caregiver relationship quality was greater for JD-Vs than or JSOs. These findings indicate that the uniqueness of the JSO population needs to be more fully investigated and future findings need to be incorporated into the literature to enhance existing theories.

A second strength of this study is its inclusion of the JC group. Among the few studies that have examined JSOs as a unique population, almost none of them have included a non-incarcerated control group. The results of this study indicate that this comparison may be particularly valuable, especially in light of the additional contrasts made with the other groups of incarcerated youth. Findings from this investigation demonstrate that JSOs have dramatically different home lives than do the average, noncriminal teen. Compared to JC youth, JSOs were at greater risk for every single aspect of caregiver disruption. This finding points to potential areas for the prevention of juvenile sexual offending by intervening with families on the brink of disrupting a child's primary caregiving relationships.

Finally, the measurement of variables related to caregiver disruption is one of this study's strengths in-and-of itself. To date, the literature examining family factors in the 
formation of juvenile sexual offenders has been sporadic and disjointed. This study offers a touchstone for important further research which may consider the construct of caregiver disrupted as a whole. There is much more work to be done in this area, but the results of this study suggest that continuing research on this line of inquiry will be both informative and valuable.

\section{Study Limitations}

Despite the strengths of this study, it is also not without its limitations. First, all the data comes from self-report surveys. Those surveys touch upon a number of sensitive topics. The primary, and most serious, limitation is that some of the participants may not have answered the questions truthfully. The literature has established that abuse histories are generally underreported. Though the participants were assured of the anonymity of this data, incarcerated youth might well have felt that that reporting on their poor relationships with their primary caregivers could have negative consequences for their therapy or release plans. Thus, this data has to be evaluated with caution. Second, as the data was collected while both the JSO and JD youth were incarcerated, they were asked to report on their relationships with their primary caregivers during the last year that they were living in the community. This is particularly problematic insofar as youth who had been incarcerated for long sentences may well have more distorted memories about the quality of their relationships at that time. Furthermore, this evaluation method creates a disparity between incarcerated youth and controls, since control youth were reporting on their current relationship with their caregivers, while those incarcerated responded retrospectively. Third, the very idea of organizing youth by latest offense type is a dubious and unstable system for categorization. Many of these youth may have 
committed crimes previously that would have placed them in different categories. Some may go on to recidivate with a different type of criminal offenses. Though this study did confirm that no youth in the JD groups had previously been convicted of a sexual offense, this study fails to take into account the potential fluidity of criminal activity by these subjects over time. Finally, a fourth limitation relates to the relationship quality scale used in this study. The original researchers asked youth to identify a single primary caregiver. Yet, it is possible that youth living in two-parent families may have had difficulty in choosing only one parent to rate. Therefore, we lack comparative data on the relative quality of the youth's relationship between parents, as well as data which would allow for a comparison of two-parent households as opposed to single-parent households.

\section{Treatment Implications}

Understanding risk and protective factors in family relationships has broad implications for encouraging and shaping family therapy for young sexual offenders. Since family dynamics are critical to the development and maintenance of appropriate sexual behavior among at-risk youth (Yoder, 2014), services that are attuned to the particular risk factors present in a JSO's family structure may be more effective at facilitating a positive home environment for the youth. The findings of this study suggest that service providers ought to be on the lookout for youth who have experienced caregiver disruptions. In particular, youth who are being primarily cared for by men and those youth who have experienced childhood physical and sexual abuse seem to be at increased risk for relationship quality problems. Providers may consider encouraging households with these risk factors to engage in more extensive family therapy than they would otherwise. 
On the other hand, previous research has also demonstrated that family dynamics may be a protective factor against sexual recidivism in youth (Spice et al., 2013). Though contrary to our hypothesis, study findings suggest that non-biological caregivers may be more accepting, understanding, and compassionate toward delinquent youth. One may tentatively conclude from these results that a move to a non-biological home may, in fact, be particularly beneficial for young sexual offenders, since it gives them a chance to start fresh with a family that has not been personally impacted by their assaultive behavior. This result should certainly not be used to recommend that youth be removed from their biological homes in favor of foster or adoptive homes. However, it does suggest a potential for strengths-based approaches that may be used by therapists and other treatment practitioners to capitalize on the emotional distance that is present in nonbiological living environments in a proactive therapeutic manner.

\section{Future Directions}

This study's findings lend themselves to a number of future directions for research on sexual offending and caregiver disruption. First, a more in-depth examination of the interconnectedness of caregiver disruption risk-factors is warranted. Though outside the scope of this study, information should be gathered regarding the impact on relationship quality of caregivers who represent two or more areas of disrupted caregiving (e.g., a step-father, who is both male and non-biological). Second, due to small cell sizes, some nuance was lost in the moderators in this study. For example, too few youth lived with a non-parental family member (e.g. custodial grandparents) for that type of family structure to be examined independently. It would be valuable for future researchers to seek samples of youth who have lived with a broader variety of caregivers 
(e.g., grandmothers, foster care) in order to gain a clearer picture of the ways in which a disruption can affect youth. Third, literature which includes variables related to caregiver disruption are scarce. This is especially true of studies including an examination of changes in primary caregiver relationships over time. To date, this is the first study that has specifically examined the impact of changing caregivers multiple times, as it relates to sexual offending. As noted above, though this study attempted to address that question, it was prevented from doing so due to a lack of variability in the juvenile controls' history of caregiving. This question would benefit from a comprehensive study examining the impact of one or multiple changes to primary caregiver.

\section{Conclusion}

This thesis has developed a perspective on how caregiver disruption can negatively affect relations between caregivers and juvenile sexual offenders. Within the current data there are glints of potentially surprising risk and protective factors related to caregiver-child bonds amongst incarcerated youth. Future researchers using this thesis can be guided in crafting their projects with an eye towards caregiver disruption as a potential locus of greater understanding of young people who commit sexual offenses. It is submitted with hope and promise of further elaboration, particularly with regards to the need for further psychometric attention to be paid to the construct of disrupted caregiving. 
Tables

Table 1. Charge coding.

\begin{tabular}{c|c|c} 
Non-Violent Crimes & Violent Crimes & Unclear \\
\hline Theft/Burglary/Larceny & Robbery/Armed Robbery & Threats \\
$\begin{array}{c}\text { Possession/Distribution of } \\
\text { Drugs/Paraphernalia } \\
\text { Violation of Probation }\end{array}$ & Assault/Battery/Domestic Violence & Arson \\
Absconding/Fleeing Scene/Runaway & Kidnapping & \\
Trespassing & Use of a Deadly Weapon & \\
Vandalism/Destruction of Property & & \\
Fraud & &
\end{tabular}

Table 2. Raw count and percentages of disrupted caregiving by offense type.

\begin{tabular}{r|cccc}
\multicolumn{1}{c}{} & $J C$ & $J D-N V$ & $J D-V$ & $J S O$ \\
\hline Nuclear Families & 192 & 75 & 66 & 100 \\
& $(77.7 \%)$ & $(56.4 \%)$ & $(53.2 \%)$ & $(29.8 \%)$ \\
Male Caregiver & 23 & 42 & 29 & 111 \\
& $(9.3 \%)$ & $(31.6 \%)$ & $(30.3 \%)$ & $(33.0 \%)$ \\
Non-Parental Family Caregiver & 14 & 12 & 10 & 33 \\
& $(5.7 \%)$ & $(10.9 \%)$ & $(8.1 \%)$ & $(9.8 \%)$ \\
Non-Biological Caregiver & 4 & 9 & 10 & 44 \\
& $(1.6 \%)$ & $(6.8 \%)$ & $(8.9 \%)$ & $(13.1 \%)$ \\
Lived in Foster Care & 7 & 16 & 14 & 96 \\
& $(2.8 \%)$ & $(12.0 \%)$ & $(11.3 \%)$ & $(28.6 \%)$ \\
Lived with a Step-Parent & 32 & 79 & 86 & 145 \\
& $(13 \%)$ & $(54.2 \%)$ & $(50.5 \%)$ & $(43.2 \%)$ \\
Changed Homes 1+ Times & 55 & 58 & 58 & 236 \\
& $(22.3 \%)$ & $(43.6 \%)$ & $(46.8 \%)$ & $(70.2 \%)$ \\
Experienced Physical Abuse & 25 & 31 & 44 & 185 \\
Experienced Sexual Abuse & $(10.1 \%)$ & $(23.3 \%)$ & $(35.5 \%)$ & $(55.1 \%)$ \\
Experienced Neglect & 3 & 10 & 9 & 195 \\
& $(1.2 \%)$ & $(7.5 \%)$ & $(7.3 \%)$ & $(58.0 \%)$ \\
& 14 & 29 & 31 & 120 \\
& $(5.7 \%)$ & $(21.8 \%)$ & $(25.0 \%)$ & $(35.7 \%)$
\end{tabular}


Table 3. Model summary for the full moderated multiple regression.

\begin{tabular}{ccccccccc}
$\boldsymbol{R}$ & Adj. $\boldsymbol{R}^{\mathbf{2}}$ & $\begin{array}{c}\text { Std. } \\
\text { Error }\end{array}$ & $\begin{array}{c}\boldsymbol{R} 2 \\
\text { Change }\end{array}$ & $\begin{array}{c}\boldsymbol{F} \\
\text { Change }\end{array}$ & Df1 & Df2 & p & $\begin{array}{c}\text { Durbin } \\
\text { Watson }\end{array}$ \\
\hline 373 & .126 & .804 & .134 & 6.066 & 23 & 862 & $<.001$ & 2.07
\end{tabular}

Table 4. Full model of the moderated multiple regression.

\begin{tabular}{|c|c|c|c|c|c|}
\hline & $\begin{array}{c}B \\
{[C I]}\end{array}$ & $S E B$ & $t$ & $p$ & Tol. \\
\hline Constant & $\begin{array}{c}3.12 \\
{[3.00,3.23]}\end{array}$ & .057 & 55.17 & $<.001$ & \\
\hline$J D-N V$ & $\begin{array}{c}-.134 \\
{[-.367, .093]}\end{array}$ & .116 & -.1 .161 & .242 & .429 \\
\hline$J D-V$ & $\begin{array}{c}.100 \\
{[-.144, .345]}\end{array}$ & .125 & .806 & .421 & .394 \\
\hline JSO & $\begin{array}{c}-.115 \\
{[-.352, .122]}\end{array}$ & .121 & -.954 & .340 & .214 \\
\hline Male Caregiver & $\begin{array}{c}.056 \\
{[-.107, .219]}\end{array}$ & .083 & .673 & .501 & .591 \\
\hline Male $x J D-N V$ & $\begin{array}{c}.236 \\
{[-.207, .680]}\end{array}$ & .226 & 1.046 & .296 & .807 \\
\hline Male $x J D-V$ & $\begin{array}{c}-.489 \\
{[-.979,-.002]}\end{array}$ & .250 & -1.956 & .050 & .753 \\
\hline Male $x J S O$ & $\begin{array}{c}-.324 \\
{[-.577,-.071]}\end{array}$ & .129 & -2.513 & .012 & .754 \\
\hline Non-Bio Caregiver & $\begin{array}{c}-.298 \\
{[-.632,-.035]}\end{array}$ & .170 & -1.758 & .048 & .181 \\
\hline Non-Bio $x J D-N V$ & $\begin{array}{c}.145 \\
{[-.365, .655]}\end{array}$ & .260 & .558 & .577 & .468 \\
\hline Non-Bio $x \mathrm{JD}-\mathrm{V}$ & $\begin{array}{c}.223 \\
{[-.297,7.42]}\end{array}$ & .265 & .842 & .400 & .451 \\
\hline Non-Bio x JSO & $\begin{array}{c}.547 \\
{[.151, .943]}\end{array}$ & .202 & 2.709 & .007 & .226 \\
\hline
\end{tabular}

Note. Model is continued on the following page. 
Table 4 (continued). Full model of the moderated multiple regression.

\begin{tabular}{|c|c|c|c|c|c|}
\hline & $\begin{array}{c}B \\
{[C I]}\end{array}$ & $S E B$ & $t$ & $p$ & Tol. \\
\hline Constant & $\begin{array}{c}3.12 \\
{[3.00,3.23]}\end{array}$ & .057 & 55.17 & $<.001$ & \\
\hline Change Caregiver & $\begin{array}{c}.037 \\
{[-2.06,2.80]}\end{array}$ & .124 & .300 & .764 & .192 \\
\hline Change $x \mathrm{JD}-\mathrm{NV}$ & $\begin{array}{c}-.096 \\
{[-.473, .281]}\end{array}$ & .192 & -.500 & .617 & .330 \\
\hline Change $x J D-V$ & $\begin{array}{c}-.267 \\
{[-.667, .132]}\end{array}$ & .204 & -1.312 & .190 & .293 \\
\hline Change $x$ JSO & $\begin{array}{c}-.100 \\
{[-.409, .209]}\end{array}$ & .157 & -.637 & .524 & .152 \\
\hline Experience Phys. Abuse & $\begin{array}{c}-.303 \\
{[-.600,-.006]}\end{array}$ & .151 & -.2004 & .045 & .131 \\
\hline Phys. Abuse $x J D-N V$ & $\begin{array}{c}.047 \\
{[-.403, .497]}\end{array}$ & .229 & .205 & .838 & .349 \\
\hline Phys. Abuse $x J D-V$ & $\begin{array}{c}-.488 \\
{[-.968,-.008]}\end{array}$ & .244 & -1.997 & .046 & .239 \\
\hline Phys. Abuse x JSO & $\begin{array}{c}-.051 \\
{[-.315, .416]}\end{array}$ & .186 & .272 & .786 & .104 \\
\hline Experience Neglect & $\begin{array}{c}-.190 \\
{[-.557, .176]}\end{array}$ & .187 & -1.021 & .308 & .120 \\
\hline Neglect $x J D-V$ & $\begin{array}{c}.040 \\
{[-.480, .560]}\end{array}$ & .265 & .150 & .881 & .332 \\
\hline Neglect $x J D-V$ & $\begin{array}{c}-.011 \\
{[-.565, .544]}\end{array}$ & .283 & -.038 & .970 & .271 \\
\hline Neglect $x J S O$ & $\begin{array}{c}-.108 \\
{[-.523, .307]}\end{array}$ & .211 & -.511 & .610 & .141 \\
\hline
\end{tabular}


Figures

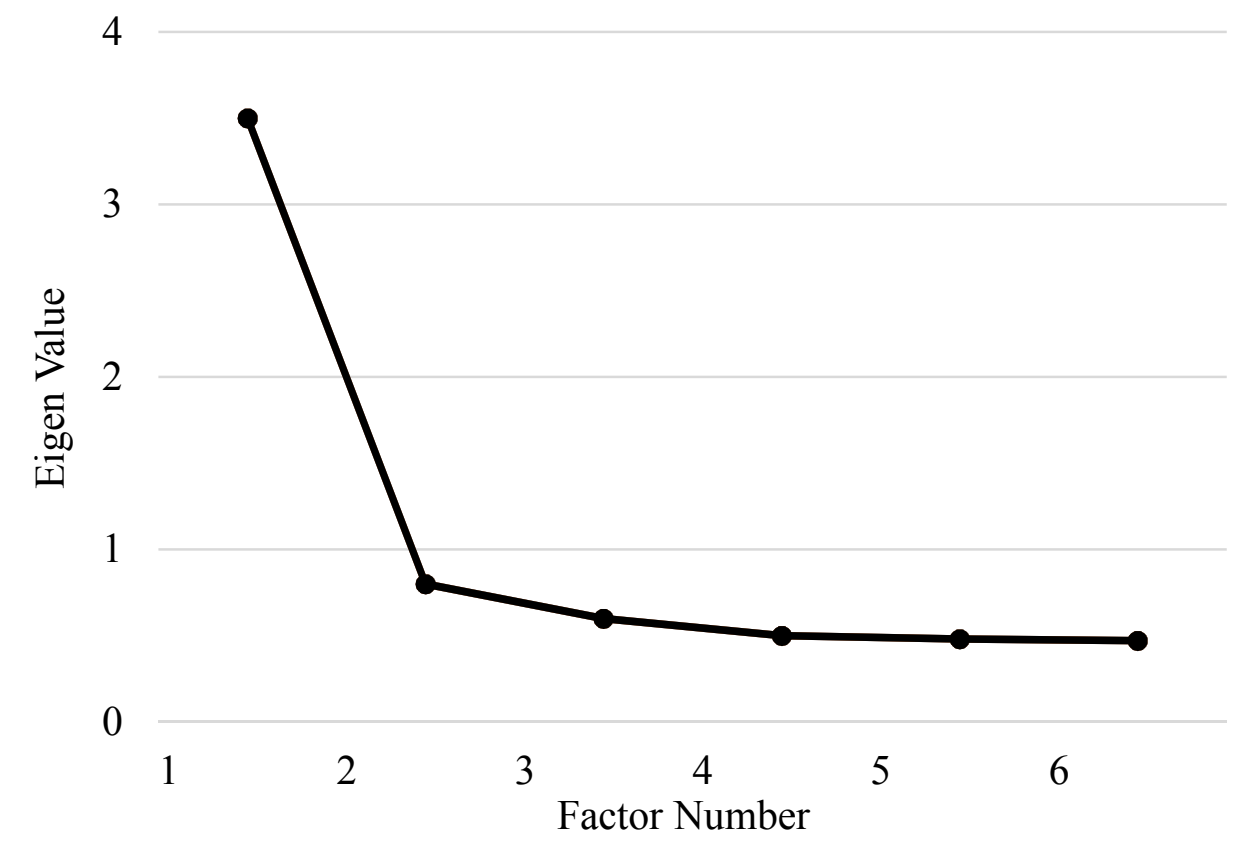

Figure 1.

Scree plot of the Perceived Relationship with Supervisor Scale.

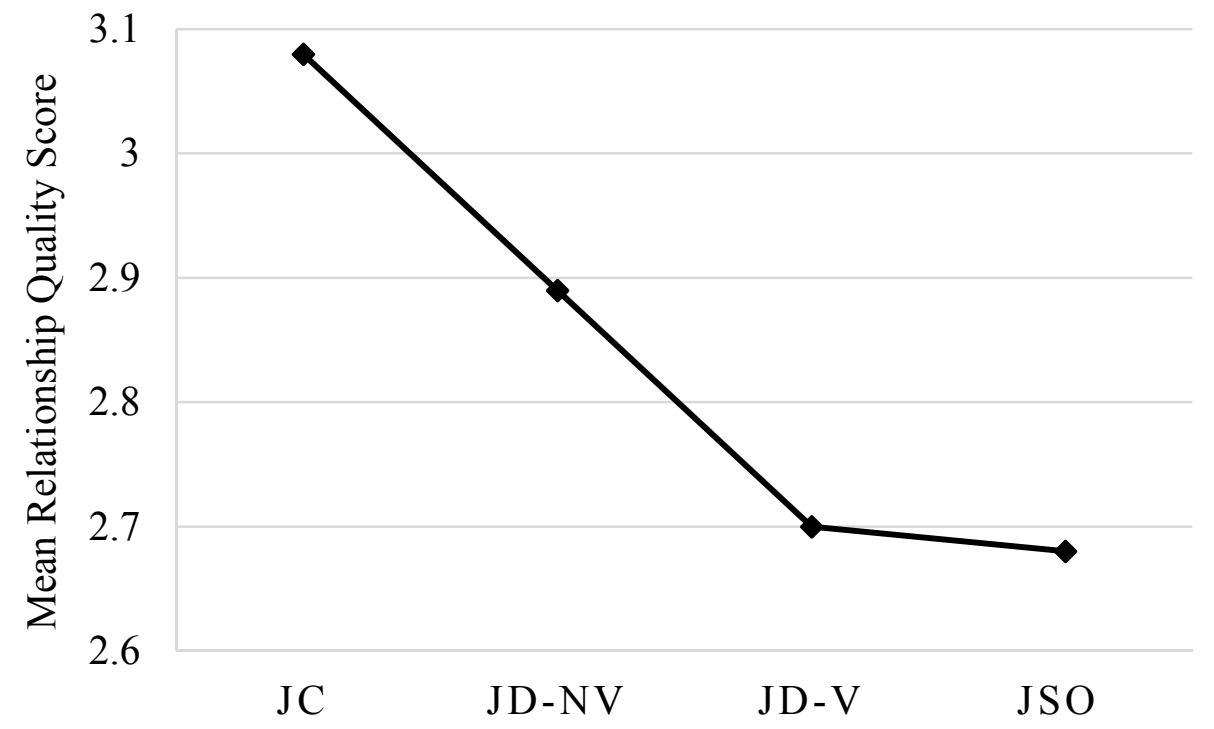

Figure 2.

Mean values of the PRSS by offense type. 


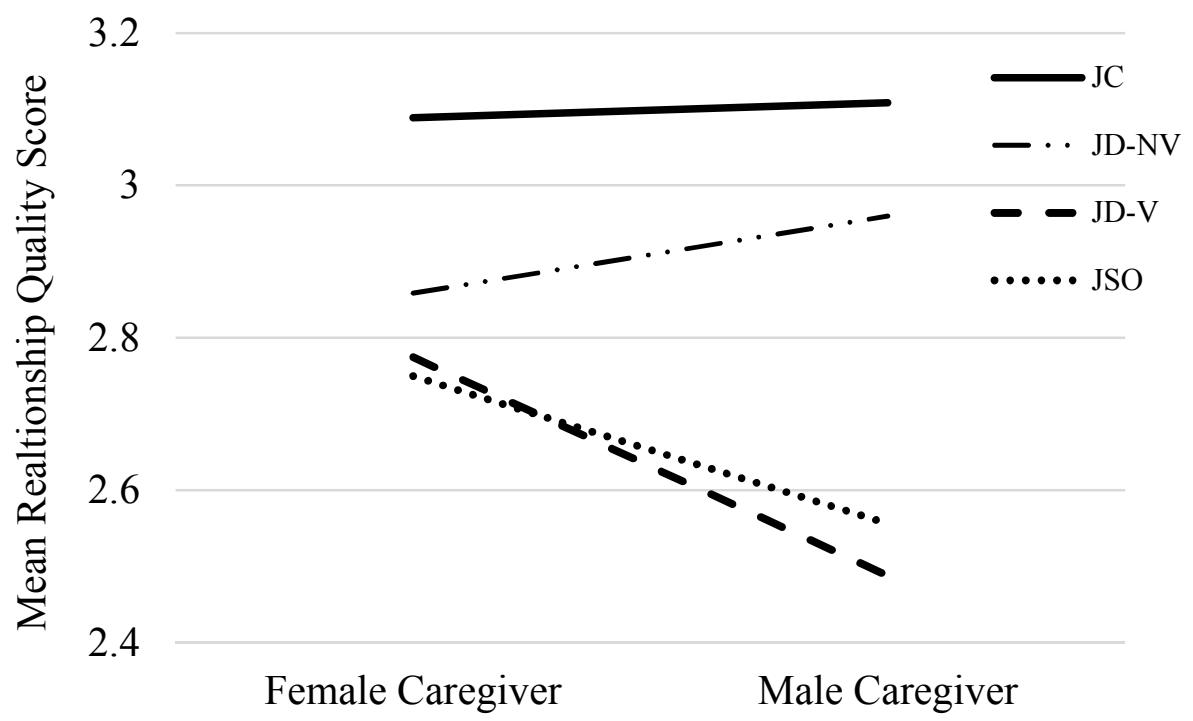

Figure 3.

Moderating effect of gender of caregiver between offense status and relationship quality.

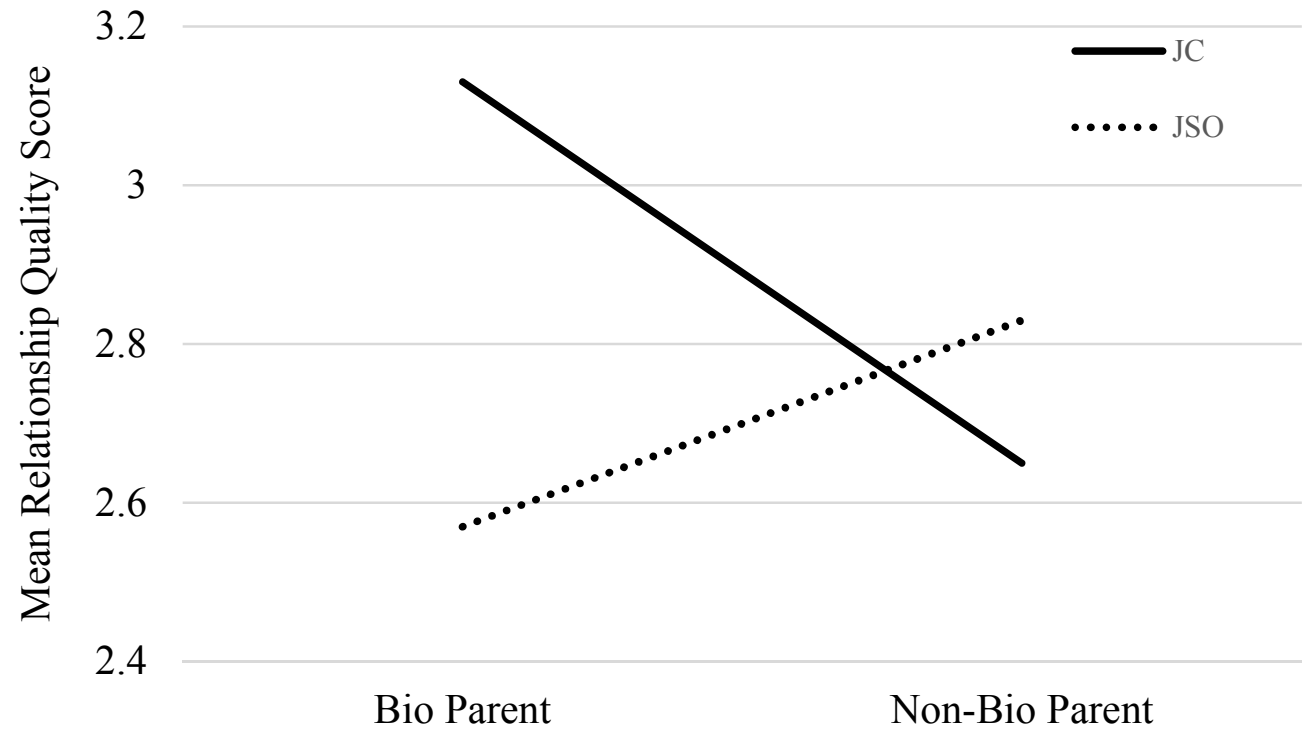

Figure 4.

Moderated effect of biological-parent on the relationship quality of JCs and JSOs. 


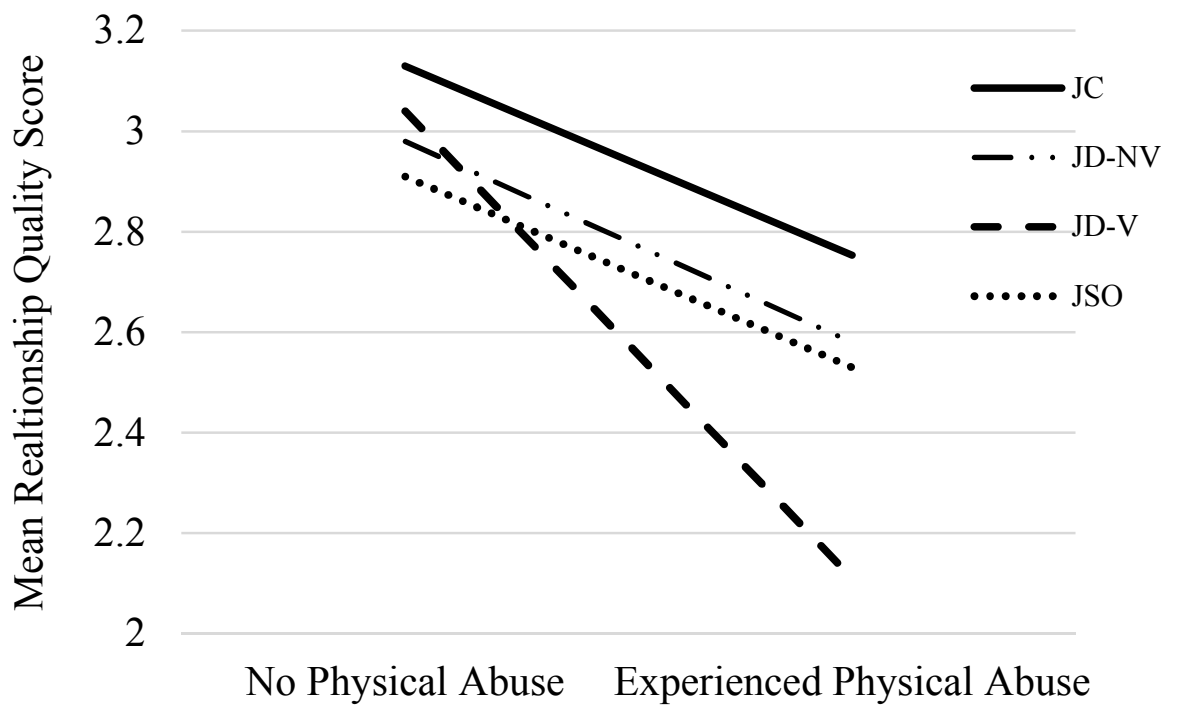

Figure 5.

Moderated effect of physical abuse on the relationship quality.

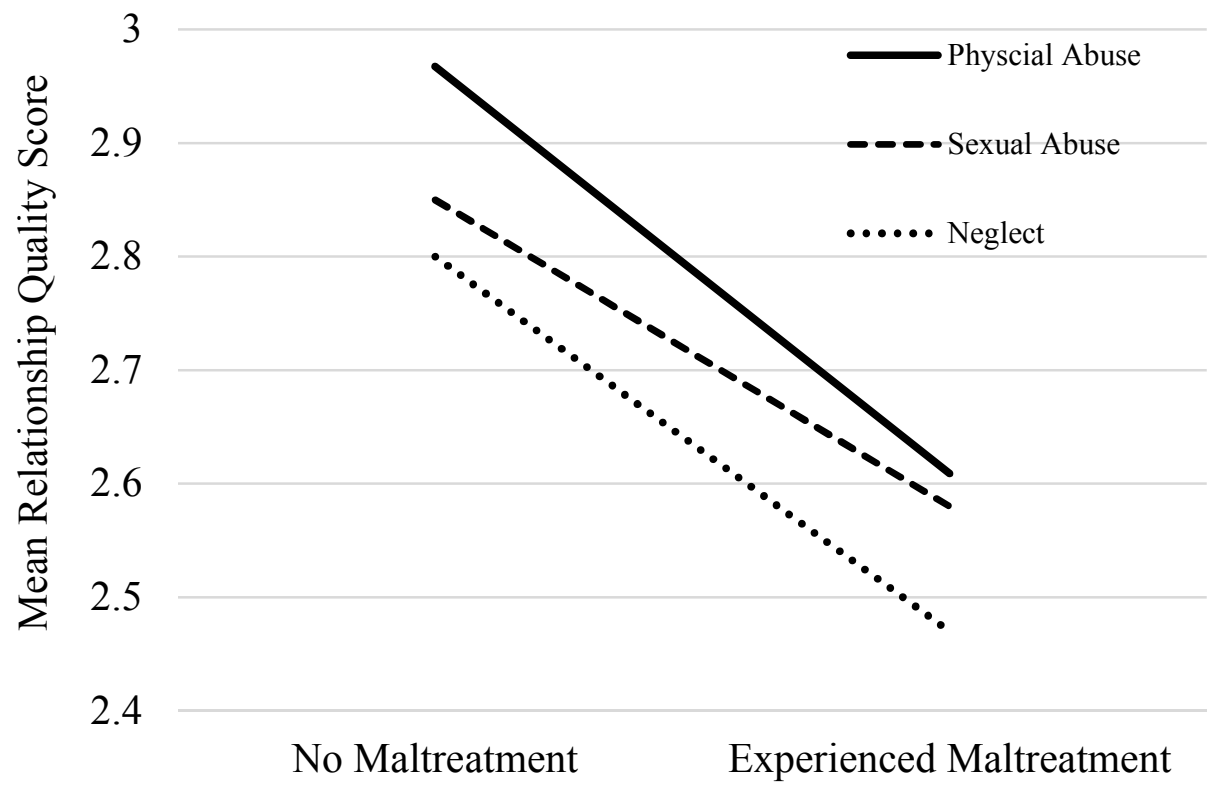

Figure 6.

Mean differences of maltreatment on the relationship quality of JSOs. 


\section{References}

Adopted Children In The United States: A Profile Based On A National Survey of Child Health, Congress, 1-7 (1995) (testimony of Nicholas Zill).

Ainsworth, M. D. S., \& Bowlby, J. (1991). An ethological approach to personality development. American Psychologist, 46, 331-341.

Ainsworth, M. D. S., Blehar, M. C, Waters, E., \& Wall, S. (1978). Patterns of attachment: A psychological study of the strange situation. Hillsdale, NJ: Erlbaum.

Allen, R. E., \& Oliver, J. M. (1982). The effects of child maltreatment on language development. Child Abuse \& Neglect, 6, 299-305.

Amato, P. R. (2001). Children of divorce in the 1990s: An update of the Amato and Keith (1991) meta-analysis. Journal of Family Psychology, 15, 355-370.

Amato, P. R., \& Keith, B. (1991). Parental divorce and the well-being of children: A meta-analysis. Psychological Bulletin, 110, 26-46.

Apel, R., \& Kaukinen, C. (2008). On the relationship between family structure and antisocial behavior: Parental cohabitation and blended households. Criminology, 46(1), 35-70.

Bachman, H. J., \& Chase-Lansdale, P. L. (2005). Custodial grandmothers' physical, mental, and economic well-being: Comparisons of primary caregivers from lowincome neighborhoods. Family Relations, 54(4), 475-487.

Bachman, R., \& Saltzman, L. (1995). Violence against women: Estimates from the redesigned survey (No. NCJ-15325). Washington, DC: U.S. Department of Justice, Bureau of Justice Statistics.

Baer, J. C., \& Martinez, C. D. (2006). Child maltreatment and insecure attachment: a meta-analysis. Journal of Reproductive and Infant Psychology, 24(3), 187-197.

Banyard, V. L., Moynihan, M. M., Walsh, W. A., Cohn, E. S., \& Ward, S. (2010). Friends of survivors: The community impact of unwanted sexual experiences. Journal of Interpersonal Violence, 25, 242-256. 
Barber, J. G., \& Delfabbro, P. H. (2003). Placement stability and the psychosocial wellbeing of children in foster care. Research on Social Work Practice, 13(4), 415431.

Beck, A. J., Adams, D. B., \& Guerino, P. (2008). Sexual violence reported by juvenile correctional authorities, 2005-06. US Department of Justice, Office of Justice Programs, Bureau of Justice Statistics.

Beck, M. (2016). 4 months at Lincoln Hills School: nearly 500 incidents, 32 injuries to youth. Wisconsin State Journal. Retrieved from:

http:/host.madison.com/wsj/news/local/govt-and-politics/months-at-lincoln-hillsnearly-incidents-injuries-to-youth/article_9521cc74-224b-53c1-81de6e6e563f47f2.html

Bowlby, J. (1944). Forty-four juvenile thieves: Their characters and home lives. International Journal of Psycho-Analysis, 25, 19-52.

Bowlby, J. (1969). Attachment and loss, Vol. I: Attachment. New York: Basic Books. Breivik, K., \& Olweus, D. (2006). Adolescent's adjustment in four post-divorce family structures: Single mother, stepfather, joint physical custody and single father families. Journal of Divorce \& Remarriage, 44, 99-124.

Bretherton, I. (1992). The origins of attachment theory: John Bowlby and Mary Ainsworth. Developmental Psychology, 28, 759-775.

Bronte-Tinkew, J., Scott, M. E., \& Lilja, E. (2010). Single custodial fathers' involvement and parenting: Implications for outcomes in emerging adulthood. Journal of Marriage and Family, 72(5), 1107-1127.

Brosky, B. A., \& Lally, S. J. (2004). Prevalence of trauma, PTSD, and disassociation in court-referred adolescents. Journal of Interpersonal Violence, 19, 801-814.

Brown, J. (2011). Sexual abuse: A public health challenge. National Center for Prevention of Cruelty to Children. Washignton DC: Department of Justice.

Brown, J., Cohen, P., Chen, H., Smailes, E., \& Johnson, J. G. (2004). Sexual trajectories of abused and neglected youths. Journal of Developmental and Behavioral Pediatrics, 25, 77-82. 
Burk, L. R., \& Burkhart, B. R. (2003). Disorganized attachment as a diathesis for sexual deviance: Developmental experience and the motivation for sexual offending. Aggression and Violent Behavior, 8, 487-511.

Burke, J. D., Loeber, R., \& Birmaher, B. (2002). Oppositional defiant disorder and conduct disorder: a review of the past 10 years, part II. Journal of the American Academy of Child \& Adolescent Psychiatry, 41(11), 1275-1293.

Burton, D. (2003). Male adolescents: Sexual victimization and subsequent sexual abuse. Child and Adolescent Social Work Journal, 20, 277-296.

Caldwell, M. F. (2002). What we do not know about juvenile sexual reoffense risk. Child Maltreatment, 7, 291-302.

Center for Disease Control (CDC). (2014). Child maltreatment: Facts at a glance. Retrieved from: https://www.cdc.gov/violenceprevention/pdf/childmaltreatmentfacts-at-a-glance.pdf

Center for Sex Offender Management (CSOM). (2014). Fact sheet: What you need to know about sex offenders. Retrieved from: http://www.csom.org/pubs/needtoknow_fs.pdf

Chaffin, M., Lawson, L., Selby, A., \& Wherry, J. N. (1997). False negatives in sexual abuse interviews: Preliminary investigation of a relationship to dissociation. Journal of Child Sexual Abuse, 6, 15-29.

Chen, L. P., Murad, M. H., Paras, M. L., Colbenson, K. M., Sattler, A. L., Goranson, E. N., Elamin, M. B., Seime, R. J., Shinozaki, G., Prokop, L. J., \& Zirakzadeh, A. (2010). Sexual abuse and lifetime diagnosis of psychiatric disorders: systematic review and meta-analysis. Mayo Clinic Proceedings, 85, 618-629.

Children's Bureau. (2016). Child maltreatment, 2014. Washington, DC: US Department of Health and Human Services. Retrieved from: http://www.acf.hhs.gov/programs/cb/research-data-technology/statisticsresearch/child-maltreatment

Child Welfare Information Gateway (CWIGa). (2016). Child abuse and neglect fatalities 2014: Statistics and interventions. Washington, DC: U.S. Department of Health and Human Services, Children's Bureau. 
Child Welfare Information Gateway (CWIGb). (2016). Foster care statistics: 2015. Washington, DC: U.S. Department of Health and Human Services, Children's Bureau.

Chris Fraley, R. (2002). Attachment stability from infancy to adulthood: Meta-analysis and dynamic modeling of developmental mechanisms. Personality and Social Psychology Review, 6, 123-151.

Claussen, A. \& Crittenden, P. (1991). Physical and psychological maltreatment: Relations among types of maltreatment. Child Abuse and Neglect, 15, 5-18.

Cohn, D. A. (1990). Child-mother attachment of six-year-olds and social competence at school. Child Development, 61, 152-162.

Coleman, D. (2005). Trauma and incarcerated youth. Journal of Evidence-Based Social Work, 2, 113-124.

Coleman, D., \& Stewart, L. M. (2010). Prevalence and impact of childhood maltreatment in incarcerated youth. American Journal of Orthopsychiatry, 80(3), 343-349.

Coles, R. L. (2015). Single-father families: A review of the literature. Journal of Family Theory \& Review, 7, 144-166.

Collin-Vézina, D., Daigneault, I., \& Hébert, M. (2013). Lessons learned from child sexual abuse research: prevalence, outcomes, and preventive strategies. Child and Adolescent Psychiatry and Mental Health, 7, 22-31.

Connor, D. F. (2012). Aggression and antisocial behavior in children and adolescents: Research and treatment. New York, NY: Guilford Press.

Cortoni, F., \& Marshall, W. L. (2001). Sex as a coping strategy and its relationship to juvenile sexual history and intimacy in sexual offenders. Sexual Abuse: A Journal of Research and Treatment, 13, 27-43.

Crittenden, P. M. (1992). Children's strategies for coping with adverse home environments: An interpretation using attachment theory. Child Abuse \& Neglect, 16, 329-343.

Daane, D. M. (2005). The ripple effects: Secondary sexual assault survivors. In F. P. Reddington \& B. W. Kreisel (Eds.), Sexual assault: The victims, the perpetrators 
and the criminal justice system (pp. 113-131). Durham, NC: Carolina Academic Press.

Daly, M., \& Wilson, M. (1988). Homicide. Hawthorne, NY: Aldine de Gruyter.

Daversa, M. T., \& Knight, R. A. (2007). A structural examination of the predictors of sexual coercion against children in adolescent sexual offenders. Criminal Justice and Behavior, 34, 1313-1333.

Dembo, R., Wothke, W., Shemwell, M., Pacheco, K., Seeberger, W., Rollie, M., \& Livingston, S. (2000). A structural model of the influence of family problems and child abuse factors on serious delinquency among youths processed at a juvenile assessment center. Journal of Child \& Adolescent Substance Abuse, 10(1), 17-31.

Demuth, S., \& Brown, S. L. (2004). Family structure, family processes, and adolescent delinquency: The significance of parental absence versus parental gender. Journal of Research in Crime and Delinquency, 41(1), 58-81.

Department of Justice, Federal Bureau of Investigation. (2004). National incident-based reporting system, 2004. Ann Arbor, MI.

Diener, M. J., Hilsenroth, M. J., Weinberger, J., \& Monroe, J. M. (2014). A primer on meta-analysis of correlation coefficients: The relation between adult attachment style and therapeutic alliance as an illustration. In W. Lutz, \& S. Knox (Eds.), Quantitative and qualitative methods in psychotherapy research; quantitative and qualitative methods in psychotherapy research (pp. 235-246), New York: Taylor and Francis.

Dong, M., Anda, R. F., Felitti, V. J., Dube, S. R., Williamson, D. F., Thompson, T. J., ... \& Giles, W. H. (2004). The interrelatedness of multiple forms of childhood abuse, neglect, and household dysfunction. Child Abuse \& Neglect, 28(7), 771-784.

Duane, Y., Carr, A., Cherry, J., McGrath, K., \& O'Shea, D. (2003). Profiles of the parents of adolescent CSA perpetrators attending a voluntary outpatient treatment programme in Ireland. Child Abuse Review, 12(1), 5-24.

Dube, S. R., Anda, R. F., Whitfield, C. L., Brown, D. W., Felitti, V. J., Dong, M., \& Giles, W. H. (2005). Long-term consequences of childhood sexual abuse by gender of victim. American Journal of Preventive Medicine, 28, 430-438. 
Durose, M., Cooper, A., \& Snyder. (2014). Recidivism of prisoners released in 30 States in 2005: Patterns from 2005 to 2010. Washington, D.C.: Bureau of Justice Statistics.

Dutton, D. G., \& Hart, S. D. (1992). Evidence for long-term, specific effects of childhood abuse and neglect on criminal behavior in men. International Journal of Offender Therapy and Comparative Criminology, 36(2), 129-137.

Egeland, B., Yates, T., Appleyard, K., \& Van Dulmen, M. (2002). The long-term consequences of maltreatment in the early years: A developmental pathway model to antisocial behavior. Children's Services: Social Policy, Research, and Practice, 5(4), 249-260.

Elliott, A. N., \& Carnes, C. N. (2001). Reactions of nonoffending parents to the sexual abuse of their child: A review of the literature. Child Maltreatment, 6, 314-331.

Ellis, R. R., \& Simmons, T. (2014). Coresident grandparents and their grandchildren: 2012. US Census Bureau. Retrieved from: https://www.census.gov/content/dam/Census/library/publications/2014/demo/p20576.pdf

Emick, M. A., \& Hayslip Jr, B. (1999). Custodial grandparenting: Stresses, coping skills, and relationships with grandchildren. The International Journal of Aging and Human Development, 48(1), 35-61.

English, D. J., Widom, C. S., \& Brandford, C. (2002). Childhood victimization and delinquency, adult criminality, and violent criminal behavior: A replication and extension. Final Report to NIJ.

Evenhouse, E., \& Reilly, S. (2004). A sibling study of stepchild well-being. Journal of Human Resources, 39(1), 248-276.

Ewigman, B., Kivlahan, C., \& Land, G. (1993). The Missouri child fatality study: underreporting of maltreatment fatalities among children younger than five years of age, 1983 through 1986. Pediatrics, 91, 330-337.

Fagan, J., \& Wexler, S. (1988). Explanations of sexual assault among violent delinquents. Journal of Adolescent Research, 3, 363-385. 
Fang, X., Brown, D. S., Florence, C. S., \& Mercy, J. A. (2012). The economic burden of child maltreatment in the United States and implications for prevention. Child Abuse \& Neglect, 36, 156-165.

Fapul, S. (2014). Etiology of adult sexual offending. In C. Lobanov-Rotovsky \& R. Przybylski (Eds.) Sex offender management and planning initiative (pp. 33-53). Washington DC: Department of Justice.

Fehrenbach, P. A., Smith, W., Monastersky, C., \& Deisher, R. W. (1986). Adolescent sexual offenders: Offender and offense characteristics. American Journal of Orthopsychiatry, 56, 225-233.

Felizzi, M. V. (2015). Family or caregiver instability, parental attachment, and the relationship to juvenile sex offending. Journal of Child Sexual Abuse, 24(6), 641658.

Finkelhor, D. (1994). Current information on the scope and nature of child sexual abuse. The Future of Children, 4, 31-53.

Finkelhor, D., \& Hashima, P. (2001). The victimization of children and youth: A comprehensive overview. In S. O. White (Ed.), Handbook of youth and justice (pp. 49-78). New York: Kluwer Academic/Plenum.

Finkelhor, D., Ormrod, R., \& Chaffin, M. (2009). Juveniles who commit sexual offenses against minors. Washington, D.C.: Office of Juvenile and Delinquency Prevention.

Finkelhor, D., Shattuck, A., Turner, H. A., \& Hamby, S. L. (2014). The lifetime prevalence of child sexual abuse and sexual assault assessed in late adolescence. Journal of Adolescent Health, 55, 329-333.

Frazier, E. F. (1950). Problems and needs of Negro children and youth resulting from family disorganization. The Journal of Negro Education, 19(3), 269-277.

Funari, S. K. (2005). An exploration of impediments to attachment in a juvenile offender population: Comparisons between juvenile sex offenders, juvenile violent offenders and juvenile non-sex, non-violent offenders (Doctoral dissertation, Virginia Commonwealth University Richmond, Virginia). 
Gavin, H. (2011). Sticks and stones may break my bones: The effects of emotional abuse. Journal of Aggression, Maltreatment, \& Trauma, 20, 503-529.

Gore-Felton, C., Koopman, C., McGarvey, E., Hernandez, N., \& Canterbury Ii, R. J. (2002). Relationships of sexual, physical, and emotional abuse to emotional and behavioral problems among incarcerated adolescents. Journal of Child Sexual Abuse, 10(1), 73-88.

Gorman-Smith, D., Tolan, P. H., Loeber, R., \& Henry, D. B. (1998). Relation of family problems to patterns of delinquent involvement among urban youth. Journal of Abnormal Child Psychology, 26(5), 319-333.

Green, A. H. (1996). Overview of child sexual abuse. In S.J. Kaplan (Ed.) Family violence: A clinical and legal guide (pp. 73-104). Washington DC: American Psychiatric Press.

Groh, A. M., Fearon, R. M., IJzendoorn, M. H., Bakermans-Kranenburg, M. J., \& Roisman, G. I. (2016). Attachment in the early life course: Meta-analytic evidence for its role in socioemotional development. Child Development Perspectives, 11, 70-76.

Hadden, B. W., Smith, C. V., \& Webster, G. D. (2014). Relationship duration moderates associations between attachment and relationship quality: Meta-analytic support for the temporal adult romantic attachment model. Personality and Social Psychology Review, 18, 42-58.

Hanlon, T. E., Carswell, S. B., \& Rose, M. (2007). Research on the caretaking of children of incarcerated parents: Findings and their service delivery implications. Children and Youth Services Review, 29(3), 348-362.

Hanson, J. (2016). Probing the neural correlates of associative learning in adolescents who have suffered physical abuse (Unpublished Doctoral Dissertation). University of Wisconsin - Madison, Madison, WI.

Hanson, J., Nacewicz, B. M., Sutterer, M. J., Cavo, A. A., Schaefer, S. M., Rudolph, K. D., \& Davidson, R. J. (2015). Behavioral problems after early life stress: contributions of the hippocampus and amygdala. Biological Psychiatry, 77, 314323. 
Hanson, R. K., Bourgon, G., Helmus, L., \& Hodgson, S. (2009). A meta-analysis of the effectiveness of treatment for sexual offenders: Risk, need, and responsivity. User Report, 2009-01. Ottawa: Public Safety.

Hayslip Jr, B., \& Kaminski, P. L. (2005). Grandparents raising their grandchildren. Marriage \& Family Review, 37, 147-169.

Hildyard, K. L., \& Wolfe, D. A. (2002). Child neglect: developmental issues and outcomes. Child Abuse \& Neglect, 26(6), 679-695.

Hilton, N. Z., Harris, G. T., \& Rice, M. E. (2015). The step-father effect in child abuse: Comparing discriminative parental solicitude and antisociality. Psychology of Violence, 5(1), 8-15.

Hockenberry, S. (2016). Juveniles in residential placement, 2013. Washington, DC: US Department of Justice, Office of Justice Programs, Office of Juvenile Justice and Delinquency Prevention.

Hoeve, M., Dubas, J. S., Eichelsheim, V. I., Van Der Laan, P. H., Smeenk, W., \& Gerris, J. R. (2009). The relationship between parenting and delinquency: A metaanalysis. Journal of Abnormal Child Psychology, 37, 749-775.

Howe, D. (2001). Age at placement, adoption experience and adult adopted people's contact with their adoptive and birth mothers: An attachment perspective. Attachment \& Human Development, 3(2), 222-237.

Irish, L., Kobayashi, I., \& Delahanty, D. L. (2009). Long-term physical health consequences of childhood sexual abuse: A meta-analytic review. Journal of Pediatric Psychology, 35, 450-461.

Jacobson, J. L., \& Wille, D. E. (1986). The influence of attachment pattern on developmental changes in peer interaction from the toddler to the preschool period. Child Development, 57, 338-347.

James, S. (2004). Why do foster care placements disrupt? An investigation of reasons for placement change in foster care. Social Service Review, 78(4), 601-627.

Jensen, T. K., Gulbrandsen, W., Mossige, S., Reichelt, S., \& Tjersland, O. A. (2005). Reporting possible sexual abuse: A qualitative study on children's perspectives and the context for disclosure. Child Abuse \& Neglect, 29, 1395-1413. 
Jespersen, A. F., Lalumière, M. L., \& Seto, M. C. (2009). Sexual abuse history among adult sex offenders and non-sex offenders: A meta-analysis. Child Abuse \& Neglect, 33(3), 179-192.

Johnson-Reid, M., \& Barth, R. P. (2000). From maltreatment report to juvenile incarceration: The role of child welfare services. Child Abuse \& Neglect, 24, 505520.

Jones, S. (2015). Parents of adolescents who have sexually offended: Providing support and coping with the experience. Journal of Interpersonal Violence, 30, 12991321.

Juffer, F., \& van IJzendoorn, M. H. (2005). Behavior problems and mental health referrals of international adoptees: A meta-analysis. Jama, 293(20), 2501-2515.

Kaplan, S. J., Pelcovitz, D., Salzinger, S., Weiner, M., Mandel, F. S., Lesser, M. L., \& Labruna, V. E. (1998). Adolescent physical abuse: Risk for adolescent psychiatric disorders. The American Journal of Psychiatry, 155(7), 954-959.

Kaufman, K. (2001). Perceived Relationship with Supervisor Scale. Available from author, Portland, OR: Portland State University.

Keene, A. C., \& Epps, J. (2016). Childhood physical abuse and aggression: Shame and narcissistic vulnerability. Child Abuse \& Neglect, 51, 276-283.

Kelley, S. J. (1993). Caregiver stress in grandparents raising grandchildren. Journal of Nursing Scholarship, 25(4), 331-337.

Kempton, T., \& Forehand, R. (1992). Juvenile sex offenders: Similar to, or different from, other incarcerated delinquent offenders? Behaviour Research and Therapy, 30(5), 533-536.

Knox, L. A. (2014). Attachment and adolescent offending: An examination of the links between sexually abusive behavior and the level of attachment to parents and peers. (Unpublished doctoral dissertation). Portland State University, Portland, Oregon, USA.

Korn, P. (2013, February 14). Portland: Sex offender magnet? Portland Tribune. 
Kreider, R. M., \& Lofquist, D. A. (2014). Adopted children and stepchildren: 2010. US Census Bureau. Retrieved from: https://www.census.gov/prod/2014pubs/p20572.pdf

Lahna, D., \& Long, C. (2014). Oregon's sex offender registry: How to handle juvenile offenders. City Club of Portland Bulletin, 97, 1-52.

Laird, R. D., Pettit, G. S., Bates, J. E., \& Dodge, K. A. (2003). Parents' monitoringrelevant knowledge and adolescents' delinquent behavior: Evidence of correlated developmental changes and reciprocal influences. Child Development, 74, 752768.

Lansford, J. E., Chang, L., Dodge, K. A., Malone, P. S., Oburu, P., Palmérus, K., \& Tapanya, S. (2005). Physical discipline and children's adjustment: Cultural normativeness as a moderator. Child Development, 76(6), 1234-1246.

Leclerc, B., \& Tremblay, P. (2007). Strategic behavior in adolescent sexual offenses against children: Linking modus operandi to sexual behaviors. Sexual Abuse: A Journal of Research and Treatment, 19(1), 23-41.

Leeb, R. T., Paulozzi, L. J., Melanson, C., Simon, T. R., \& Arias, I. (2008). Child maltreatment surveillance. Uniform definitions for public health and recommended data elements. National Center for Injury Prevention and Control. Atlanta, Georgia: Centers for Disease Control and Prevention.

Leon, S. C., Saucedo, D. J., \& Jachymiak, K. (2016). Keeping it in the family: The impact of a family finding intervention on placement, permanency, and wellbeing outcomes. Children and Youth Services Review, 70, 163-170.

Levenson, J. S., Brannon, Y., Fortney, T., \& Baker, B. (2007). Public perceptions about sex offenders and community protection policies. Analyses of Social Issues and Public Policy, 7, 1-25.

Lobanov-Rostovsky, C. (2014). Recidivism of juveniles who commit sexual offenses. Retrieved from https://www.smart.gov/SOMAPI/sec2/ch3_recidivism.html

Loeber, R., \& Stouthamer-Loeber, M. (1986). Family factors as correlates and predictors of juvenile conduct problems and delinquency. Crime and Justice, 7, 29-149. 
Lösel, F., \& Schmucker, M. (2005). The effectiveness of treatment for sexual offenders: A comprehensive meta-analysis. Journal of Experimental Criminology, 1, 117 146.

Lyn, T. S., \& Burton, D. L. (2005). Attachment, anger and anxiety of male sexual offenders. Journal of Sexual Aggression, 11, 127-137.

MacMillian, H., Fleming, J. E., Trocoma, N., Boyle, M. H., Wong, M., Racine, Y. A., Beardslee, W. R., \& Offord, D. R. (1997). Prevalence of child physical and sexual abuse in the community: Results from the Ontario Health Supplement. Journal of the American Medical Association, 278, 131-135.

Main, M., \& Hesse, E. (1990). Parents' unresolved traumatic experiences are related to infant disorganized attachment status: Is frightened and/or frightening parental behavior the linking mechanism? In M.T. Greenberg, D. Cicchetti, \& E. M. Cummings (Eds.), Attachment in preschool years: Theory, research, and intervention (pp. 161-184). Chicago: University of Chicago Press.

Main, M., \& Solomon, J. (1990). Procedures for identifying infants as disorganized/disoriented during the Ainsworth Strange Situation. In M.T. Greenberg, D. Cicchetti, \& E. M. Cummings (Eds.), Attachment in preschool years: Theory, research, and intervention (pp. 121-160). Chicago: University of Chicago Press.

Main, M., Kaplan, N., \& Cassidy, J. (1985). Security in infancy, childhood, and adulthood: A move to the level of representation. Monographs of the Society for Research in Child Development, 50(1 \& 2), 66-104.

Malinosky-Rummell, R., \& Hansen, D. J. (1993). Long-term consequences of childhood physical abuse. Psychological Bulletin, 114(1), 68-79.

Maniglio, R. (2012). The role of parent-child bonding, attachment, and interpersonal problems in the development of deviant sexual fantasies in sexual offenders. Trauma, Violence, and Abuse, 13, 83-96.

Manion, I. G., McIntyre, J., Firestone, P., Ligezinska, M., Ensom, R., \& Wells, G. (1996). Secondary traumatization in parents following the disclosure of 
extrafamilial child sexual abuse: Initial effects. Child Abuse \& Neglect, 20, $1095-$ 1109.

Manly, J.T., Kim, J. E., Rogosch, F. A., \& Cicchetti, D. (2001). Dimensions of child maltreatment and children's adjustment: contributions of developmental timing and subtype. Development and Psychopathology, 13, 759-782.

Manning, W. D., \& Lamb, K. A. (2004). Adolescent well-being in cohabiting, married, and single-parent families. Journal of Marriage and Family Therapy, 65, 876893.

Marsa, F., O'Reilly, G., Carr, A., Murphy, P., O'Sullivan, M., Cotter, A., \& Hevey, D. (2004). Attachment styles and psychological profiles of child sex offenders in Ireland. Journal of Interpersonal Violence, 19, 228-251.

Marshall, W. L. (1989). Intimacy, loneliness, and sexual offenders. Behavior Research and Therapy, 27, 491-503.

Marshall, W. L., Hudson, S. M., \& Hodkinson, S. (1993). The importance of attachment bonds in the development of juvenile sex offending. In H. E. Barbaree, W. L. Marshall, \& S. M. Hudson (Eds.), The juvenile sex offender (pp. 164-181). New York: Guildford Press.

Maxfield, M. G., \& Widom, C. S. (1996). The cycle of violence: Revisited 6 years later. Archives of Pediatrics \& Adolescent Medicine, 150, 390-395.

McCormack, J., M-Hudson, S., \& Ward, T. (2002). Sexual offenders' perceptions of their early interpersonal relationships: An attachment perspective. Journal of Sex Research, 39(2), 85-93.

McCoy, M. L., \& Keen, S. M. (2009). Child abuse and neglect. Philadelphia, PA: Taylor \& Francis.

McCurley, C., \& Snyder, H. N. (2004). Victims of violent juvenile crime. US Department of Justice, Office of Justice Programs, Office of Juvenile Justice and Delinquency Prevention.

Miller, B. C., Fan, X., Christensen, M., Grotevant, H. D., \& Van Dulmen, M. (2000). Comparisons of adopted and nonadopted adolescents in a large, nationally representative sample. Child Development, 71(5), 1458-1473. 
Miner, M.H., Robinson, B.E., Knight, R.A., Berg, D., Swinburne Romine, R., \& Netland, J. (2010). Understanding sexual perpetration against children: Effects of attachment style, interpersonal involvement, and hypersexuality. Sexual Abuse: A Journal of Research and Treatment, 20, 58-77.

Murray, J., \& Farrington, D. P. (2005). Parental imprisonment: effects on boys' antisocial behaviour and delinquency through the life-course. Journal of Child Psychology and Psychiatry, 46(12), 1269-1278.

Murray, J., \& Farrington, D. P. (2010). Risk factors for conduct disorder and delinquency: key findings from longitudinal studies. The Canadian Journal of Psychiatry, 55(10), 633-642.

National Center for Missing and Exploited Children (NCMEC). (2016). Registered sex offenders in the United States and its territories per 100,000 population. Retrieved from: http://www.missingkids.com/en_US/documents/Sex_Offenders_Map.pdf

National Institute of Justice. (2014). Recidivism. Retrieved from: https://www.nij.gov/topics/corrections/recidivism/Pages/welcome.aspx

National Society for Prevention of Cruelty to Children. (2017). Physical abuse at a glance. Retrieved from: https://www.nspcc.org.uk/preventing-abuse/child-abuseand-neglect/physical-abuse/

Neelum. A. (2011). State trends: Legislative victories from 2005 to 2010 removing youth from the adult criminal justice system. Washington, DC: Campaign for Youth Justice.

Newberger, C. M., Gremy, I. M., Waternaux, C. M., \& Newberger, E. H. (1993). Mothers of sexually abused children: Trauma and repair in longitudinal perspective. American Journal of Orthopsychiatry, 63, 92-102.

Norman, R. E., Byambaa, M., De, R., Butchart, A., Scott, J., \& Vos, T. (2012). The longterm health consequences of child physical abuse, emotional abuse, and neglect: a systematic review and meta-analysis. PLoS Med, 9, e1001349.

Oregon Department of Human Services: Children, Adults, and Families Division. (2016). 2015 child welfare data book. Retrieved from: 
https://www.oregon.gov/DHS/CHILDREN/CHILD-ABUSE/Documents/2015cw-data-book.pdf

Oregon Youth Authority. (2017). OYA Quick Facts. Retrieved from http://www.oregon.gov/oya/docs/QuickFacts/QuickFacts-Jan2017.pdf

Palacios, J., \& Brodzinsky, D. (2010). Adoption research: Trends, topics, outcomes. International Journal of Behavioral Development, 34(3), 270-284.

Pallini, S., Baiocco, R., Schneider, B. H., Madigan, S., \& Atkinson, L. (2014). Early child-parent attachment and peer relations: A meta-analysis of recent research. Journal of Family Therapy, 28, 118-123.

Paolucci, E. O., Genuis, M. L., \& Violato, C. (2001). A meta-analysis of the published research on the effects of child sexual abuse. The Journal of Psychology, 135, 1736.

Pardini, D. A., Lochman, J. E., \& Powell, N. (2007). The development of callousunemotional traits and antisocial behavior in children: Are there shared and/or unique predictors? Journal of Clinical Child and Adolescent Psychology, 36(3), 319-333.

Pelcovitz, D., Kaplan, S. J., DeRosa, R. R., Mandel, F. S., \& Salzinger, S. (2000). Psychiatric disorders in adolescents exposed to domestic violence and physical abuse. American Journal of Orthopsychiatry, 70(3), 360-369.

Planty, M., Langton, L., Krebs, C., Berzofsky, M., \& Smiley-McDonald, H. (2013). Female victims of sexual violence, 1994-2010. Washington DC: Department of Justice.

Poehlmann, J. (2003). An attachment perspective on grandparents raising their very young grandchildren: Implications for intervention and research. Infant Mental Health Journal, 24(2), 149-173.

Poehlmann, J. (2005). Representations of attachment relationships in children of incarcerated mothers. Child Development, 76(3), 679-696.

Poehlmann, J., Park, J., Bouffiou, L., Abrahams, J., Shlafer, R., \& Hahn, E. (2008). Representations of family relationships in children living with custodial grandparents. Attachment \& Human Development, 10(2), 165-188. 
Pruchno, R. A., \& McKenney, D. (2002). Psychological well-being of black and white grandmothers raising grandchildren: Examination of a two-factor model. The Journals of Gerontology Series B: Psychological Sciences and Social Sciences, 57(5), 444-452.

Quiroga, M. G., \& Hamilton-Giachritsis, C. (2016). Attachment styles in children living in alternative care: A systematic review of the literature. Child \& Youth Care Forum, 45, 625-653.

RAINN (Rape, Abuse, and Incest National Network). (2015). The criminal justice system: Statistics. Retrieved from https://www.rainn.org/statistics/criminaljustice-system

Rebellon, C. J., \& Van Gundy, K. (2005). Can control theory explain the link between parental physical abuse and delinquency? A longitudinal analysis. Journal of Research in Crime and Delinquency, 42(3), 247-274.

Rich, P. (2006). The relationship of attachment to juvenile sexual offending. In P. Rich (Ed.), Attachment and sexual offending: Understanding and applying attachment theory to the treatment of juvenile sexual offenders (pp. 6-18), Sussex: John Wiley \& Sons.

Ritakallio, M., Kaltiala-Heino, R., Kivivuori, J., \& Rimpelä, M. (2005). Brief report: Delinquent behaviour and depression in middle adolescence: A Finnish community sample. Journal of Adolescence, 28, 155-159.

Ryan, J. P., Williams, A. B., \& Courtney, M. E. (2013). Adolescent neglect, juvenile delinquency and the risk of recidivism. Journal of Youth and Adolescence, 42, 454-465.

Salter, D., McMillan, D., Richards, M., Talbot, T., Hodges, J., Bentovim, A., \& Skuse, D. (2003). Development of sexually abusive behaviour in sexually victimised males: a longitudinal study. The Lancet, 361, 471-476.

Schaffer, M., Clark, S., \& Jeglic, E. L. (2009). The role of empathy and parenting style in the development of antisocial behaviors. Crime \& Delinquency, 55(4), 586-599. 
Schneider, B. H., Atkinson, L., \& Tardif, C. (2001). Child-parent attachment and children's peer relations: A quantitative review. Developmental Psychology, 37, 86-100.

Schore, A. N. (2001). The effects of early relational trauma on right brain development, affect regulation, and infant mental health. Infant Mental Health Journal, 22, 201269.

Seidman, B., Marshall, W. L., Hudson, S. M., \& Robertson, P. J. (1994). An examination of intimacy and loneliness in sex offenders. Journal of Interpersonal Violence, 9, 518-534.

Seto, M. C., \& Lalumiere, M. (2010). What is so special about male adolescent sexual offending? A review and test of explanations through meta-analysis. Psychology Bulletin, 136, 526-575.

Shears, J., Robinson, J., \& Emde, R. N. (2002). Fathering relationships and their associations with juvenile delinquency. Infant Mental Health Journal, 23, 79-87.

Sickmund, M., Sladky, T. J., Kang, W., \& Puzzanchera, C. (2008). Easy access to the census of juveniles in residential placement. Washington, DC: U.S. Department of Justice, Office of Juvenile Justice and Delinquency Prevention. Retrieved from: http://ojjdp.ncjrs.gov/ojstatbb/ezacjrp/.

Sigre-Leirós, V., Carvalho, J., \& Nobre, P. J. (2016). Early parenting styles and sexual offending behavior: A comparative study. International Journal of Law and Psychiatry, 46, 103-109.

Silva, T. C., Graña, J. L., \& González-Cieza, L. (2013). Self-reported physical and emotional abuse among youth offenders and their association with internalizing and externalizing psychopathology. International Journal of Offender Therapy and Comparitive Criminology, 58, 590-606.

Simons, D. (2015). Sex offender typologies. In C. Lobanov-Rotovsky \& R. Przybylski (Eds.) Sex offender management and planning initiative (pp. 55-75). Washington DC: Department of Justice. 
Smallbone, S. (2006). Social and psychological factors in the development of delinquency and sexual deviance. In H. E. Barbaree, \& W. L. Marshall, (Eds.), The juvenile sex offender, (2nd ed., pp. 105-127). New York: Guildford Press.

Smallbone, S. W., \& Dadds, M. R. (1998). Childhood attachment and adult attachment in incarcerated adult male sex offenders. Journal of Interpersonal Violence, 13, $555-573$.

Smallbone, S. W., \& Dadds, M. R. (2001). Further evidence for a relationship between attachment insecurity and coercive sexual behavior in nonoffenders. Journal of Interpersonal Violence, 16, 22-35.

Smallbone, S. W., \& McCabe, B. A. (2003). Childhood attachment, childhood sexual abuse, and onset of masturbation among adult sexual offenders. Sexual Abuse: A Journal of Research and Treatment, 15, 1-9.

Smith, B. J., \& Trepper, T. S. (1992). Parents' experience when their sons sexually offend: A qualitative analysis. Journal of Sex Education and Therapy, 2, 93-103.

Smith, S., Wampler, R., Jones, J., \& Reifman, A. (2005). Differences in self-report measures by adolescent sex offender risk group. International Journal of Offender Therapy and Comparative Criminology, 49(1), 82-106.

Snyder, H. N. (2000). Sexual assault of young children as reported to law enforcement: Victim, incident, and offender characteristics. Washington, DC: U.S. Department of Justice.

Snyder, H.N. (2012). Arrest in the United States, 1990-2010. Washington, DC: U.S. Department of Justice.

Spice, A., Viljoen, J. L., Latzman, N. E., Scalora, M. J., \& Ullman, D. (2013). Risk and protective factors for recidivism among juveniles who have offended sexually. Sexual Abuse, 25, 347-369.

Stand Up for What's Right and Just (SURJ). (2011). The case for modifying juvenile sex offender registry requirements in Delaware. Wilmington, DE: Delaware Center for Justice.

Starzyk, K. B., \& Marshall, W. L. (2003). Childhood family and personological risk factors for sexual offending. Aggression and Violent Behavior, 8(1), 93-105. 
Steinberg, L., Blatt-Eisengart, I., \& Cauffman, E. (2006). Patterns of competence and adjustment among adolescents from authoritative, authoritarian, indulgent, and neglectful homes: A replication in a sample of serious juvenile offenders. Journal of Research on Adolescence, 16(1), 47-58.

Stoltenborgh, M., van IJzendoorn, M. H., Euser, E. M., \& Bakermans-Kranenburg, M. J. (2011). A global perspective on child sexual abuse: meta-analysis of prevalence around the world. Child Maltreatment, 16, 79-101.

Terry, K. J., \& Ackerman, A. R. (2009). A brief history of major sex offender laws. In R. Wright (Ed.), Sex offender laws: Failed policies, new directions (pp. 50-68). New York, NY: Springer.

Tewksbury, R. (2012). Stigmatization of sex offenders. Deviant Behavior, 33(8), 606623.

Truman, J. L., \& Morgan, R.E. (2016). Criminal victimization, 2015. Washington, DC: Department of Justice.

Turner, H. A., Finkelhor, D., \& Ormrod, R. (2010). Poly-victimization in a national sample of children and youth. American Journal of Preventive Medicine, 38(3), 323-330.

U.S. Census Bureau. (1970). All parent/child situations, by type, race, and Hispanic origin of householder or reference person: 1970 to present. Retrieved from: https://www.census.gov/data/tables/time-series/demo/families/families.html

U.S. Census Bureau. (2016). Household relationship and living arrangements of children under 18 years, by age and sex: 2016. Retrieved from: https:/www.census.gov/data/tables/2016/demo/families/cps-2016.html

Valliant, P. M., Pottier, D., Gauthier, T., \& Kosmyna, R. (2000). Moral reasoning, interpersonal skills, and cognition of rapists, child molesters, and incest offenders. Psychological Reports, 86(1), 67-75.

Van Ijzendoorn, M. H., Schuengel, C., \& Bakermans-Kranenburg, M. J. (1999). Disorganized attachment in early childhood: Meta-analysis of precursors, concomitants, and sequelae. Development and Psychopathology, 11, 225-250. 
Van Wijk, A., Loeber, R., Vermeiren, R., Pardini, D., Bullens, R., \& Doreleijers, T. (2005). Violent juvenile sex offenders compared with violent juvenile nonsex offenders: Explorative findings from the Pittsburgh Youth Study. Sexual Abuse: A Journal of Research and Treatment, 17(3), 333-352.

Van Wijk, A., Vermeiren, R., Loeber, R., Hart-Kerkhoffs, L. T., Doreleijers, T., \& Bullens, R. (2006). Juvenile sex offenders compared to non-sex offenders: A review of the literature 1995-2005. Trauma, Violence, \& Abuse, 7, 227-243.

Vandivere, S., \& Malm, K. (2015). Family finding evaluations: A summary of recent findings. In Child Trend Research Brief. Retrieved from: https://www.childtrends.org/publications/family-finding-evaluations-a-summaryof-recent-findings/

Ward, T., \& Beech, A. (2006). An integrated theory of sexual offending. Aggression and Violent Behavior, 11, 44-63.

Ward, T., \& Marshall, W. L. (1996). Attachment style in sexual offenders: a preliminary study. Journal of Sex Researcher, 33, 17-26.

Ward, T., Hudson, S. M., \& Marshall, W. L. (1996). Attachment style in sex offenders: A preliminary study. Journal of Sex Research, 33, 17-26.

Wells, L. E., \& Rankin, J. H. (1991). Families and delinquency: A meta-analysis of the impact of broken homes. Social Problems, 38(1), 71-93.

Whitaker, D. J., Le, B., Hanson, R. K., Baker, C. K., McMahon, P. M., Ryan, G., \& Rice, D. D. (2008). Risk factors for the perpetration of child sexual abuse: A review and meta-analysis. Child Abuse \& Neglect, 32, 529-548.

Widom, C. S. (1989). The cycle of violence. Science, 244, 160-166.

Williamson, J., Softas-Nall, B., \& Miller, J. (2003). Grandmothers raising grandchildren: An exploration of their experiences and emotions. The Family Journal, 11, 23-32.

Wilkinson, G. S. (1993). The Wide Range Achievement Test administration manual. Wilmington, DE: Wide Range.

Wissow, L. S. (1996). What clinicians want to know about teaching families new disciplinary tools. Pediatrics, 98, 815-817. 
Wolff, N., Blitz, C. L., Shi, J., Siegel, J., \& Bachman, R. (2007). Physical violence inside prisons: Rates of victimization. Criminal Justice and Behavior, 34(5), 588-599.

Wolock, I., \& Horowitz, B. (1984). Child maltreatment as a social problem: the neglect of neglect. American Journal of Orthopsychiatry, 54(4), 530-543.

Woodhouse, S., Ayers, S., \& Field, A. P. (2015). The relationship between adult attachment style and post-traumatic stress symptoms: A meta-analysis. Journal of Anxiety Disorders, 35, 103-117.

Yoder, J. R. (2014). Service approaches for youths who commit sexual crimes: A call for family-oriented models. Journal of Evidence-Based Social Work, 11, 360-372.

Zankman, S., \& Bonomo, J. (2004). Working with parents to reduce juvenile sex offender recidivism. Journal of Child Sexual Abuse, 13, 139-156. 